Please do not remove this page

RMIT

UNIVERSITY

\title{
Transition metal oxides - Thermoelectric properties
}

Walia, Sumeet; Balendhran, Sivacarendran; Nili Ahmadabadi, Hussein; Zhuiykov, Serge; Rosengarten, Gary; Wang, Qing Hua; Bhaskaran, Madhu

https://researchrepository.rmit.edu.au/esploro/outputs/9921859498801341/filesAndLinks?institution=61RMIT_INST\&index=null

Walia, S., Balendhran, S., Nili Ahmadabadi, H., Zhuiykov, S., Rosengarten, G., Wang, Q. H., Bhaskaran, M., Sriram, S., Strano, M., \& Kalantar Zadeh, K. (2013). Transition metal oxides - Thermoelectric properties. Progress in Materials Science, 58(8), 1443-1489. https://doi.org/10.1016/j.pmatsci.2013.06.003

Document Version: Accepted Manuscript

Published Version: https://doi.org/10.1016/j.pmatsci.2013.06.003

Repository homepage: https://researchrepository.rmit.edu.au

(c) 2013 Elsevier Ltd. All rights reserved.

Downloaded On 2023/04/26 17:45:23 +1000

Please do not remove this page 
Thank you for downloading this document from the RMIT Research Repository.

The RMIT Research Repository is an open access database showcasing the research outputs of RMIT University researchers.

RMIT Research Repository: http://researchbank.rmit.edu.au/

\section{Citation:}

Walia, S, Balendhran, S, Nili Ahmadabadi, H, Zhuiykov, S, Rosengarten, G, Wang, Q, Bhaskaran, M, Sriram, S, Strano, M and Kalantar Zadeh, K 2013, 'Transition metal oxides Thermoelectric properties', Progress in Materials Science, vol. 58, no. 8, pp. 1443-1489.

See this record in the RMIT Research Repository at:

http://researchbank.rmit.edu.au/view/rmit:22350

Version: Accepted Manuscript

Copyright Statement: (c) (c) 2013 Elsevier Ltd. All rights reserved.

Link to Published Version:

http://dx.doi.org/10.1016/j.pmatsci.2013.06.003 


\title{
Transition metal oxides - thermoelectric properties
}

Sumeet Walia, ${ }^{a}$ Sivacarendran Balendhran, ${ }^{a}$ Hussein Nili, ${ }^{a, b}$ Serge Zhuiykov, ${ }^{c}$ Gary

Rosengarten, ${ }^{d}$ Qing Hua Wang, ${ }^{e}$ Madhu Bhaskaran, ${ }^{a, b}$ Sharath Sriram, ${ }^{a, b}$ Michael S. Strano ${ }^{e}$ and Kourosh Kalantar-zadeh ${ }^{a *}$

${ }^{a}$ School of Electrical and Computer Engineering, RMIT University, Melbourne, Australia

${ }^{b}$ Functional Materials and Microsystems Research Group, RMIT University, Melbourne, Australia

${ }^{c}$ Materials Science and Engineering Division, CSIRO, Highett, Victoria, Australia

${ }^{d}$ School of Aerospace, Mechanical and Manufacturing Engineering, RMIT University, Melbourne, Australia

${ }^{e}$ Department of Chemical Engineering, Massachusetts Institute of Technology, Cambridge, Massachusetts, USA.

*Corresponding author emails: kourosh.kalantar@rmit.edu.au, and sumeet.walia@rmit.edu.au RMIT University, GPO 2476, Melbourne-3000, Victoria, Australia.

$\mathrm{Ph}:+61-3-9925-3254$

\begin{abstract}
Transition metal oxides (TMOs) are a fascinating class of materials due to their wide ranging electronic, chemical and mechanical properties. Additionally, they are gaining increasing attention for their thermoelectric (TE) properties due to their high temperature stability, tunable electronic and phonon transport properties and well established synthesis techniques. In this article, we review TE TMOs at cryogenic, ambient and high temperatures. An overview of strategies used for morphological, composting and stoichiometric tuning of their key TE parameters is presented. This article also provides an outlook on the current and future prospects of implementing TMOs for a wide range of TE applications.
\end{abstract}

Keywords: transition metal oxides, thermoelectric, Seebeck coefficient, electrical conductivity, thermal conductivity, doping, stoichiometry, compositing, nanostructuring 


\section{Table of Contents}

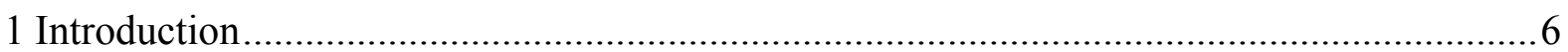

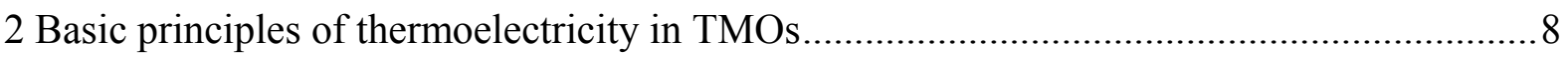

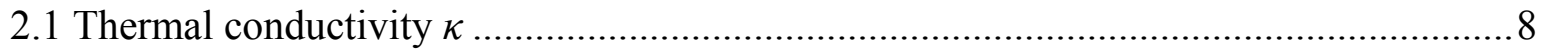

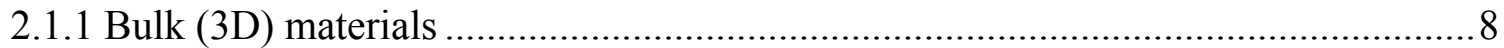

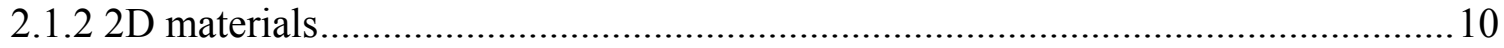

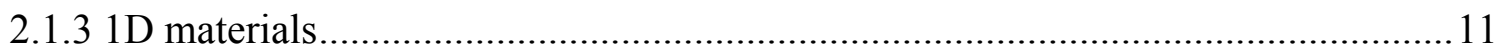

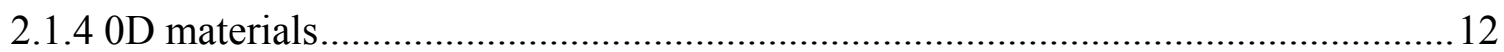

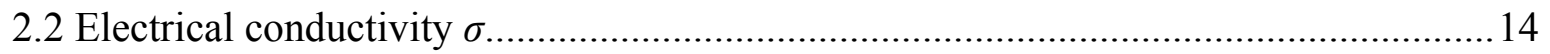

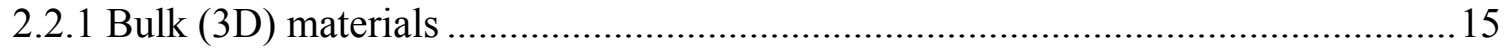

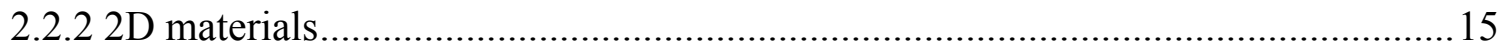

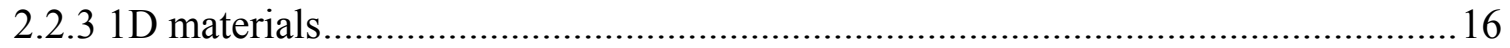

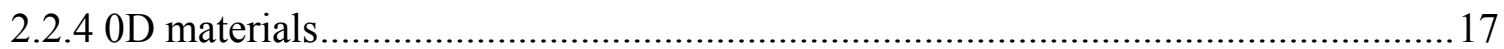

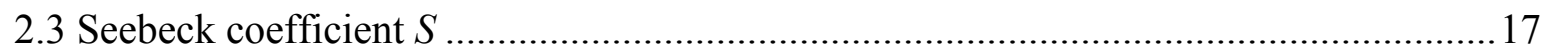

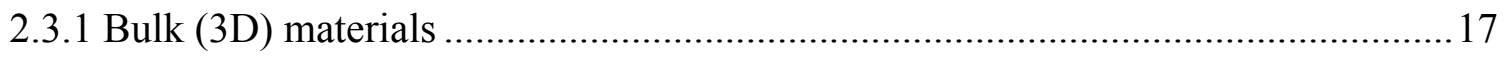

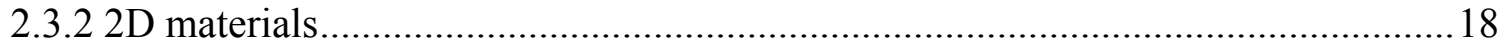

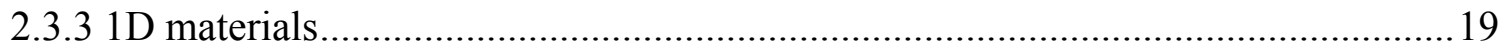

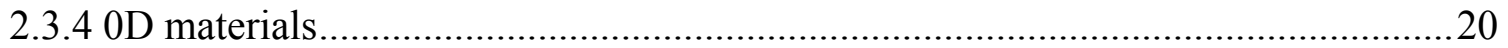

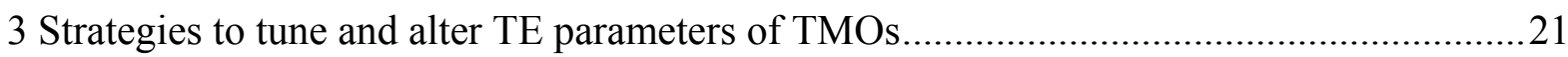

3.1 Optimization using stoichiometry and doping techniques .......................................22

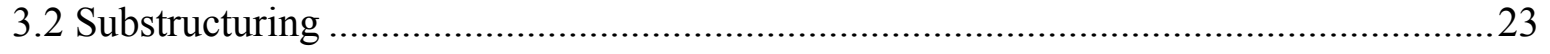

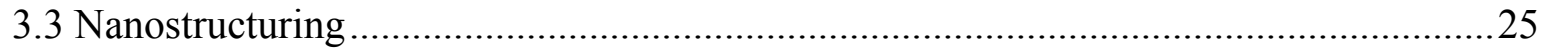

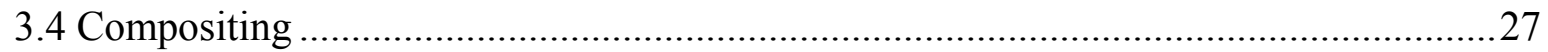

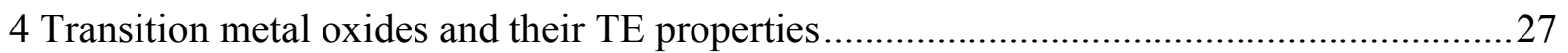

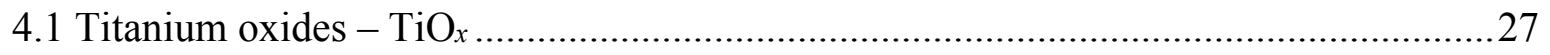

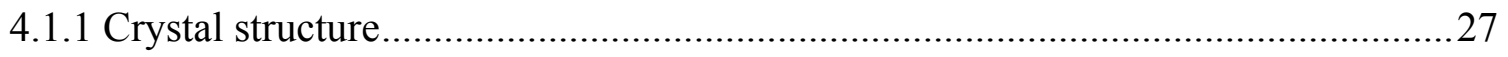

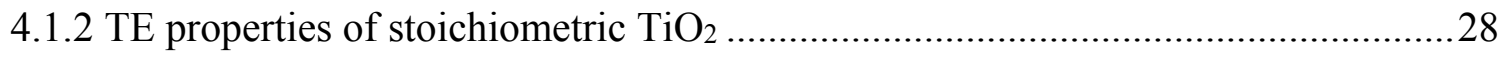

4.1.3 TE properties of non-stoichiometric, doped and composite $\mathrm{TiO}_{x} \ldots \ldots \ldots \ldots \ldots \ldots \ldots \ldots . . .28$

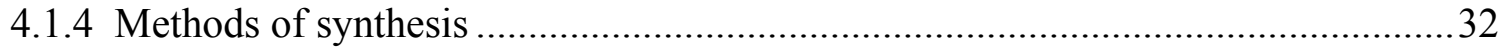

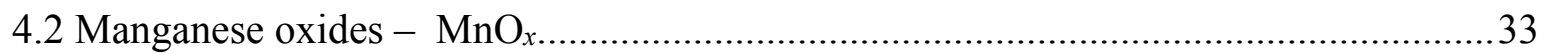

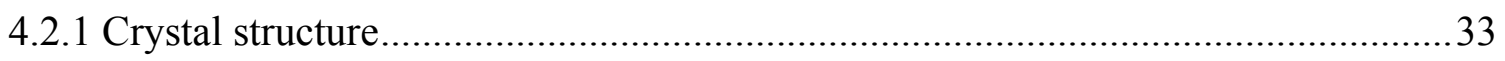

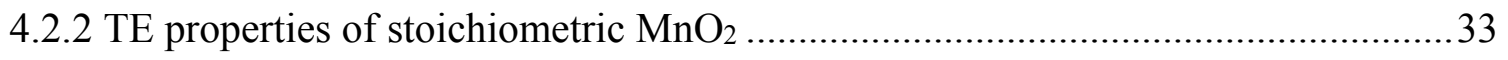


4.2.3 TE properties of non-stoichiometric, doped and composite $\mathrm{MnO}_{x}$ .34

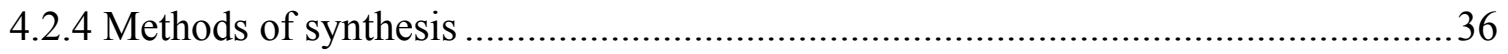

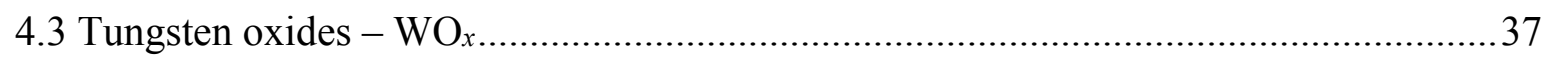

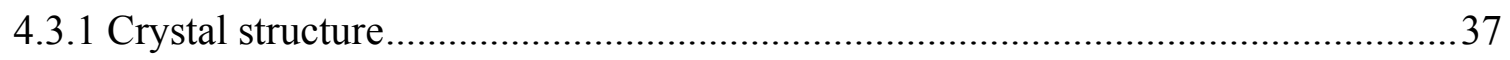

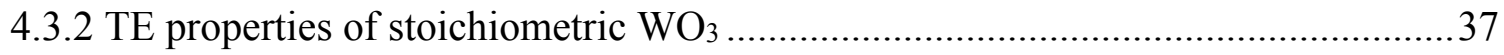

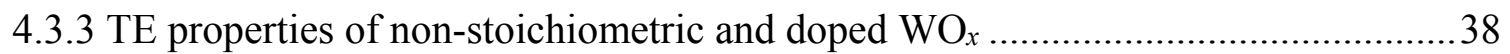

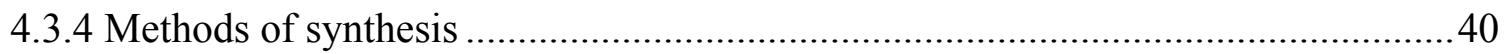

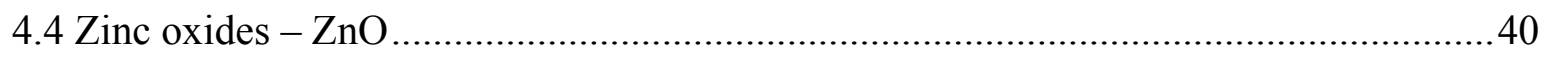

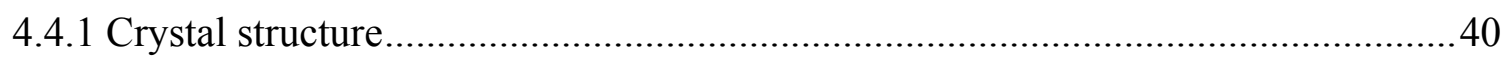

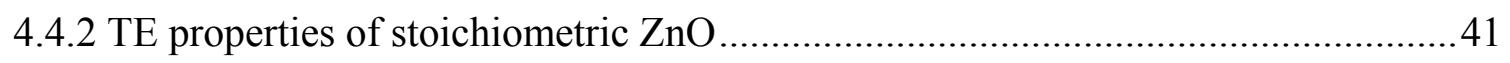

4.4.3 TE properties of non-stoichiometric and doped $\mathrm{ZnO}$.........................................42

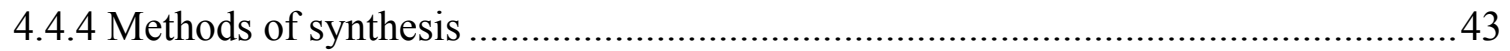

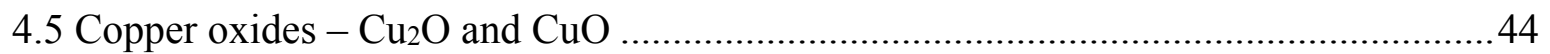

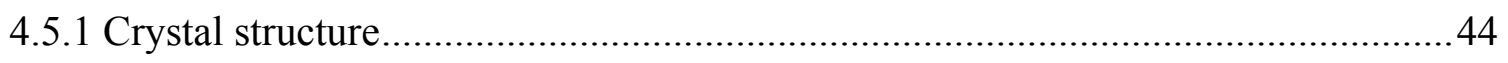

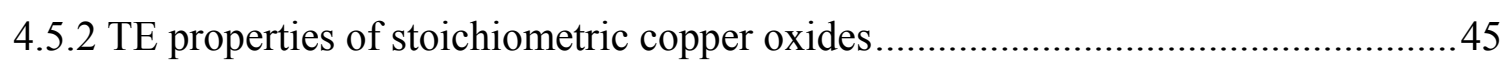

4.5.3 TE properties of non-stoichiometric, doped and composite copper oxides ............45

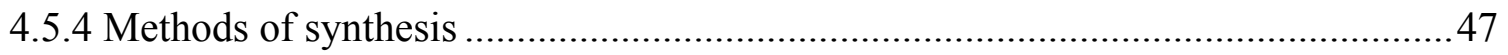

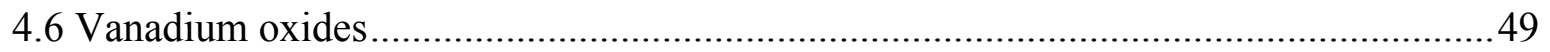

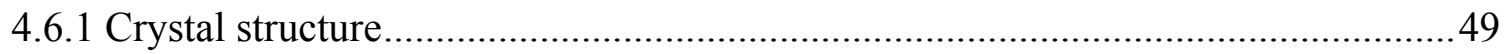

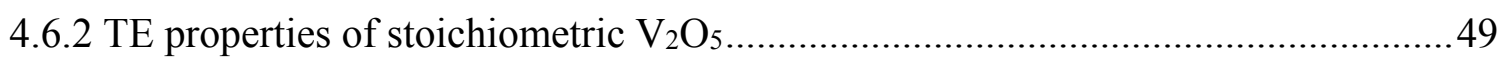

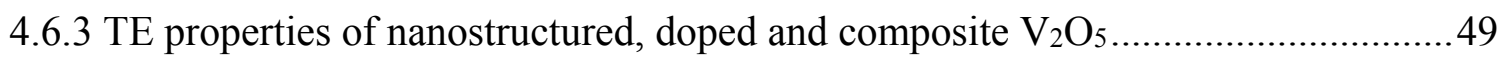

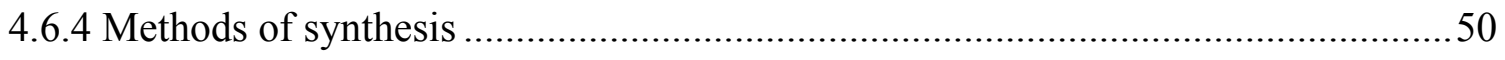

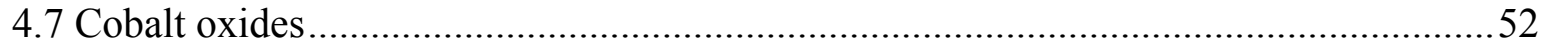

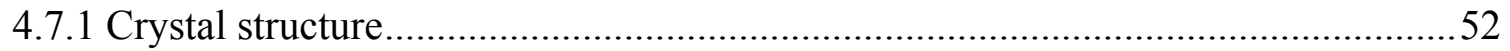

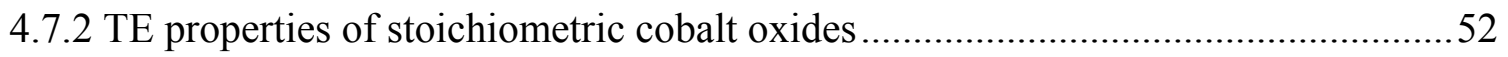

4.7.3 TE properties of non-stoichiometric, doped, composite and nanostructured cobalt

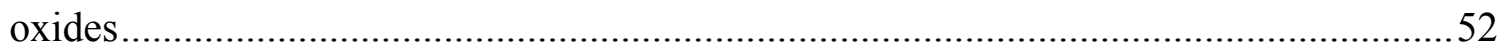

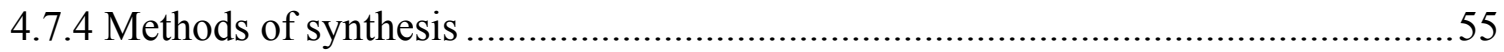

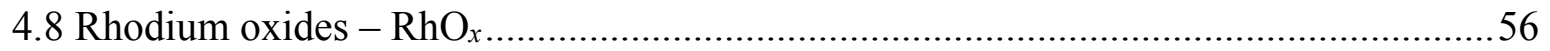

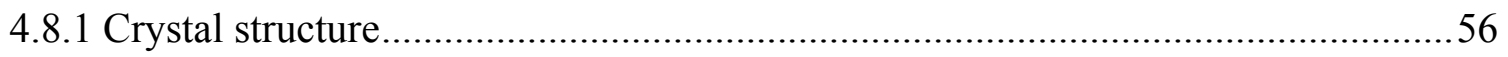

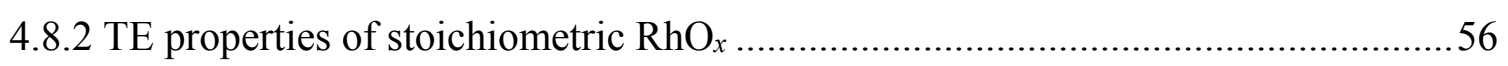

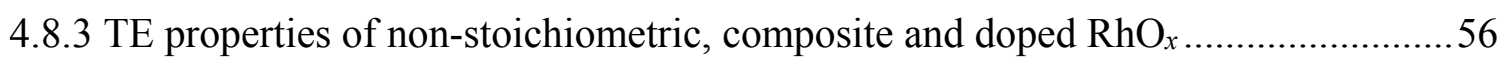

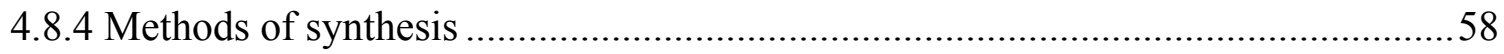




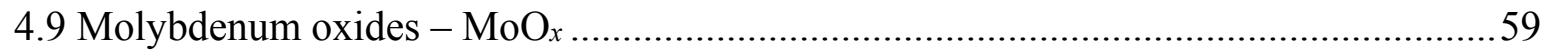

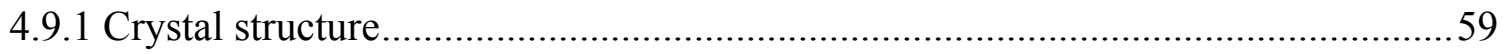

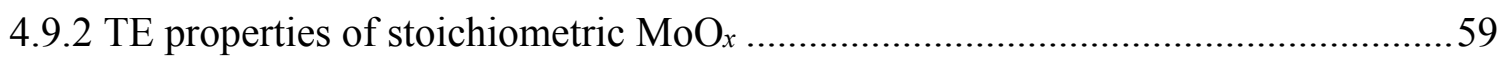

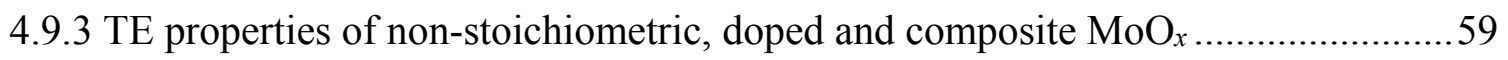

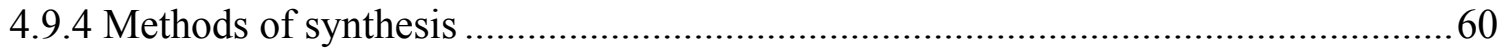

4.10 Other transition metal oxides and their TE properties ..............................................61

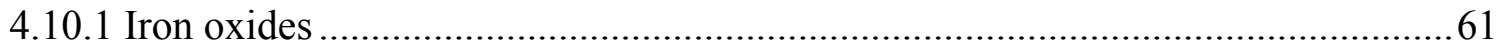

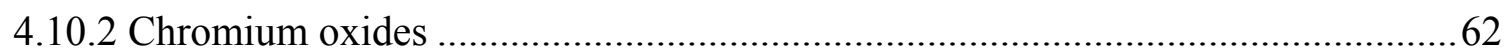

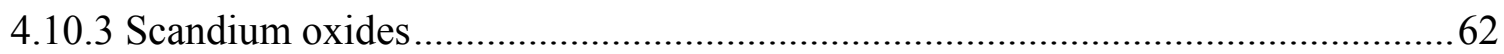

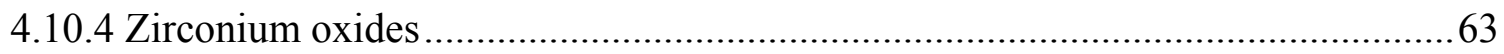

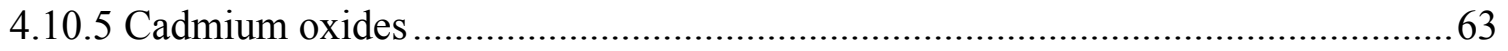

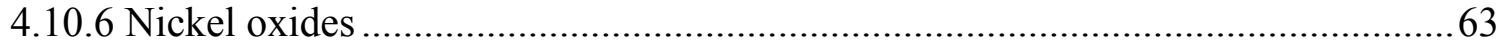

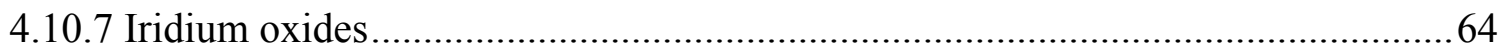

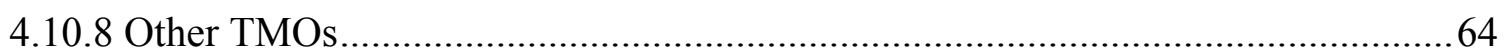

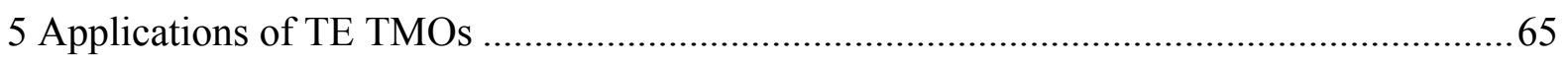

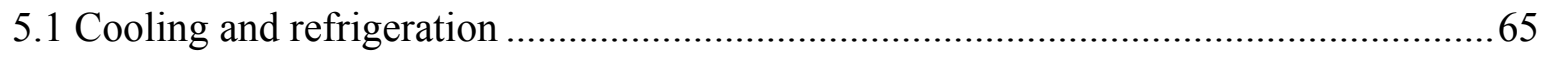

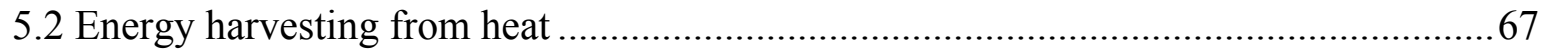

5.3 Photovoltaic (PV) - solar thermoelectric generators (STEGs) and radioisotope

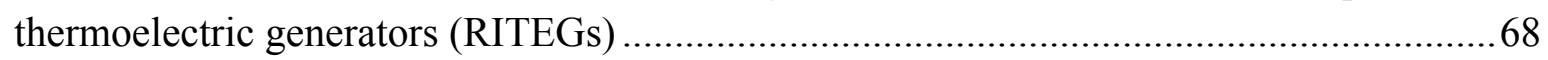

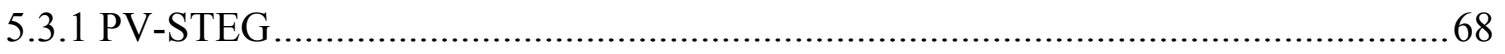

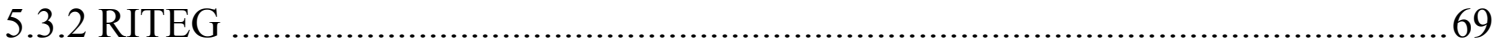

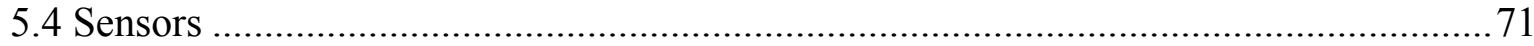

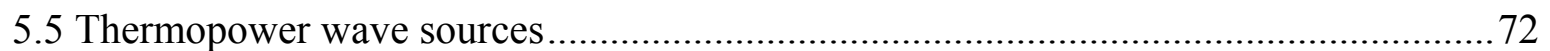

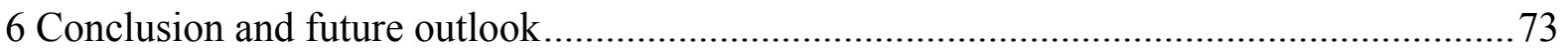

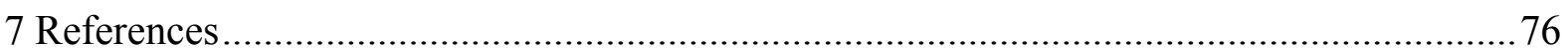




\section{Nomenclature}

\section{Acronyms}

TE

Thermoelectric

TMOs Transition metal oxides

TPF Thermoelectric power factor

QDSL Quantum dot superlattice

SNW Segmented nanowire

DOS Density of states

2DEG Two-dimensional electron gas

RTA Relaxation time approximation

DFT Density functional theory

SPS $\quad$ Spark plasma sintering

EBE Electron beam evaporation

RF Radio frequency

PLD Pulsed laser deposition

ALD Atomic layer deposition

MBE Molecular beam epitaxy

CVD Chemical vapour deposition

MOCVD Metal organic chemical vapour deposition

VDWE Van der Waals epitaxy

SSR Solid state reaction

GPR Gas phase reaction

LPR Liquid phase reaction

STEG Solar thermoelectric generator

RITEG Radio isotope thermoelectric generator

LED Light emitting diode 


\section{Introduction}

Thermoelectric (TE) materials are utilized for the conversion of a temperature gradient to a voltage gradient and vice versa. TE materials are widely regarded as the materials that can provide potential solutions for power generation and refrigeration technologies as well as their future advancements[1-4]. Additionally, they offer opportunities for the development of technologies in areas such as smart sensors, energy harvesting, and the new concept of thermopower wave sources[5-9].

Transition metal oxides (TMOs) are a vast but conventionally less widely studied family of TE materials, which include materials such as titanium, manganese, tungsten, zinc, copper, vanadium, cobalt, rhodium, and molybdenum oxides. However, these materials are now drawing increasing attention. Metal oxides can show a wide range of electronic properties ranging from insulating to semiconducting and conducting[10]. Their electronic properties can be engineered by changing their morphology, doping and stoichiometry. The phonon generation and propagation properties in many TMOs are well understood and molecular engineering methods have been developed for tuning them. Additionally, TMOs show a wide range of interesting thermal properties at cryogenic, ambient and high temperatures (Fig. 1). Many TMOs offer high Seebeck coefficients, with desired thermal and electrical conductivities and heat capacities, at targeted temperatures that can be exploited for different applications[11-14]. Their abundance in nature is another important advantage for technologies to be widely adopted.

Despite all the aforementioned promising properties, TMOs have yet to achieve their true potential in the TE realm. This review article will provide a comprehensive outlook on the TE properties of various TMOs and assess their performance. The critical parameters of thermal conductivity, electrical conductivity and Seebeck coefficient will be thoroughly discussed. The effect of changing the morphology and nanostructuring on the thermal and electrical 
conductivities and Seebeck coefficient of TMOs will be presented. Critical discussions on different types of TMOs and the effect of oxidation, reduction and dopants on their TE properties will also be presented. This paper will discuss the most significant recent advances in the development of metal oxides for a wide range of applications including conventional purposes such as waste heat harvesting, refrigeration, and sensors as well as new concepts such as thermopower waves. Finally, we will provide an outlook for future directions and applications for TMOs in TEs at a range of operating temperatures.

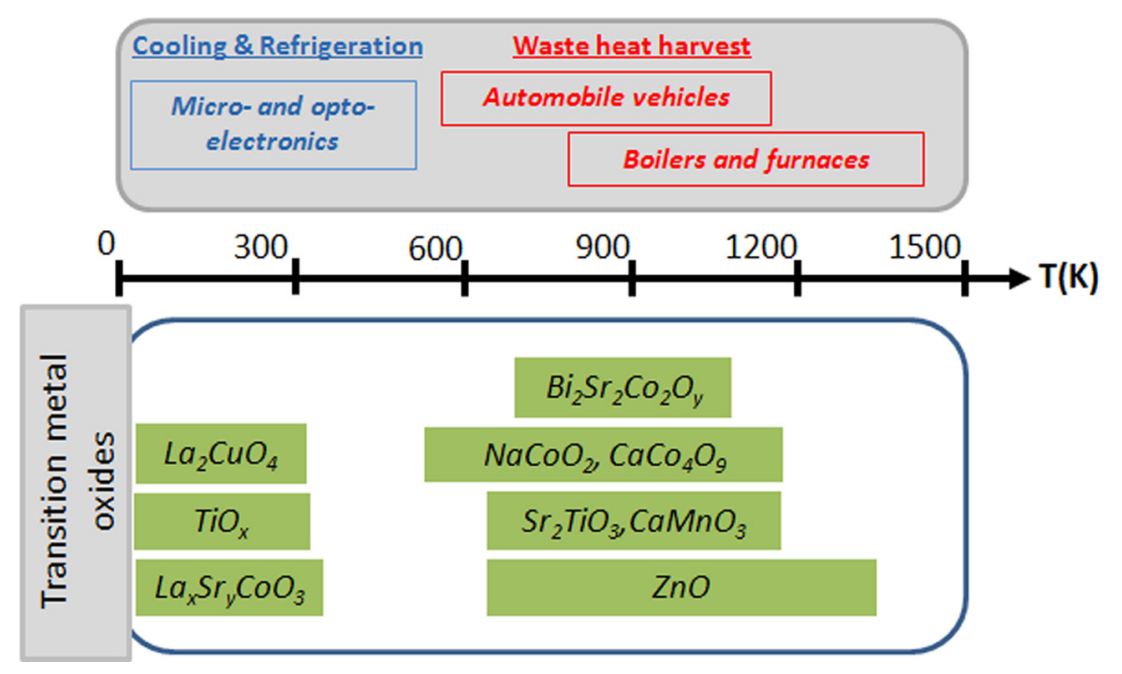

Fig. 1. Operating temperature ranges of various TMOs and TMO composites. (Reproduced with permission from [15].) 


\section{Basic principles of thermoelectricity in TMOs}

The fundamental factors that govern TE properties are thermal conductivity $(\kappa)$, electrical conductivity $(\sigma)$ and Seebeck coefficient $(S)$. The performance of TE materials is generally assessed by the figures of merit (ZT) defined as $S^{2} \sigma / \kappa$, and the thermoelectric power factor (TPF) defined as $S^{2} \sigma$. In this section, we present an overview of the main equations governing the aforementioned TE parameters for bulk three dimensional (3D) and low dimensional (2D, $1 \mathrm{D}$ and $0 \mathrm{D})$ structures.

\subsection{Thermal conductivity $\kappa$}

Thermal conductivity is the ability of a material to conduct heat. The main contributors to the thermal conductivity are phonons and charge carriers (electrons and holes). The overall thermal conductivity ( $\kappa$ total) of a material is defined as: $[16,17]$

$$
\kappa_{\text {total }}=\kappa_{\text {phonon }}+\kappa_{\text {electron }}
$$

where, $\kappa_{\text {phonon }}$ is the lattice thermal conductivity due to acoustic phonons travelling through the crystal lattice and $\kappa_{\text {electron }}$ is the electronic thermal conductivity due to charge carriers. Phonons and charge carriers can undergo scattering due to other phonons, lattice defects, impurities, electrons, grain boundaries and interfaces[18]. Such scattering then results in changes of thermal conductivity. The fundamentals of $\kappa_{\text {phonon }}$ and $\kappa_{\text {electron }}$ for bulk as well as low dimensional materials are discussed next.

\subsubsection{Bulk (3D) materials}

For semiconducting and insulating TMOs, acoustic phonons are the major contributors to אtotal. However, for highly doped and non-stoichiometric TMOs the electronic thermal conductivity also plays an important role. For bulk materials, the kinetic theory of gases defines the $\kappa_{\text {phonon }}$ and $\kappa_{\text {electron }}$ as: 


$$
\begin{gathered}
\kappa_{\text {phonon }}=\frac{1}{3} v_{s} C_{v} L_{p h} \\
\kappa_{\text {electron }}=\frac{1}{3} c_{v} v \Lambda=L \sigma T
\end{gathered}
$$

where $v_{\mathrm{s}}$ is the velocity of sound, $C_{v}$ is the heat capacity at constant volume, $L_{p h}$ is the phonon mean free path, $c_{v}$ is the electronic specific heat per volume, $v$ is the electron velocity that can be assumed to be the Fermi velocity $v_{F}, \Lambda$ is the electron mean free path, $L$ is the Lorenz number $\left(2.45 \times 10^{-8} \mathrm{~V}^{2} \cdot \mathrm{K}^{2}\right), \sigma$ is the electrical conductivity, and $T$ is the temperature in Kelvin.

$C_{v}$ and $v_{s}$ are typically temperature independent for $T>300 \mathrm{~K}$; hence at high temperatures,

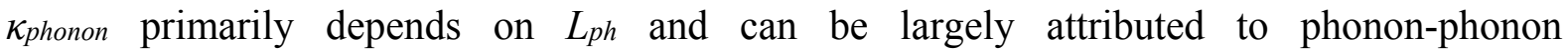
scattering[19].

On the other hand, אelectron depends on the electron mean free path. The Wiedemann-Franz law as shown in Eq. $2 \mathrm{~b}$ states that $\kappa_{\text {electron }}$ is directly proportional to $\sigma$ and $T$, so that any variation in $\kappa_{\text {electron }}$ affects $\sigma$. Hence, the only TE parameter that is independent of the electronic band structure is $\kappa_{\text {phonon }}$

In semiconducting and insulating TMOs, phonons are the majority contributors to $\kappa_{\text {total, }}$ making it possible to tune their $\kappa_{\text {total }}$ with a negligible effect on $\sigma$. A comprehensive theoretical analysis of $\kappa$ has been provided elsewhere[17]. In order to improve the performance of TE materials for conventional applications such as cooling and energy scavenging, a reduction in $\kappa_{\text {phonon }}$ is desirable. In theory, the minimum $\kappa_{\text {phonon }}$ is achieved when the mean free path of the phonons is no more than the interatomic spacing of the constituent atoms[4]. Limiting $L_{p h}$ by confining phonons can help achieve this goal. Such a confinement can be obtained by creating low dimensional materials, which are described next. 


\subsubsection{D materials}

A two-dimensional (2D) quantum well structure consists of a very thin layer of material that is nanometers thick in one dimension and semi-infinitely large in the other two dimensions. 2D quantum well structures are likely to reduce the $\kappa_{\text {total }}$ of TMOs compared to their bulk counterparts because phonons mainly scatter at the interfaces, while the motion of the electrons can be confined parallel to the layers. $\kappa_{\text {electron } 2 D}$ is a strong function of the thickness of layers $(W)$. For 2D quantum well structures, $\kappa_{\text {phonon} 2 D}$ and $\kappa_{\text {electron} 2 D}$ along the $x$-axis (Fig.

2a) have been defined as:[20,21]

$$
\begin{gathered}
\kappa_{\text {phonon } 2 D}=\frac{k_{B}}{2 \pi^{2} v}\left(\frac{k_{B}}{h}\right)^{3} T^{3} \int_{0}^{\theta / T} \frac{\tau_{c} \xi^{4} e^{\xi}}{\left(e^{\xi}-1\right)^{2}} d \xi \\
\kappa_{\text {electron } 2 D}=\frac{\tau h^{2}}{4 \pi W}\left(\frac{2 k_{B} T}{h^{2}}\right)^{2}\left(\frac{m_{y}}{m_{x}}\right)^{1 / 2} k_{B}\left(3 F_{2}-4 \frac{F_{1}^{2}}{F_{0}}\right)
\end{gathered}
$$

where, $k_{B}$ is the Boltzmann constant, $h$ is the Planck constant, $e$ is the electron charge, $m_{x, y, z}$ are the three components of the effective mass, $\theta$ is the Debye temperature, $\xi=h \omega / k_{B} T$ ( $h \omega$ being the phonon energy), $T$ is the absolute temperature, $\tau$ is the electron relaxation time and is defined as $\tau=\mu_{x} m_{x} / e$ where $\mu_{x}$ is the mobility along the $x$-axis (Fig. 2a), $v$ is the velocity of sound, $F_{i}$ are the Fermi-Dirac functions and $\tau_{c}$ is the combined phonon relaxation time due to all resistive processes (which include boundary scattering, mass difference scattering, scattering at dislocations and Umklapp scattering processes), which is governed by the Matthiessen's rule (see ref. [21] for details). According to Eq. 3a, the theoretical value of $\kappa_{\text {phonon } 2 D}$ is strongly influenced by the phonon-phonon energy, its relaxation time $\tau_{c}$, which is a function of the quantum well dimension and temperature.

$\kappa_{\text {electron } 2 D}$ depends only on two effective mass components of the electrons as shown in Eq. $3 \mathrm{~b}$. This is because, unlike phonons, electrons can only move in a $2 \mathrm{D}$ motion parallel to the 
layers due to the quantum confinement. Additionally, a stronger confinement (by decreasing

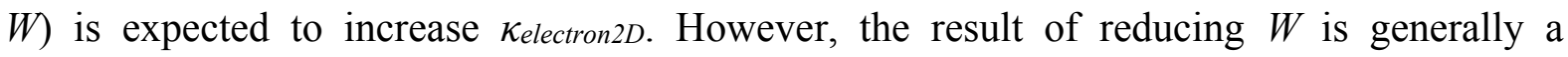
decrease in the overall thermal conductivity. This is especially useful in engineering ZT when both Seebeck coefficient and electrical conductivity of the material remain constant. There are practical examples of employing 2D TMOs such as $\mathrm{TiO}_{2}$, cobalt oxides and manganese oxides[22] which will be discussed in their relevant sections. The application of 2D TMOs with increased ZT values [22] has been demonstrated in energy scavenging at elevated temperatures that will also be discussed later.

\subsubsection{D materials}

Hicks et al. developed a theoretical model and predicted that materials in 1D form (such as quantum wires, nanobelts and nanorods) can result in further reduction of $\kappa$ electron, compared to bulk and 2D structures[23]. The thermal conductivity of phonons in 1D structures were theoretically modelled by Zou and Balandin. [24] The equations describing $\kappa_{\text {phonon }}$ and $\kappa_{\text {electron }}$ for 1D structures are: [23, 24]

$$
\begin{gathered}
\kappa_{\text {phonon } 1 D}=\frac{k_{B}}{2 \pi^{2} v}\left(\frac{k_{B}}{h}\right)^{3} T^{3} \int_{0}^{\theta / T} \frac{\tau_{c} \xi^{4} e^{\xi}}{\left(e^{\xi}-1\right)^{2}} d \xi \times\left[1-\frac{24}{\pi} G(\eta(\xi), p)\right] d \xi \\
\kappa_{\text {electron } 1 D}=\frac{2 \tau}{\pi a^{2}}\left(\frac{2 k_{B} T}{h^{2}}\right)^{1 / 2}\left(m_{x}\right)^{-1 / 2}{k_{B}}^{2} T\left(\frac{5}{2} F_{3 / 2}-\frac{9 F_{1 / 2}^{2}}{2 F_{-1 / 2}}\right)
\end{gathered}
$$

where, $a$ is the width of a $1 \mathrm{D}$ structure with a square cross section, $m_{x}$ is the effective mass component in the $x$ direction (Fig. 2b), $v$ is the phonon group velocity, $T$ is the temperature, $\theta$ is the Debye temperature, $\xi=h \omega / k_{B} T$ ( $h \omega$ being the phonon energy), $\Lambda$ is the phonon mean free path $\left(\Lambda(\xi)=v(\xi) \tau_{c}(\xi)\right), \eta$ is the ratio between the wire width and $\Lambda(\eta(\xi)=a \pi / \Lambda(\xi)), p$ is a parameter which characterizes the interface roughness and its effect on the phonon scattering. 
The value of $p$ represents the probability of a phonon undergoing diffusive scattering (refer to [24] for additional details). Other parameters have been defined in Eq. 3a \& 3b.

The theoretical ZT calculations using Eqs.4a and $4 \mathrm{~b}$ for a 1D structure show that it strongly depends on its width. For widths smaller than the thermal de Broglie wavelength of the carriers, the ZT increases significantly with decreasing the width of the 1D structure. TMOs such as $\mathrm{ZnO}$ and $\mathrm{TiO}_{2}$ have been extensively synthesised in $1 \mathrm{D}$ morphologies (nanorods, nanoribons and nanotubes) $[25,26]$ and the thermal conductivity of such materials are strongly affected by such morphological manipulations[25].

\subsubsection{D materials}

Unlike 2D or 1D structures, the carriers in $0 \mathrm{D}$ structures such as quantum dots are confined in all directions. The transport mechanism in 0D structures is thus different from others, in the sense that unconventional conduction behaviour such as tunnelling is required to maintain its electronic conductivity. Therefore, 0D structures such as quantum dot superlattices (QDSLs) and segmented nanowires (SNWs) were proposed to provide a conduction pathway. As the name suggests, such segmented structures consist of a series of interwoven quantum dots of two different materials (Fig.2c). The electronic transport along the wire axis occurs by tunnelling between adjacent quantum dots. Furthermore, due to the wire boundaries and interfaces between the quantum dots, the phonon conduction along the wire axis is impeded, resulting in a reduced lattice thermal conductivity.

The lattice thermal conductivity for 0D structures $\left(\kappa_{\text {phononoD }}\right)$ such as QDSLs and SNWs comprising of two different materials $A$ and $B$ is defined as:[27, 28]

$$
\begin{aligned}
\frac{L}{\kappa_{\text {phonon } 0 D}}= & \frac{L_{A}}{\kappa_{\text {phonon } A}}+\frac{L_{B}}{\kappa_{\text {phonon } B}}+4\left(\frac{1}{C_{A} v_{A} t_{A B}}+\frac{1}{C_{B} v_{B} t_{B A}}\right)\left(1-\frac{t_{A B}+t_{B A}}{2}\right) \\
& +\frac{3}{d_{w}}\left(\frac{L_{A}}{C_{A} v_{A} \propto_{A}}+\frac{L_{B}}{C_{B} v_{B} \propto_{B}}\right)
\end{aligned}
$$


where, $C_{A, B}$ is the heat capacity, $v_{A, B}$ is the sound velocity of the nanodot material, $L_{A, B}$ is the length of the material's segment, $t_{A B}$ and $t_{B A}$ are the average transmissivity of phonons from quantum $\operatorname{dot} A$ to $B$ and vice versa, $\alpha_{A, B}$ is the geometric factor that depends on the aspect ratio $\left(L_{A} / d_{w}\right.$ or $\left.L_{B} / d_{w}\right)$ of the quantum dots in which $d_{w}$ is the diameter of the wire. The first two terms in Eq.5 account for the intrinsic phonon scattering events, while the third and fourth terms account for the contribution of the segment interface and the wire boundary

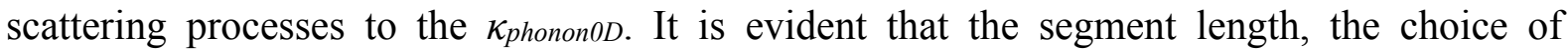
materials $A$ and $B$, as well as the aspect ratio of the quantum dots play a vital role in determining $\kappa_{\text {phonon } 0 D}$ and hence, the design of the QDSL or SNW structure is the most important factor governing the thermal properties. In order to quantify the electronic contribution of the thermal conductivity ( $\kappa_{\text {electronoD) }}$ in a QDSL or SNW structure, the Kroenig-Penney model is used. This model determines the dispersion relation $E_{n, m}(k)$ for the electrons that move along the axis in the $n, m$ sub-band of the wire experiencing a square periodic potential[29], where $k$ is a $1 \mathrm{D}$ wave vector that describes the energies of these electrons in the square potential[28]. The electronic band structure of each sub-band is highly dependent on the segment length $\left(L_{A}\right.$ or $\left.L_{B}\right)$, the potential barrier height and the transport effective masses[28].

The constant relaxation time approximation is used for calculating the following fundamental integrals for the conduction band: [27]

$$
\begin{gathered}
K_{(\alpha)}=\frac{4 \tau}{\pi^{2} h^{2} d_{w}^{2}} \sum_{n, m} \int \frac{1}{g_{n, m}(E)}\left(E_{n, m}-E_{F}\right)^{\alpha}\left(-\frac{\delta f}{\delta E}\right) d E \\
g_{n, m}(E)=\frac{2}{\pi}\left(\frac{\delta E_{n, m}}{\delta \kappa}\right)^{-1}
\end{gathered}
$$

where, $\alpha=0,1$ or $2, \tau$ is the relaxation time of the carriers, $E_{F}$ is the Fermi energy, $f(E)$ is the Fermi-dirac distribution function and $g_{n, m}(E)$ is the density of states of the $n, m$ sub-band, 
which is defined in Eq. 6b. The electronic component of the lattice thermal conductivity in OD structures (KelectronoD) is defined as:[27]

$$
\kappa_{\text {electron } 0 D}=\frac{1}{T}\left(K_{(2)}-\frac{K_{(1)}^{2}}{K_{(0)}}\right)^{1 / 2}
$$

From Eq. $6 \mathrm{a}, \mathrm{b} \& \mathrm{z}$, it is clear that KelectronoD is strongly dependent on the diameter of the SNWs, as well as the carrier relaxation time. However, as discussed before, the electronic contribution towards the thermal conductivity in semiconducting TMOs is generally much lower, compared to the phonon contribution at small diameters. The superlattice interfaces in TMO-based 0D structures such as SNWs are expected to enhance the phonon scattering to further suppress the thermal conductivity compared to the bulk form[30].

The above discussion shows that a reduction in the dimensionality of the system can result in a reduced lattice thermal conductivity, due to the phonon mean free paths being limited by the nanostructuring, and consequently increased phonon scattering. This can potentially enhance the efficiency of TE TMOs for energy scavenging applications, while can increase the performance of temperature sensors, which are based on such structures.

\subsection{Electrical conductivity $\sigma$}

The electrical conductivity of TMOs in bulk and low dimensional form has been extensively studied[31-34]. Most TMOs exhibit low $\sigma$ in their bulk due to low mobilities of charge carriers[35]. However, it has been shown that quantum confinement of these carriers alters the electronic density of states (DOS). Various nanostructuring and doping techniques can be employed to alter the carrier concentrations by adjusting the bandgap and surface energy in TMOs[31]. In this section, we will discuss the theoretical equations that govern the electrical conductivity of TMOs in bulk and low dimensional forms. 


\subsubsection{Bulk (3D) materials}

For bulk TMOs, the electrical conductivity can be defined in a simplistic form as follows:[16, 29]

$$
\sigma=n(E) e \mu(E)=n(E) e^{2} \frac{\tau(E)}{m^{*}}
$$

where, $n(E)$ is the density of carriers which is a function of the density of states $g(E), e$ is the electronic charge, $\mu(E)$ is the differential carrier mobility, $\tau(E)$ is the relaxation time and $m^{*}$ is the carrier effective mass.

The $m^{*}$ of many TE TMOs such as $\mathrm{TiO}_{2}$ and layered cobalt oxides is relatively large.[16, 36] Additionally, they also suffer due to short relaxation times[37-39]. As a result, the charge carrier mobilities of many TMOs are relatively small. The carrier concentrations of bulk TMOs, which is affected by the thermionic effect, depend on their bandgap and temperature. As a result, the carrier mobilities and concentrations in TMOs can be tuned using various doping and nanostructuring techniques.

\subsubsection{D materials}

The electrical conductivity of TMOs can be enhanced by fabricating quantum well structures, which result in the quantum confinement of carriers. For a $2 \mathrm{D}$ quantum well structure discussed previously in section 2.1.2, Hicks et al. defined the electrical conductivity $\left(\sigma_{2 D}\right)$ as:[20]

$$
\sigma_{2 D}=\frac{1}{2 \pi W}\left(m_{x}^{*} m_{y}^{*}\right)^{1 / 2} F_{0} e \mu_{x}\left(\frac{2 k_{B} T}{h^{2}}\right)
$$

where, $W$ is the quantum well width, $m_{x}^{*}$ and $m_{y}^{*}$ are the effective mass components in the $x$ and $y$ direction (in the plane of the 2D material) respectively, $F_{0}$ is the Fermi energy, $e$ is the electron charge, $\mu_{x}$ is the mobility, $T$ is the temperature, $k_{B}$ is the Boltzmann constant and $h$ is 
the Planck's constant. In such structures the electrons are confined only to a 2D motion that is parallel to the layers. Eq.9 shows that a reduction in $W$ enhances $\sigma_{2 D}$. In TMOs, the Fermi level can be adjusted using various doping techniques and methods that control stoichiometry. In these materials, the Fermi level is a strong function of morphology and the temperature[40]. As expected, enhanced electrical conductivities have been demonstrated in various 2D TMOs such as $\mathrm{MoO}_{3}, \mathrm{CoO}_{2}$ and $\mathrm{ZnO}$ nanobelts[41] [42] [43].

\subsubsection{D materials}

In morphologies such as one-dimensional nanorods, nanotubes or nanobelts of TMOs, $\sigma$ is predicted to increase by reducing the cross sectional area of the structure. Such enhancement is mainly due to increased charge carrier mobilities via changes in DOS[44, 45]. $\sigma$ in such 1D structures is defined as:[23]

$$
\sigma_{1 D}=\frac{1}{\pi a^{2}}\left(m_{x}^{*}\right)^{1 / 2} F_{-1 / 2} e \mu_{x}\left(\frac{2 k_{B} T}{h^{2}}\right)^{1 / 2}
$$

where, $a$ is the width of a $1 \mathrm{D}$ structure with a square cross section, $m_{x}^{*}$ is the effective mass component in the $x$ direction. Other parameters have been defined in Eq. 9. Additionally, $\sigma$ can be tuned by changing the Fermi level of the TMOs, which result in the carrier concentration change as well[46] [47].

TMOs such as $\mathrm{TiO}_{2}$ and $\mathrm{ZnO}$ are widely synthesised in various $1 \mathrm{D}$ morphologies[25, 26]. As predicted, $\sigma$ in such quasi-1D structures is shown to increase compared to the bulk forms[46]. The carrier concentrations in such structures can be adjusted by the use of suitable dopants[46, 48]. There are many good review articles that cover the topic of electrical conductivity in various 1D TE TMO structures[46, 49]. 


\subsubsection{D materials}

QDSL or SNW structures, described in section 2.1.4, allow for electrical conduction through mechanisms such as tunnelling or hopping. Well-separated discrete energy states of the segments alter the fundamental properties such as DOS and bandgap energy in an alternating manner along the $1 \mathrm{D}$ wire $[50,51]$. At the same time, the $0 \mathrm{D}$ characteristics, and in particular the electrical conductivity, of each quantum dot is maintained by the energy differential of the conduction or valence bands between the two constituent materials that form the wire[28]. The electrical conductivity for such 0D structures is defined as: [27, 28]

$$
\sigma_{0 D}=e^{2} K_{(0)}
$$

$K_{(\alpha)}$ is defined in Eq. 6a. It can be seen from Eq. 11 that the $\sigma_{0 D}$ is a strong function of the diameter as well as the electronic DOS. An enhanced $\sigma$ is expected in QDSL and SNW structures with reducing diameters. This is mainly because of the increased carrier relaxation times in such low dimensional structures[51].

\subsection{Seebeck coefficient $S$}

The Seebeck coefficient is the magnitude of the induced voltage divided by the temperature gradient across a material. The Seebeck effect is caused by charge-carrier diffusion and phonon drag. Many TE TMOs such as $\mathrm{TiO}_{2}, \mathrm{ZnO}, \mathrm{CoO}$ and $\mathrm{MnO}_{2}$ exhibit large Seebeck coefficients. High $S$ values in TMOs usually arises from either high effective masses $\left(m^{*}\right)$ due to electronic correlations[52] or from electron-electron interactions[53]. An enhancement in the $S$ of TMOs can be achieved by altering the DOS through nanostructuring techniques. The theory governing the $S$ of bulk and low dimensional TE TMOs is presented in this section.

\subsubsection{Bulk (3D) materials}

For semiconducting TMOs in bulk form, the simplified Seebeck coefficient can be estimated by the following expression:[16] 


$$
S_{b u l k}=\frac{8 m^{*} \pi^{2} k_{B}^{2}}{3 e h^{2}} T\left(\frac{\pi}{3 n}\right)^{2 / 3}
$$

where, $n$ is the carrier concentration, $m^{*}$ is the carrier effective mass, $e$ is the electronic charge, $T$ is the temperature, $h$ is Planck's constant and $k_{B}$ is the Boltzmann constant.

Eq.12 shows that a higher $m^{*}$ results in larger Seebeck coefficients. TMOs usually exhibit high effective carrier masses, which explain the high $S$ values observed in many TMOs. From Eq. 12 it is also predicted that in an increase in $T$ also enhances $S$. Dramatically enhanced $S$ has been observed in many TMOs such as $\mathrm{ZnO}$ and $\mathrm{MnO}_{2}$ at elevated temperatures[5, 9] and will be discussed in their relevant sections.

\subsubsection{D materials}

2D quantum well structures can result in enhanced $S$ of TE TMOs materials due to changes in the Fermi energy of the carriers as well as the electronic DOS. For a 2D quantum well structure, the Seebeck coefficient is defined as:[20]

$$
\begin{gathered}
S_{2 D}=-\frac{k_{B}}{e}\left(\frac{2 F_{1}}{F_{0}}-\chi_{2 D}^{*}\right) \\
\chi_{2 D}^{*}=\frac{1}{k_{B} T}\left(E_{F}-\frac{\pi^{2} k_{B}^{2} T^{2}}{12 E_{F}}-\frac{h^{2} \pi^{2}}{2 m_{z}^{*} W^{2}}\right)
\end{gathered}
$$

where, $k_{B}$ is the Boltzmann constant, $e$ is the electron charge, $E_{F}$ is the Fermi energy, $T$ is the temperature, $m_{z}^{*}$ is the component of the effective mass, $W$ is the quantum well width and $F_{i}$ are Fermi-Dirac functions. $\chi^{*} 2$ is the reduced chemical potential for quasi-2D structures.

The decrease in $W$ of the quantum well is predicted to result in an enhanced $S$ as can be seen from Eq. 13a \& b. Additionally, the electron filtering (i.e. only high energy electrons can pass while others are scattered)[54] in such low-dimensional heterostructures is expected to decouple the $S$ and $\sigma$, allowing fairly independent control over these properties. The 
phenomenon of electron filtering is explained in more detail elsewhere[51, 55]. In 2D TMOs, an increase in $S$ has been experimentally observed. Ohta et al. demonstrated dramatic increases in $S$ (up to $\sim 5$ times) for $2 \mathrm{D}$ electron gas (2DEG) systems based on doped $\mathrm{TiO}_{2}$ which will be discussed in detail in Section 4.1.3[56, 57]. 2D layered cobalt oxides and rhodium oxide also show higher $S$ compared to their bulk forms[58, 59].

\subsubsection{D materials}

TMOs are widely synthesised in various 1D morphologies[26, 60-62]. Size reduction to a single dimension is expected to enhance $S$ due to the altered DOS. The $S$ for a $1 \mathrm{D}$ structure is defined as:[23]

$$
S_{1 D}=-\frac{k_{B}}{e}\left(\frac{3 F_{1 / 2}}{F_{-1 / 2}}-\eta\right)
$$

where, $F_{i}$ is the Fermi Dirac function, $e$ is the electronic charge, $k_{B}$ is the Boltzmann constant and $\eta=\zeta / k_{B} T$ is the reduced chemical potential, in which $\zeta$ is the chemical potential relative to the lowest bound state. In a 1D structure, $S$ is influenced by the Fermi level of the carriers (Eq.14), which in turn is strongly influenced by the width of the 1D structure.(see ref.[23] for details). Hence, an enhancement of $S$ is predicted with decreasing width of the 1D structure. $S$ is also a function of the energy derivative of the electronic DOS[35]. As the dimensionality decreases, an increase in Seebeck coefficient is expected because of changes in the DOS due to quantum confinement $[20,21,23,63]$. Due to the extensive information that is available about the crystal structures of TMOs, such morphological tuning of the DOS can be conveniently carried out. As predicted, the $S$ in 1D TE TMO such as $\mathrm{ZnO}$ nanowires is shown to increase due to quantum confinement[49] and exhibits a value of $\sim-450 \mu \mathrm{V} / \mathrm{K}$ at room temperature. 


\subsubsection{D materials}

QDSL and SNW structures as described in section 2.1.4 exhibit sharper DOS compared to higher dimensional structures, due to the superlattice-like structure along the wire axis (Fig. 2c). An electronic structure with sharp maxima in the DOS like this is predicted to be the best for TE materials[50,64]. Due to their unique electronic band structure and sharp density of states, an enhancement of $S$ is expected in QDSLs and SNWs[50].

The Seebeck coefficient of a segmented nanowire is defined as:[27, 28]

$$
S_{0 D}=-\frac{1}{e T}\left(\frac{K_{(1)}}{K_{(0)}}\right)
$$

From Eq. 6 a, b and 15 it is obvious that a sharp maximum in the electronic DOS (Fig. 2d) will result in a strong increase in the Seebeck coefficient. As the diameter is decreased, the size quantisation effects prevail, resulting in an enhanced $S$. The increase of $S$ in such $0 \mathrm{D}$ TMO structures is expected to be more pronounced. Even though metal oxide based SNWs have been synthesised[46, 65], there are no reports investigating their Seebeck coefficients. This presents a vast potential for future work in the field of TE TMOs.

From the discussion in this section, it is evident that reducing the dimensionality of TMOs offers opportunities to tune the key TE parameters of $\kappa, \sigma$ and $S$ independently. There has been a continuous development in the synthesis techniques of TMOs and there is a vast amount of information available about their crystal structure, phases and various morphologies. This allows flexibility in their fabrication which can be carried out at both large and small scales using liquid and gas phase deposition techniques, allowing tuning of their TE properties at low dimensions to engineer TMOs with high TPFs and figures of merit. A recent review article comprehensively discusses the latest developments in the synthesis of metal oxide nanostructures[66]. 

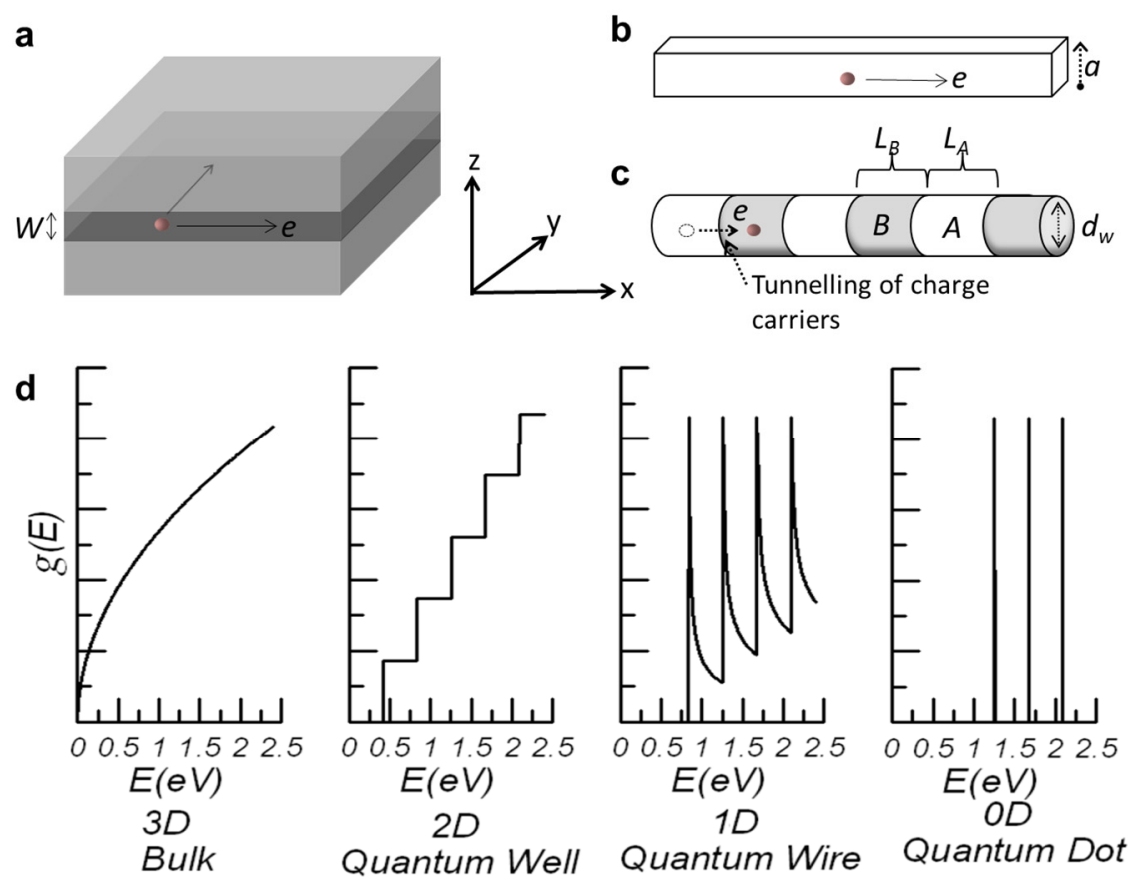

Fig. 2. (a) A 2D quantum well structure with width $W$, (b) $1 \mathrm{D}$ conductor (nanowire) with a square cross section of width $a$, (c) a segmented nanowire superlattice of diameter $d_{w}$ comprising of quantum dots $(0 \mathrm{D})$ of alternating materials $\mathrm{A}$ and $\mathrm{B}$, with respective segment lengths $L_{A}$ and $L_{B}$. (d) Energy dependence of the electronic DOS in 3D, 2D, 1D and 0D materials. ((c), (d) Reproduced with permission from [28] and [29].)

\section{Strategies to tune and alter TE parameters of TMOs}

The TE performance of TMOs is assessed on the basis of the application. Applications of TE TMOs can be classified into four major categories: (1) cooling and refrigeration, (2) energy scavenging from heat, (3) sensors and (4) thermopower wave sources, all of which will be discussed in detail in section 5. For cooling, refrigeration, and energy scavenging, a high TPF along with a low $\kappa$ is desirable[67, 68]. Sensors generally require high $S$ and low $\kappa$, while $\sigma$ can be either high or low depending on the type of sensor. Thermopower wave sources require a high TPF and benefit from a high $\kappa[5-7,69]$. Hence, the tuning of the key TE parameters in TMOs depends on the application.

Furthermore, a fundamental understanding of the carrier transport processes contributing to the TE effect in TMOs is required. There are however, many complexities in determining the 
key quantities in electron and phonon transport both theoretically and experimentally[70-72]. Tuning of transport properties of TE TMOs, such as reducing electronic thermal conductivity[73] or reducing the bipolar effect[74, 75], is possible. In their recent review papers, Minnich et al.[72] and Zebarjadi et al.[70] have extensively covered the challenges and strategies for improving our understanding of carrier transport processes.

In this section, the techniques that are commonly used to alter the TE parameters of TMOs are briefly discussed.

\subsection{Optimization using stoichiometry and doping techniques}

The incorporation of dopants and altering of stoichiometry are widely employed for adjusting the TE parameters of TMOs[76]. The type of application plays a crucial role in determining the correct technique in this regard[77]. For cooling, refrigeration, heat scavenging and sensing applications, methods that reduce $\kappa_{\text {phonon }}$ are generally desirable. Crystal disorder in the unit cell can be created by doping or altering stoichiometry of the TMO crystal lattice[34]. Such manipulations change the vibrational properties of the crystal and influence $\kappa_{\text {phonon }}[16]$ or by introducing additional scattering sites for phonons, thereby limiting $\kappa_{\text {phonon }}[78-82] . \kappa_{\text {electron }}$ is also affected by changing the stoichiometry and doping level of the TE TMOs. Kelectron depends on the electrical conductivity of TMOs (Eq. 2b) and is also a function of the Fermi level and charge carrier concentration, which are directly affected by changes of stoichiometry or incorporation of dopants[17]. In many refrigeration and heat scavenging applications, high electrical conductivity is desired, which generally directly increases $\kappa_{\text {electron. }}$ However, this is not desirable as it enhances the exchange of heat between two sides. Hence, doping, compositing and processes altering the oxygen deficiency can be implemented to achieve the desired thermal conductivity. Conversely, in thermopower wave sources, high TPF and $\kappa$ are desirable. This can be achieved by the use of metallic dopants or reducing the TMOs to a degree that the Seebeck coefficient is not compromised. Such 
dopants result in enhanced TPFs in TMOs such as $\mathrm{ZnO}$ and $\mathrm{CoO}_{2}$, which will be discussed in details in sections 4.4 and 4.7 respectively[83-95] [96].

After incorporating dopants and altering the stoichiometry, the most challenging issue is the determination of electronic band structures[70]. Theoretical methods such as density functional theory (DFT) can help; however, underestimation of the band gap by DFT calculations generally results in inaccuracy of theoretical predictions of the Seebeck coefficient and the bipolar effect[70]. Many methods have been developed to address this issue, such as the dynamical mean-field theory (DMFT)[97] which has been successfully applied to the case of TMOs[98].

The calculation of electron mobility and carrier lifetime is even more challenging. First principles calculations can only be performed on limited supercell sizes and the inclusion of long range potentials is difficult[70]. More importantly, inelastic scattering mechanisms at the elevated operating temperatures of TE TMOs renders relaxation time approximations (RTA) calculated from first-principles and DFT mostly invalid[99, 100]. The details of carrier lifetime in many TE TMOs are still relatively unknown. Hence, an improved fundamental understanding of the mechanisms governing the formation, stability, and properties of interfaces is required[54].

\subsection{Substructuring}

In engineering TE TMOs, it is generally desirable to decouple $\kappa_{\text {phonon }}$ and $\kappa_{\text {electron. For many }}$ refrigeration and heat scavenging applications it is desired to adjust $\kappa_{\text {phonon }}$ without affecting $\sigma$

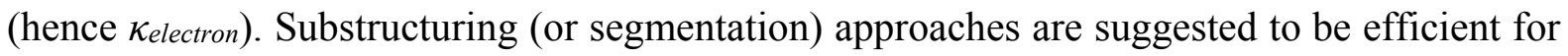
such manipulations. Substructuring relies on a periodic arrangement of layers with different electron and phonon transport characteristics, resulting in a complex material structure with distinct regions providing particular functionalities (Fig. 3). For many refrigeration and heat 
scavenging applications, an ideal TE TMO would comprise a high mobility semiconductor region entwined with a phonon scattering region that houses disordered structures (dopants and lack of stoichiometry), without affecting the carrier mobilities of the other region[16]. A detailed discussion on the substructuring approach is provided in another review[16]. TMOs occurring as natural superlattices can provide an independent control of transport properties, providing an excellent platform to engineer high performance TE materials. TMOs such as the doped cobalt oxide systems are a classic example of the benefits of substructuring approach, which will be discussed in detail later[11]. Another advantage of TMOs is that they can be fabricated in a variety of well-studied structures and a large number of synthesis techniques to fabricate them in different morphologies and structures have been wellestablished, making the substructuring approach highly attractive in order to tune their TE parameters according to the desired application.

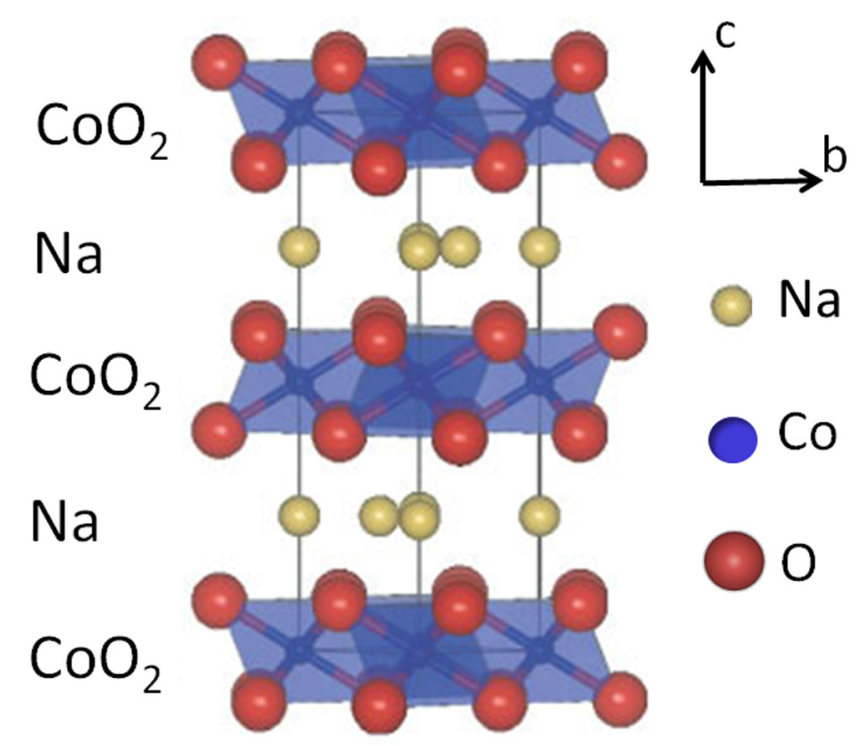

Fig. 3. Schematic depiction of the substructuring approach in doped cobalt oxide, comprising of ordered $\mathrm{CoO}_{2}$ layers that are separated by disordered layers (of $\mathrm{Na}$ dopant) to achieve a good electrical conductivity and poor phonon conductivity. (Reproduced with permission from[42].) 


\subsection{Nanostructuring}

As discussed earlier, the $S, \sigma$ and $\kappa$ for conventional 3D crystalline TMOs are interrelated and cannot be controlled independently. Any increase in $\sigma$ results in an enhanced $\kappa_{\text {electron }}$ (Eq. 2b). Additionally, a change in the Fermi level and carrier concentration affects both $\kappa_{\text {electron }}$ and $\kappa$ phonon.

At the nanometer scale, there are significant changes to the electronics of TE TMOs (see section 2), which allow for alternative techniques to control the $S, \sigma$ and $\kappa$ in a relatively independent manner. In nanostructured materials, quantum confinement effects [51] and surface properties become much more important, and result in properties that are changed from those of the bulk forms. The quantum confinement of carriers in nanostructured TMOs is predicted to enhance both their TPF and ZT (see section 2.2 and 2.3) [63]. Additionally, it is well known that nanostructuring of TMOs alters their Fermi level and carrier concentration.[31] Nanostructures also introduce additional scattering mechanisms. If the spacing between the nanoparticles is larger than the electron mean free path (MFP), they will act as an additional source of electron scattering in the host material. If however, the spacing is smaller than the electron MFP, the scattering mechanisms will become much more complex since the leakage of the electron wave into the nanoparticles is no longer negligible.[70, 101] The nanostructuring technique has resulted in enhanced TPFs and ZTs in TMOs such as $\mathrm{TiO}_{2}, \mathrm{ZnO}$, cobalates and manganates which will be discussed in detail in Section 4[56] [91] [102, 103].

In addition to the electronics of TMOs, their phonon propagation properties and as a result $\kappa_{\text {phonon }}$ can be tuned via nanostructuring (see section 2.1), resulting in enhanced phonon scattering and altered phonon mean free paths.[103] If the dimensions of semiconducting TE TMOs are smaller than the mean free path of the phonons, but larger than the mean free path of the charge carriers, a reduction in $\kappa_{\text {phonon }}$ can be obtained due to boundary scatterings, 
without affecting $\sigma$. Koumoto et al. have reviewed the progress in the development of nanostructured TE TMOs[22].

Nanostructuring can be implemented to decrease the lattice thermal conductivity by introducing many interfaces with spacing smaller than the phonon mean free path. Although reducing lattice thermal conductivity through alloying and/or nanostructuring techniques has been the most effective way to improve performance of TE TMOs for conventional applications, details of phonon transport mechanisms are still not very well understood[72]. Even in bulk form, theoretical and experimental determination of quantities such as phonon mean free path is still a challenge[72]. Phonon transport models based on Callaway model of thermal conductivity[104] usually require adjusting various fitting parameters causing inconsistency in the models fundamental predictions such as phonon's wavelength and mean free path. Calculations of the thermal conductivity and phonon mean free path in TE TMOs using combined density functional theory (DFT) $[105,106]$ and molecular dynamics (MD) [107-109] simulations on the other hand are difficult and computationally costly because of the extremely complex crystal structure of alloys and misfit layered oxides. Moreover, the introduction of many interfaces in the material via nanostructuring adds more complexity to the problem.

The problem is even more complex in case of electron transport. In case of heavily doped complex TE TMOs, the standard analysis based on the Boltzmann equation with the assumption that the mean free path is much larger than the de Broglie wavelength leads to inaccurate results[72, 110]. Nanostructuring further complicates the problem as the interfaces introduce complex scattering mechanisms that should be accounted for in theoretical analysis[111]. Therefore, modeling the transport phenomena in bulk and nanostructured TE TMOs would require more powerful tools such as the non-equilibrium Green's functions with the inclusion of electron wave effects[72]. 


\subsection{Compositing}

It is suggested that composites can be useful in controlling TE parameters of TMOs, as they can be designed to show high density of the interfaces[112], that can be used for adjusting both phonon and electron scattering. TMO composites' distinct advantages are their cost effectiveness and scalability[113]. An excellent review article discussing the impact of the bulk composite engineering approaches on $S, \sigma$ and $\kappa$ can be seen in ref. [72]. Composites of TMOs have resulted in enhanced TPFs, which will be discussed later in the relevant sections[91, 114].

\section{Transition metal oxides and their TE properties}

In this section, the most common TMOs that have been investigated for their TE properties will be discussed. An overview of their crystal structures and their TE properties in doped and various stoichiometry conditions will be presented. Additionally, different synthesis methods of these TE TMOs will be illustrated. For further information regarding the structures, properties and syntheses of TMOs, the readers can refer to comprehensive text books in this field[115-117].

\subsection{Titanium oxides $-\mathrm{TiO}_{x}$}

\subsubsection{Crystal structure}

$\mathrm{TiO}_{2}$ is one of the most investigated metal oxides for a wide variety of photocatalytic, TE, solar cell, biosensing and gas sensing applications. $\mathrm{TiO}_{2}$ has a bandgap of $\sim 3.2 \mathrm{eV}$ in its intrinsic form[118]. The most common polymorphs of $\mathrm{TiO}_{2}$ are anatase, rutile and brookite. Rutile and anatase exhibit a tetragonal structure, while brookite is orthorhombic[119]. The transformation with increasing temperature usually follows the sequence: anatase $\rightarrow$ brookite $\rightarrow$ rutile. Generally in between room temperature and $598 \mathrm{~K}$ anatase is the dominant polymorph. Above $625 \mathrm{~K}$, the anatase transforms to brookite[120]. Heating of titania in the 
temperature range of 873 to $1275 \mathrm{~K}$ leads to an alteration of phase stabilities, and it transforms almost completely to rutile. Many reviews on the various crystal structures, size and temperature dependence of the different polymorphs as well as different morphologies of stoichiometric and non-stoichiometric $\mathrm{TiO}_{x}$ exists[119-121].

\subsubsection{TE properties of stoichiometric $\mathrm{TiO}_{2}$}

$\mathrm{TiO}_{2}$ can be synthesised in many different morphologies such as spheroidal nanocrystallites, nanoparticles, nanotubes, nanosheets, nanofibers and epitaxial thin films[122]. The room temperature $S$ of crystalline $\mathrm{TiO}_{2}$ is reported to be approximately $-600 \mu \mathrm{V} / \mathrm{K}$, while $\sigma$ of the order of $10^{3} \mathrm{~S} / \mathrm{m}$ is observed, resulting in a TPF of $360 \mu \mathrm{W} / \mathrm{m} \cdot \mathrm{K}^{2}$. The $\kappa$ at room temperature is $\sim 5.8 \mathrm{~W} / \mathrm{m} . \mathrm{K}$ and is reduced with increasing temperature $(\sim 2.8 \mathrm{~W} / \mathrm{m} . \mathrm{K}$ at $1073 \mathrm{~K})$ [123]. Owing to a moderate $\sigma$ and high $\kappa$, the $\mathrm{ZT}$ in pure $\mathrm{TiO}_{2}$ is low $(<0.025)[123,124]$. However, non-stoichiometric $\mathrm{TiO}_{(2-x)}$ has been demonstrated to be promising for $\mathrm{TE}$ applications at both cryogenic [125] and elevated temperatures[124]. The TE properties of reduced, oxidized and doped $\mathrm{TiO}_{2}$ are discussed next.

\subsubsection{TE properties of non-stoichiometric, doped and composite $\mathrm{TiO}_{x}$}

Non-stoichiometric $\mathrm{TiO}_{x}$ can show fascinating TE properties both at elevated and cryogenic temperatures. Tsuyomoto et al. have shown that $\mathrm{TiO}_{x}(x=1.94)$ with an orthorhombic crystal structure, exhibits a peak $S$ of $-518 \mu \mathrm{V} / \mathrm{K}$ and $\sigma$ of $2 \times 10^{3} \mathrm{~S} / \mathrm{m}$ at $\sim 350 \mathrm{~K}$. They demonstrated that both $S$ and $\sigma$ increase with temperature, resulting in a TPF of $\sim 540 \mu \mathrm{W} / \mathrm{m} . \mathrm{K}^{2}$ at $343 \mathrm{~K}$ [126]. Interestingly, single crystal rutile $\mathrm{TiO}_{2}$ reduced to $\mathrm{TiO}_{(2-x)}$ via annealing in $\mathrm{H}_{2}$ at elevated temperatures as high as $1050 \mathrm{~K}$ shows exceptionally high TPFs at cryogenic temperatures. $\mathrm{TiO}_{(2-x)}$ generates enlarged phonon scattering by the defect planes, resulting in low thermal conductivities $(0.83 \mathrm{~W} / \mathrm{m} . \mathrm{K})$. Fig. $4 \mathrm{a} \& 4 \mathrm{~b}$ depict that $\mathrm{TiO}_{(2-x)}$ can exhibit an extraordinary $S$ of up to $-60,000 \mu \mathrm{V} / \mathrm{K}$, with TPF and ZT of $\sim 1.7 \times 10^{4} \mu \mathrm{W} / \mathrm{m} . \mathrm{K}^{2}$ and 0.1 , respectively, at temperatures in the range of $10 \mathrm{~K}[125]$. Another study showed that non- 
stoichiometric $\mathrm{TiO}_{(2-x)}$ with a rutile crystalline structure, formed after annealing and reduction in a carbon environment at $1373 \mathrm{~K}$, demonstrates a TPF of $100 \mu \mathrm{W} / \mathrm{m} \cdot \mathrm{K}^{2}$ at temperatures of up to $550 \mathrm{~K}[124]$. Obviously, the introduction of oxygen vacancies in the $\mathrm{TiO}_{2}$ crystal result in enhanced $\sigma$ due to an increase in carrier concentration (Eq. 8). In contrast, a prolonged oxidation of $\mathrm{TiO}_{2}$ at elevated temperatures, results in lower $\sigma$ and $S(-600$ to $+150 \mu \mathrm{V} / \mathrm{K})$ and therefore low TPFs and ZTs $(<0.1)$. Additionally, a transition from n-type to p-type is also observed in the oxidation process, at temperatures around $1300 \mathrm{~K}[127]$.

In addition to the change of stoichiometry, the doping technique is usually employed to tune the TE properties in $\mathrm{TiO}_{2}$. As discussed in section 3.1, metallic dopants are useful as they result in enhanced electrical conductivities. Additionally, the doping process creates crystal disorder, which reduces the lattice thermal conductivities. It has been shown that $\mathrm{Na}$ doped titanate nanotubes (DTNTs) with a composition such as $\mathrm{Na}_{2-x} \mathrm{H}_{x} \mathrm{Ti}_{3} \mathrm{O}_{7}$ result in TPFs ranging between $174-280 \mu \mathrm{W} / \mathrm{m} \cdot \mathrm{K}^{2}$, and a peak ZT of 0.3 , at elevated temperatures $(745-1032$ K).[128] 2\% $\mathrm{Nb}$ doped, anatase, n-type $\mathrm{TiO}_{2}$ epitaxial films show a $\mathrm{TPF}$ and $\mathrm{ZT}$ of $250 \mu \mathrm{W} / \mathrm{m} . \mathrm{K}^{2}$ and 0.25 , respectively, at $900 \mathrm{~K}[129]$. Similar observations have also been made by Sheppard et al. at elevated temperatures[130,131].
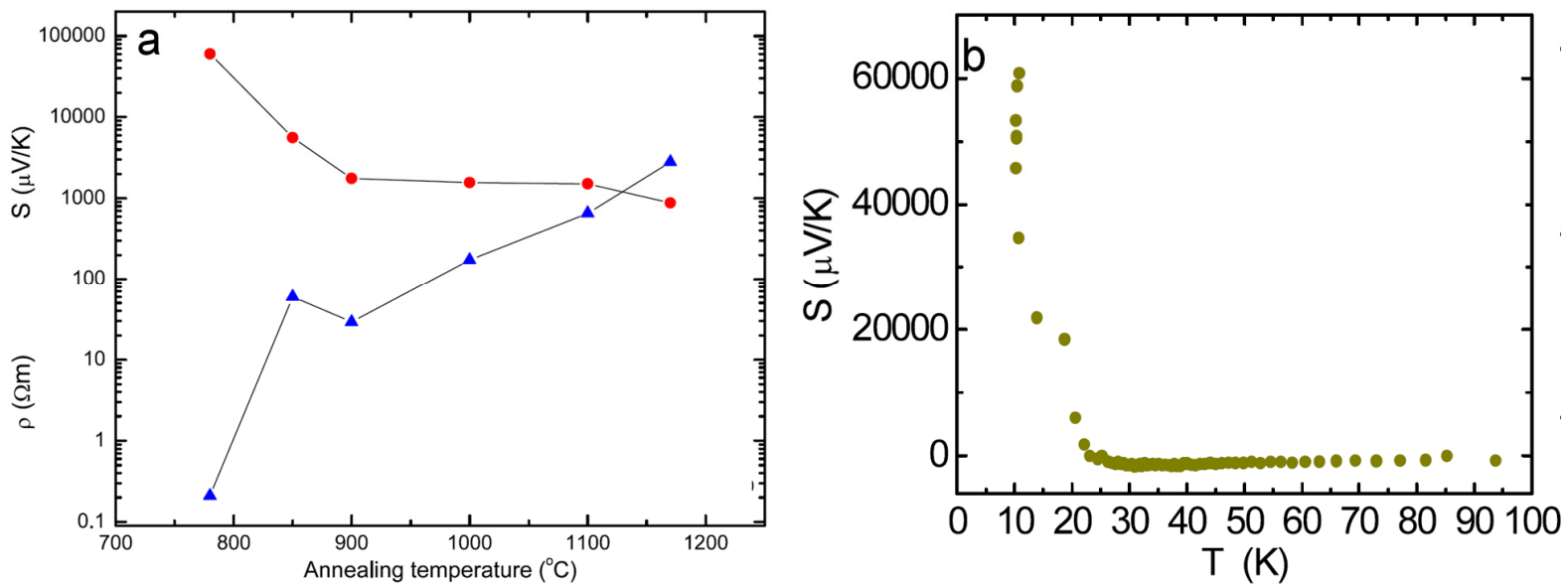

Fig. 4. (a) Seebeck coefficient (red) and electrical resistivity (blue) of reduced single crystal rutile $\mathrm{TiO}_{x}$ as a function of annealing temperature and (b) Seebeck coefficient as a function of temperature for a sample annealed in $\mathrm{H}_{2}$ at $1053 \mathrm{~K}$. (Reproduced with permission from [125].) 
A $\mathrm{TiO}_{2}$ composite commonly investigated for its excellent TE properties is strontium titanate $\left(\mathrm{SrTiO}_{3}\right)$, also known as $\mathrm{STO}[1,57,132]$. STO is a perovskite type oxide that exists in an isotropic cubic crystal structure at temperatures above $100 \mathrm{~K}$. Additionally, it shows a strong structural tolerance to substitutional doping. Due to its $d$-band nature, the effective mass of carriers is quite large in STO, resulting in a high $S$ (Eq.12). Additionally, STO exhibits a very high melting point ( $\sim 2350 \mathrm{~K})$, suggesting its stability at high temperatures[22].

In its pure form, STO is essentially an insulator; however, it can be tuned to be semiconducting or metallic by substitutional doping with $\mathrm{La}^{3+}$ or $\mathrm{Nb}^{5+}[57]$. The highest TPF and ZT for La and $\mathrm{Nb}$ doped STO single crystal has been reported to be $3600 \mu \mathrm{W} / \mathrm{m} . \mathrm{K}^{2}$ and 0.1 , respectively at room temperature, while the corresponding values at $1000 \mathrm{~K}$, are $865 \mu \mathrm{W} / \mathrm{m} . \mathrm{K}^{2}$ and 0.27 , respectively (Fig. 5a-e) [133] [1, 132] [134]. A number of studies on the TE properties of La and $\mathrm{Nb}$ doped STO thin films exist[129] [134] [135]. The ZT values are limited primarily due to its high $\kappa(\sim 11.0-3.2 \mathrm{~W} / \mathrm{m} . \mathrm{K}$ in the temperatures of $300-1000 \mathrm{~K}$ respectively) [22]. This high $\kappa$ value can be ascribed to the perovskite type structure of STO, which even in the presence of dopant cations as point defects, lacks effective phonon scattering centers.

Muta et al. suggested that a $\mathrm{Ca}^{2+}$ substitution at $\mathrm{Sr}^{2+}$ sites may result in reduced $\kappa$, as it is established that such substitutions result in the introduction of defects that usually lower $\kappa[136]$. However, Yamamoto et al. have reported that such an approach results in a dramatic reduction of the TPF, which indicates that any further improvement in $\mathrm{ZT}$ is almost impossible to achieve in a conventional 3D bulk state of STO[137].

A reduction in the STO dimensionality is a strategy that is predicted to enhance TE properties by offering independent control of the key TE parameters (section 2). The fabrication of a two-dimensional electron gas (2DEG) can be useful as it results in a $2 \mathrm{D}$ quantum 
confinement of carriers. Ohta et al. utilized a high density 2DEG, which is confined within a layer of STO that has a thickness of a unit cell $(0.3905 \mathrm{~nm})[56]$. Such $2 \mathrm{DEG}$ is realized in $\mathrm{SrTiO}_{3} / \mathrm{SrTi}_{0.8} \mathrm{Nb}_{0.2} \mathrm{O}_{3}$ superlattices and $\mathrm{TiO}_{2} / \mathrm{SrTiO}_{3}$ heterointerfaces. It was shown that in an optimised state, a 2DEG exhibits a massive TPF of $1.0 \times 10^{5} \mu \mathrm{W} / \mathrm{m} . \mathrm{K}^{2}$. The resultant $\mathrm{ZT}$ at room temperature was approximately 2.4 even if a $\kappa$ value of a bulk single crystal STO is used (12 W/m.K). A recently published review article discusses new developments in STO based thermoelectrics in detail[78]. 

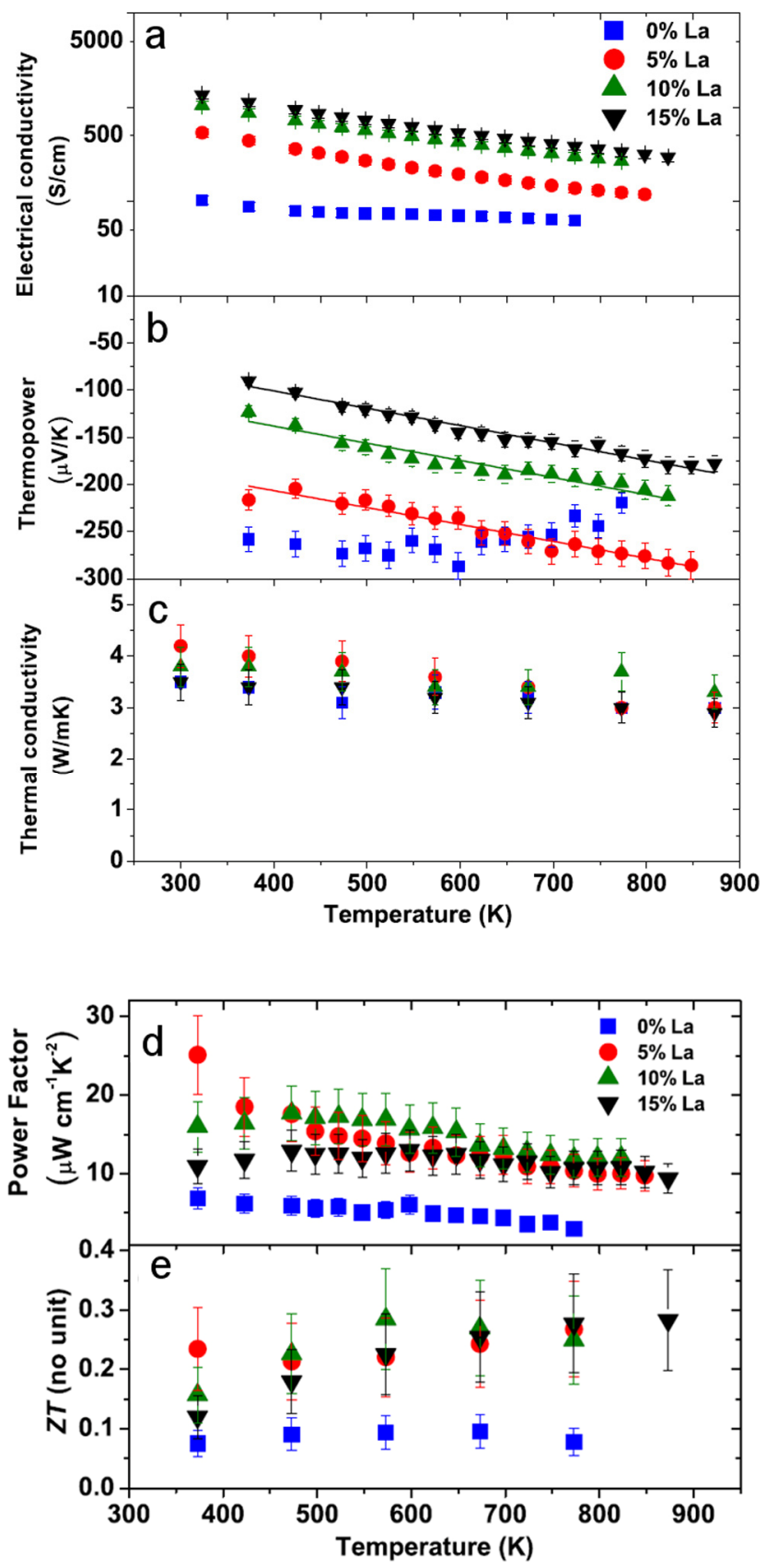

Fig. 5. (a) Electrical conductivity, (b) Seebeck coefficient, (c) thermal conductivity, (d) TPF and (e) ZT vs temperature for different concentrations of La dopant in STO thin films. (Reproduced with permission from [134].)

\subsubsection{Methods of synthesis}

Many different vapour chemical based methods have been used for forming $\mathrm{TE} \mathrm{TiO}_{2}$ materials. Chemical synthesis which involves sol gel hydrolysis, electrochemical methods such as anodization of $\mathrm{Ti}$ and hydrothermal synthesis have been commonly used for 
producing doped or non-stoichiometric $\mathrm{TiO}_{2}$, as the concentration of dopants and metal/oxygen ratios can be readily controlled in such methods[122],[138] [128].

Vapour deposition techniques including sputtering and pulsed laser deposition (PLD) have also been commonly used for forming highly crystalline $\mathrm{TiO}_{2}$ with predetermined concentrations of dopants[129]. STO thin films doped with both La and oxygen vacancies have been shown to be synthesized using the PLD technique[134] [139]. PLD can also be used in forming 2DEG STO crystals comprised of superlattices of insulating/ $\mathrm{Nb}$-doped layers of STO to achieve very high TPF of $1.0 \times 10^{5} \mu \mathrm{W} / \mathrm{m} \cdot \mathrm{K}^{2}[56,57]$.

\subsection{Manganese oxides - $\mathrm{MnO}_{x}$}

\subsubsection{Crystal structure}

$\mathrm{MnO}_{2}$, the most common form of manganese oxide, is a small bandgap $(\sim 1.3 \mathrm{eV})$, n-type semiconductor and is widely used for electrodes in supercapacitors, electrochemical batteries and microbial fuel cells[140] and as a catalytic material[141]. It exists in a number of structural forms $[142,143]$. The most common polymorphs are the $\alpha-\mathrm{MnO}_{2}$ (psilomelane monoclinic structure) and $\beta-\mathrm{MnO}_{2}$ (pyrolusite - rutile structure) [140]. Other forms known as $\delta$-, $\gamma$ - and $\lambda-\mathrm{MnO}_{2}$ also exist, and differ in the way in which the $\mathrm{MnO}_{6}$ octahedra are linked[138, 144, 145]. A detailed study of various crystal phases of $\mathrm{MnO}_{2}$ is presented elsewhere[143].

\subsubsection{TE properties of stoichiometric $\mathrm{MnO}_{2}$}

$\beta-\mathrm{MnO}_{2}$ has been reported to be promising for TE applications at elevated temperatures[9, 142]. Although, the semiconducting properties of $\alpha-, \beta$ - and $\gamma-\mathrm{MnO}_{2}$ have been studied in detail,[146] their TE properties have not been widely investigated, and only a limited number of studies exist. It has been reported that bulk and thin film $\beta-\mathrm{MnO}_{2}$ exhibit $S$ of 
approximately $-300 \mu \mathrm{V} / \mathrm{K}$ and $\sigma$ of $10^{3} \mathrm{~S} / \mathrm{m}$, resulting in a TPF of $90 \mu \mathrm{W} / \mathrm{m} \cdot \mathrm{K}^{2}[147]$. Recently, Song et al. reported extremely high Seebeck coefficients in $\beta-\mathrm{MnO}_{2}$ nanopowder[142]. The $S$ and $\sigma$ of the $\mathrm{MnO}_{2}$ thin films have been shown to increase dramatically with temperature[9]. A Seebeck coefficient of approximately $-1900 \mu \mathrm{V} / \mathrm{K}$ at a temperature of $623 \mathrm{~K}$ has been demonstrated. The $\sigma$ of the thin films at such elevated temperatures is $\sim 10^{3} \mathrm{~S} / \mathrm{m}$, resulting in a TPF of $3600 \mu \mathrm{W} / \mathrm{m} . \mathrm{K}^{2}$. The $\kappa$ for $\mathrm{MnO}_{2}$ is reported to be approximately $4 \mathrm{~W} / \mathrm{m} . \mathrm{K}[9]$.

Although the TPF of $\mathrm{MnO}_{2}$ is high, its ZT is still low. As suggested in section 3.3, nanostructuring can be used to tune the TE properties of a material. $\mathrm{MnO}_{2}$ nanostructures such as nanorods and nanowires have been synthesized via various methods [9, 142].

\subsubsection{TE properties of non-stoichiometric, doped and composite $\mathrm{MnO}_{x}$}

Doping and compositing are good strategies that can be used for increasing TE performance of $\mathrm{MnO}_{x}$ by introducing defects in the crystal structure, thereby impeding the lattice thermal conduction. Polycrystalline, bi-layered $\mathrm{LaSr}_{2} \mathrm{Mn}_{2-x} \mathrm{Co}_{x} \mathrm{O}_{7}(x<0.2)$ has been reported to exhibit extremely low TPFs[148]. However, the most commonly reported manganate stoichiometry for TE applications is the perovskite type $\mathrm{CaMnO}_{3}$. It exhibits an orthorhombic symmetry in which each Mn atom is surrounded by six Mn neighbours. It occurs in two anti-ferromagnetic crystal phases: the A-type and G-type, out of which the G-type phase is more stable. The Gtype phase exhibits an indirect bandgap of $0.7 \mathrm{eV}$, which accounts for its perfect semiconducting behaviour[149]. The mixed valent, perovskite electron doped manganite $\mathrm{CaMnO}_{3}$ has been shown to be a promising n-type TE material, especially at high temperatures[79]. This perovskite system exhibits $S$ of $-350 \mu \mathrm{V} / \mathrm{K}$ and $\sigma$ of $50 \mathrm{~S} / \mathrm{m}$, resulting in a TPF of $6.1 \mu \mathrm{W} / \mathrm{m} . \mathrm{K}^{2}$, which is very low for TE applications. However, the electrical conductivity of such an oxide can be enhanced by introducing suitable dopants[22]. The manganate may be doped on either site. The most commonly used dopant is ytterbium (Y) on 
the calcium site and niobium $(\mathrm{Nb})$ on the manganese site. The $\mathrm{Y}$ doping is particularly beneficial as it results in a lower $\kappa$ and has been shown to be the most effective dopant[7881].

A peak TPF of $300 \mu \mathrm{W} / \mathrm{m} . \mathrm{K}^{2}$ has been reported in $\mathrm{CaMn}_{0.96} \mathrm{Nb}_{0.4} \mathrm{O}_{3}$ at $1000 \mathrm{~K}$. The highest reported value of $\mathrm{ZT}$ is 0.2 at $1000 \mathrm{~K}$ for the stoichiometry $\mathrm{Ca}_{1-x} \mathrm{R}_{x} \mathrm{MnO}_{3}$, which is much less than the desired value of at least 1 , to make it practically applicable in TE modules[150]. Unfortunately, it has been predicted, using the dynamical mean field theory, that ZT $>1$ in electron doped $\mathrm{CaMnO}_{3}$ is rather unlikely to be achieved[79].

Koumoto et al. used a nanostructuring approach in an effort to enhance the TE performance as predicted in section 3.3[22]. They showed that $\mathrm{Ca} 0.9 \mathrm{Yb}_{0.1} \mathrm{MnO}_{3}$ nanoparticles synthesised using gas phase reaction (GPR) show a higher TPF and ZT compared to those synthesised using solid state reaction (SSR) or liquid phase reaction (LPR). This is because GPR generally results in smaller and impurity-free particles due to the nature of the reaction medium. The difference in the TE properties of the GPR and SSR synthesised nanoparticles over a temperature range of 300 to $1100 \mathrm{~K}$ is shown in Fig. 6a-c. The highest value of the TPF was $190 \mu \mathrm{W} / \mathrm{m} . \mathrm{K}^{2}$ at $973 \mathrm{~K}$, for the GPR synthesised nanoparticles, mainly due to lower electrical resistivity. The change of ZT with temperature for the GPR and SSR synthesised nanoparticles is shown in Fig. 6d. The maximum ZT value was 0.13 at $1073 \mathrm{~K}$ for particles synthesised using the GPR, which was approximately 1.5 times higher compared to the one's synthesised using SSR at the same temperature[22]. In this case, there was no significant enhancement in the TPF and ZT after nanostructuring. 

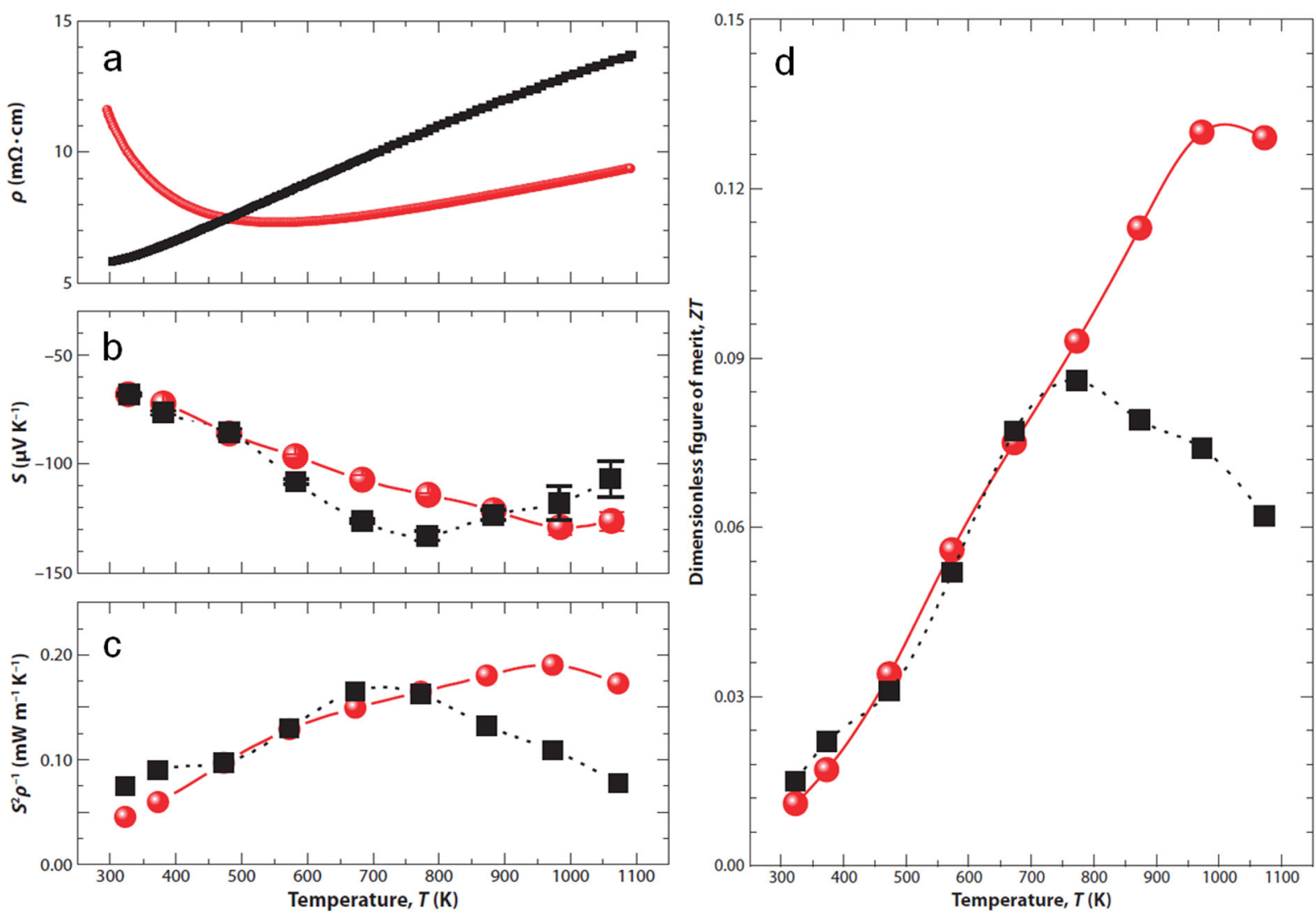

Fig. 6. (a) Resistivity, (b) Seebeck coefficient, (c) TPF and (d) ZT of GPR (red) and SSR synthesised (black) $\mathrm{Yb}$-doped $\mathrm{CaMnO}_{3}$ nanoparticles (Reproduced from [22].)

\subsubsection{Methods of synthesis}

Similar to other metal oxides, various liquid and gas phase synthesis techniques have been used for forming $\mathrm{MnO}_{2}$. Electrochemical techniques such as anodization and electrodeposition are some of the commonly used liquid phase methods[151-154]. Chemical techniques such as the sol-gel and hydrothermal are also used to prepare crystalline $\alpha$ and $\beta$ $\mathrm{MnO}_{2}$ [155-157]. Vapour phase techniques such as PLD, atomic layer deposition (ALD) and molecular beam epitaxy (MBE) have also been used to synthesise $\mathrm{MnO}_{2}$ thin films[158-160]. 


\subsection{Tungsten oxides $-\mathrm{WO}_{x}$}

\subsubsection{Crystal structure}

Tungsten oxides $\left(\mathrm{WO}_{x}\right)$ are widely studied for sensing, chromic and photocatalytic properties[60] and $\mathrm{WO}_{3}$ is the most commonly investigated stoichiometry of $\mathrm{WO}_{x} . \mathrm{WO}_{3}$ is an n-type TMO with a perovskite-like structure. It is well known for its various properties in a non-stoichiometric form, as its lattice can support a significant concentration of oxygen vacancies[60, 161]. Crystals of $\mathrm{WO}_{3}$ are formed by the corner and edge sharing of $\mathrm{WO}_{6}$ octahedra. Such corner sharing results in the following crystal phases: monoclinic I $(\gamma)$, monoclinic II $(\varepsilon)$, triclinic $(\delta)$, orthorhombic $(\beta)$, tetragonal $(\alpha)$ and cubic (although cubic is not a commonly observed phase) [60]. Under different temperature conditions, bulk $\mathrm{WO}_{3}$ follows the following sequence: monoclinic II $\left(\varepsilon-\mathrm{WO}_{3},<230 \mathrm{~K}\right) \rightarrow \operatorname{triclinic}\left(\delta\right.$ - $\mathrm{WO}_{3}, 230$ to $290 \mathrm{~K}) \rightarrow$ monoclinic $\mathrm{I}\left(\gamma-\mathrm{WO}_{3}, 290 \mathrm{~K}\right.$ to $\left.603 \mathrm{~K}\right) \rightarrow$ orthorhombic $\left(\beta-\mathrm{WO}_{3}, 603 \mathrm{~K}\right.$ to $1013 \mathrm{~K}) \rightarrow$ tetragonal $\left(\alpha-\mathrm{WO}_{3},>1013 \mathrm{~K}\right)[162,163]$. At room temperature, $\gamma-\mathrm{WO}_{3}$ is the most stable crystal phase[60]. The bandgap of $\mathrm{WO}_{3}$ ranges between $2.6-3.25 \mathrm{eV}$ depending on the crystal phase and size[60]. Tungsten oxide, which is synthesised or manipulated in liquid media, is very commonly found in hydrated form $\left(y \mathrm{H}_{2} \mathrm{O} \cdot \mathrm{WO}_{3}\right)$.

\subsubsection{TE properties of stoichiometric $\mathrm{WO}_{3}$}

There are only a few studies that have examined the TE properties of stoichiometric $\mathrm{WO}_{3}$ and $\mathrm{WO}_{3}$ hydrates $[164,165] . \mathrm{WO}_{3}$ exhibits $\sigma$ ranging between $10-10^{-2} \mathrm{~S} / \mathrm{m}$ depending on the stoichiometry[166]. Additionally, $\sigma$ is also influenced by the grain size, film thickness and dopants. Hence, the electrical properties are strongly dependent on the synthesis techniques and conditions[167]. It has been shown that the $S$ of $\mathrm{WO}_{3}$ hydrates is highly temperature dependent and generally increases linearly with temperatures between sub-zero to $323 \mathrm{~K}$. Beyond $373 \mathrm{~K}, S$ decreases exponentially and it also gradually loses the water content at 
higher temperatures. A peak $S$ with an absolute value of $480 \mu \mathrm{V} / \mathrm{K}$ is observed at $363 \mathrm{~K}[164]$. Due to a low $\sigma$, the TPF is poor.

Hutchins et al. investigated the TE properties of $\alpha-\mathrm{WO}_{3}$ films of different thicknesses (100$500 \mathrm{~nm}$ ) [168]. The $S$ of the n-type $\mathrm{WO}_{3}$ thin films varies with temperature (Fig. 7a), with the magnitude decreasing with increasing the film thickness, attaining a maximum absolute value of $\sim 780 \mu \mathrm{V} / \mathrm{K}$ at a temperature of $350 \mathrm{~K}$. Fig. $7 \mathrm{~b}$ shows that $\sigma$ of a $100 \mathrm{~nm}$ thick $\alpha-\mathrm{WO}_{3}$ film increases exponentially with temperature. The peak TPF of the $\alpha-\mathrm{WO}_{3}$ films was reported to be of the order of $1 \mu \mathrm{W} / \mathrm{m} \cdot \mathrm{K}^{2}[168]$. Additionally, Patil et al. demonstrated $S$ of $600 \mu \mathrm{V} / \mathrm{K}$ in stoichiometric $\mathrm{WO}_{3}$ films at a temperature of $473 \mathrm{~K}[165]$. The $\kappa$ of stoichiometric $\mathrm{WO}_{3}$ thin films is $1.63 \mathrm{~W} / \mathrm{m} \cdot \mathrm{K}[169]$. Undoped $\mathrm{WO}_{3}$ films thus exhibit a maximum TPF of $\sim 4 \mu \mathrm{W} / \mathrm{m} . \mathrm{K}^{2}$, which is rather too low to be considered for many TE applications except possibly in sensors for measuring temperatures.

\subsubsection{TE properties of non-stoichiometric and doped $\mathrm{WO}_{x}$}

Non-stoichiometric tungsten oxides have not shown any improvement in TE performance compared to the stoichiometric counterparts owing to the poor $\sigma[170]$. However, using other TMOs for doping $\mathrm{WO}_{3}$ appears to be an effective approach to manipulate its TE properties. Recently, the TE properties of $\mathrm{ZnO}$ doped $\mathrm{WO}_{3}$ ceramics were investigated[161]. The introduction of $\mathrm{ZnO}$ was shown to result in an increased $\sigma$, by approximately two orders of magnitude, while causing only a slight drop in $S$. A $\mathrm{ZnO}$ doping concentration of $0.5 \%$ was found to be optimal, resulting in a maximum TPF of $1.34 \mu \mathrm{W} / \mathrm{m} \cdot \mathrm{K}^{2}$ at $973 \mathrm{~K}$, which is similar to the values reported in stoichiometric $\mathrm{WO}_{3}$ and at least four orders of magnitude higher than that of non-stoichiometric $\mathrm{WO}_{3}[171]$. The variation of TPF with temperature for different levels of $\mathrm{ZnO}$ doping is shown in Fig. 7c. Aluminium oxide $\left(\mathrm{Al}_{2} \mathrm{O}_{3}\right)$ doping has also been shown to enhance $\sigma$ of $\mathrm{WO}_{3}$ by a factor of $10^{4}[166]$. Elevated $\sigma$ was also observed by adding $\mathrm{Co}_{3} \mathrm{O}_{4}, \mathrm{MnO}_{2}, \mathrm{LiO}_{2}$ and $\mathrm{TiO}_{2}$ dopants[172]. 
To make $\mathrm{WO}_{3}$ a viable TE TMO, nanostructured $\mathrm{WO}_{3}$ needs to be investigated for its $\mathrm{TE}$ properties. Although, $\mathrm{WO}_{3}$ nanostructures are widely synthesised and reported for other applications, a detailed investigation of their TE properties has not been carried out.
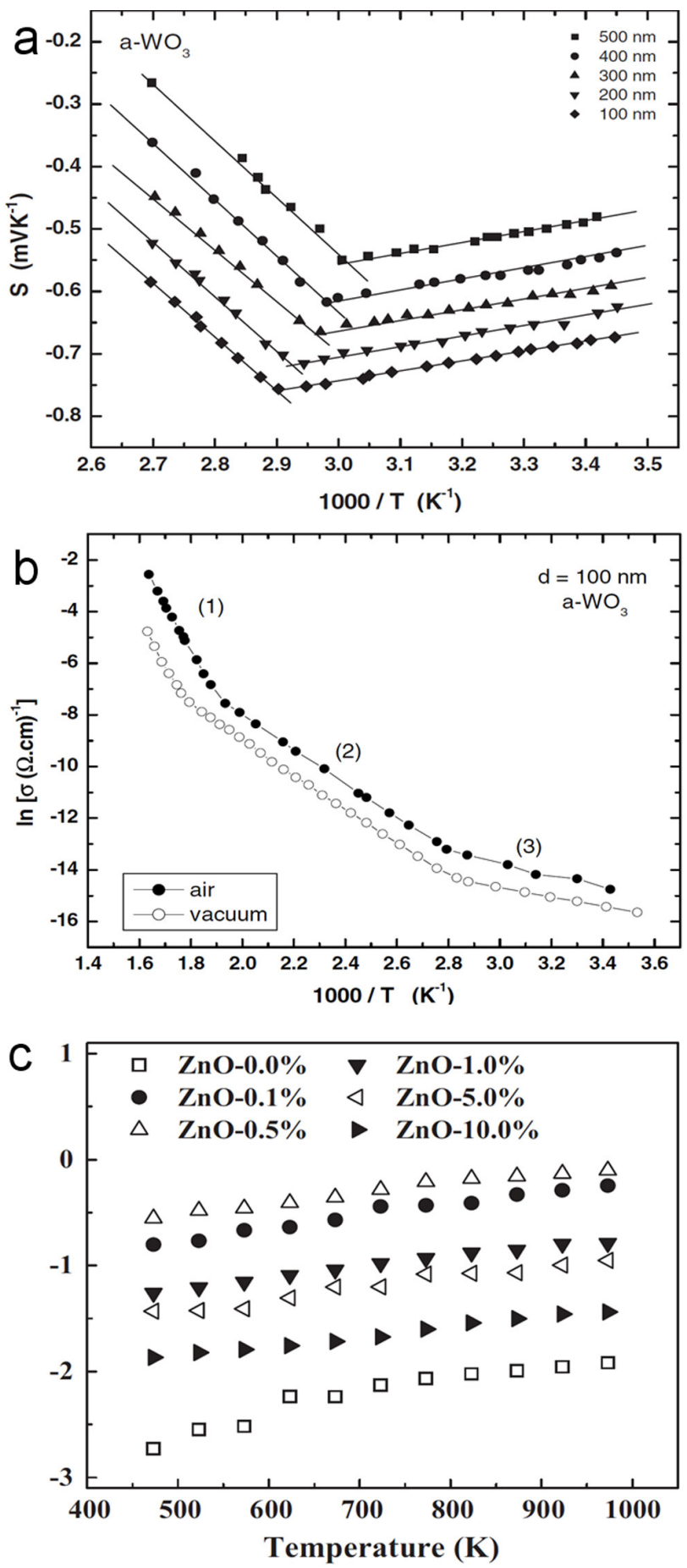

Fig. 7. (a) Seebeck coefficient, (b) electrical conductivity variation with temperature for $\alpha$ $\mathrm{WO}_{3}$ films and (c) TPF obtained for varying $\mathrm{ZnO}$ doping concentrations in $\mathrm{WO}_{3}$ ceramics. (Reproduced with permission from (a), (b) [168] and (c) [161].) 


\subsubsection{Methods of synthesis}

Many liquid and vapour phase synthesis methods have been used to synthesise $\mathrm{WO}_{3}$. Due to a high dependence of $\sigma$ on the stoichiometry, the parameters of synthesis techniques play important roles in determining the TE properties of $\mathrm{WO}_{3}$. The commonly used liquid phase techniques to synthesise crystalline $\mathrm{WO}_{3}$ are sol-gel, hydrothermal synthesis and electrochemical techniques such as anodization and electrodeposition[173-175] [60, 176, 177]. The most common vapour phase techniques include RF sputtering, PLD, electron beam evaporation and thermal evaporation[60, 178, 179]. A detailed review of synthesis techniques for various $\mathrm{WO}_{3}$ is presented elsewhere[60].

\subsection{Zinc oxides $-\mathrm{ZnO}$}

\subsubsection{Crystal structure}

$\mathrm{ZnO}$ is the most widely investigated $\mathrm{TMO}$ for a wide variety of photovoltaic, sensing, optoelectronic, piezoelectric and TE applications[43, 180-183]. ZnO is a direct bandgap binary n-type semiconductor with a bandgap of $3.3 \mathrm{eV}$ at room temperature and substantial ionic character residing at the borderline between a covalent and an ionic semiconductor[184]. It can show either a hexagonal wurtzite, cubic zinc-blende (which are both tetrahedral) or rarely rocksalt structure (which is formed at very high pressures) [43] [184]. In wurtzite structure, every $\mathrm{Zn}$ atom is surrounded by four oxygen atoms. In zincblende structure, each oxygen atom is surrounded by four $\mathrm{Zn}$ atoms in a similar fashion. At ambient temperatures and pressure wurtzite is the stable polymorph and a stable zinc-blende structure is generally obtained when $\mathrm{ZnO}$ is grown on cubic substrates[184]. 


\subsubsection{TE properties of stoichiometric $\mathrm{ZnO}$}

$\mathrm{ZnO}$ is considered as a promising high temperature TE material and can be synthesised in a variety of morphologies such as poly- and single crystal ceramics, epitaxial thin films, nanorods, nanobelts, nanorings, hierarchical nanostructures[43].

At ambient temperatures, pure $\mathrm{ZnO}$ shows a TPF of $\sim 800 \mu \mathrm{W} / \mathrm{m} . \mathrm{K}^{2}$. However, it also exhibits a high $\kappa(\sim 40 \mathrm{~W} / \mathrm{m} . \mathrm{K})$. The $\kappa$ of $\mathrm{ZnO}$ reduces at higher temperatures $(\sim 5 \mathrm{~W} / \mathrm{m} . \mathrm{K}$ at $1000 \mathrm{~K})$. This has been attributed to increased phonon scattering possibly as a result of large and substantially anisotropic thermal expansion of $\mathrm{ZnO}[185]$. Another study showed that sputtered $\mathrm{ZnO}$ thin films can exhibit TPFs as high as $1.0 \times 10^{3} \mu \mathrm{W} / \mathrm{m} . \mathrm{K}^{2}[5]$.

Although it is possible to reach low $\kappa$ 's of $2-3 \mathrm{~W} / \mathrm{m} . \mathrm{K}$ at room temperature for nanograined $\mathrm{ZnO}$ ceramics[186], these structures exhibit highly reduced $\sigma$ and therefore, neither TPF or ZTs improves. It has been postulated that the defects at grain boundaries are the major contributor to the drop in $\sigma[186]$. Overall, samples with larger grain sizes have been shown to exhibit higher $\sigma$.

As expected, nanostructuring approaches for bulk doped and undoped $\mathrm{ZnO}$ have also been shown to reduce $\kappa[91,186]$. A large number of studies on TE properties of pure and doped $\mathrm{ZnO}$ have been conducted on polycrystalline ceramics[84-86, 88-90, 92, 93, 187-198]. TE properties of $\mathrm{ZnO}$ thin films[199-201] as well as nanostructures [87, 91, 94, 202, 203] have also been targeted in a number of studies. Commonly, nanostructuring results in a significant increase in $S$. As temperature increases, both $S$ and $\sigma$ are enhanced, resulting in higher TPFs and ZTs.

Of more interest however, are the TE properties of doped and co-doped $\mathrm{ZnO}$, where the TPF and ZT can reach values as high as $1500 \mu \mathrm{W} / \mathrm{m} . \mathrm{K}^{2}$ and 0.65 respectively, making $\mathrm{ZnO}$ a viable candidate for a variety of TE applications. 


\subsubsection{TE properties of non-stoichiometric and doped $\mathrm{ZnO}$}

For heat scavenging applications, $\mathrm{ZnO}$ is commonly doped by n-type dopants such as $\mathrm{Al}, \mathrm{Ge}$, $\mathrm{Ni}$ and Ti to achieve improved TE properties. Al is the most common dopant for $\mathrm{ZnO}$ [8394]. Generally, Al doping increases the carrier mobility and reduces the phonon mean free path in the crystal lattice of $\mathrm{ZnO}$, resulting in higher $\sigma$ and lower $\kappa$. ZT has been shown to increase to as high as 0.30 at $1273 \mathrm{~K}$ for $\mathrm{Al}$ concentrations of $\sim 0.02$ and a high TPF of $1500 \mu \mathrm{W} / \mathrm{m} . \mathrm{K}^{2}$ has been achieved at such elevated temperatures [83] Beneficial effects of $\mathrm{Al}$ doping can also be described in terms of its contribution to the high $c$-axis compression of the $\mathrm{ZnO}$ lattice leading to the increase in effective mass $\left(m^{*}\right)$, resulting in enhanced $S$ (Eq. 12) [89].

The dependence of TE properties of Al-doped $\mathrm{ZnO}(\mathrm{AZO})$, on the grain structure and secondary phases is further highlighted in a study by Jood et al[91]. Bulk pellets, obtained by cold-pressing and sintering the nanocrystals that comprise of $\mathrm{ZnO}$ nanograins with $\mathrm{ZnAl}_{2} \mathrm{O}_{4}$ nanoprecipitates, were shown to reduce $\kappa$ to very low values $(1.5 \mathrm{~W} / \mathrm{m} \cdot \mathrm{K}$ at $300 \mathrm{~K})$. These nanocomposites also showed high $\sigma$ and $S$, resulting in a significantly high TPF and ZT of $900 \mu \mathrm{W} / \mathrm{m} . \mathrm{K}^{2}$ and 0.44 respectively, at $1000 \mathrm{~K}$.

There are also reports of co-doping $\mathrm{ZnO}$ with $\mathrm{Al}$ and other n-type dopants. Co-doping of $\mathrm{Fe}$, $\mathrm{Ni}$ and Sm metals with AZO has not shown significant improvement in TE properties, with the highest TPF and ZT of $675 \mu \mathrm{W} / \mathrm{m} \cdot \mathrm{K}^{2}$ and 0.126 respectively, for Ni-co-doped AZO at $1073 \mathrm{~K}$ [93]. On the other hand, co-doping of $\mathrm{AZO}$ with $\mathrm{Ga}$ resulted in significant improvement in $\mathrm{ZT}$. Ga co-doping seemed to increase the solubility of $\mathrm{Al}$ in $\mathrm{ZnO}$ and strongly reduce the $\kappa$ value at $2 \mathrm{~mol} \%$ of Ga. Also, much larger TPFs than those of AZO have been observed in co-doped samples (Fig. 8). The $\mathrm{ZT}$ value $\mathrm{Zn} 0.96 \mathrm{Al}_{0.02} \mathrm{Ga} 0.02 \mathrm{O}$ reached a maximum of 0.47 at $1000 \mathrm{~K}$ and 0.65 at $1247 \mathrm{~K}$, a significant enhancement over conventional $\mathrm{AZO}[88]$ 
A study on co-doped $\mathrm{Zn}_{0.97} \mathrm{Al}_{0.03-y} \mathrm{Ti}_{y} \mathrm{O}$ has shown an enhancement in both $\sigma$ and $S$, resulting in TPFs as high as $3.8 \times 10^{2} \mu \mathrm{W} / \mathrm{m} . \mathrm{K}^{2}$ for $\mathrm{Zn} 0.97 \mathrm{Al}_{0.02} \mathrm{Ti}{ }_{0.01} \mathrm{O}$ at $1073 \mathrm{~K}$.[86] $\kappa$ and $\mathrm{ZT}$ values of these samples have however not been reported. Ga doping has also been reported to improve $\mathrm{TE}$ properties of $\mathrm{ZnO}$ resulting in $\mathrm{ZT}$ values close to the best Al-doped $\mathrm{ZnO}$ ceramics[198].

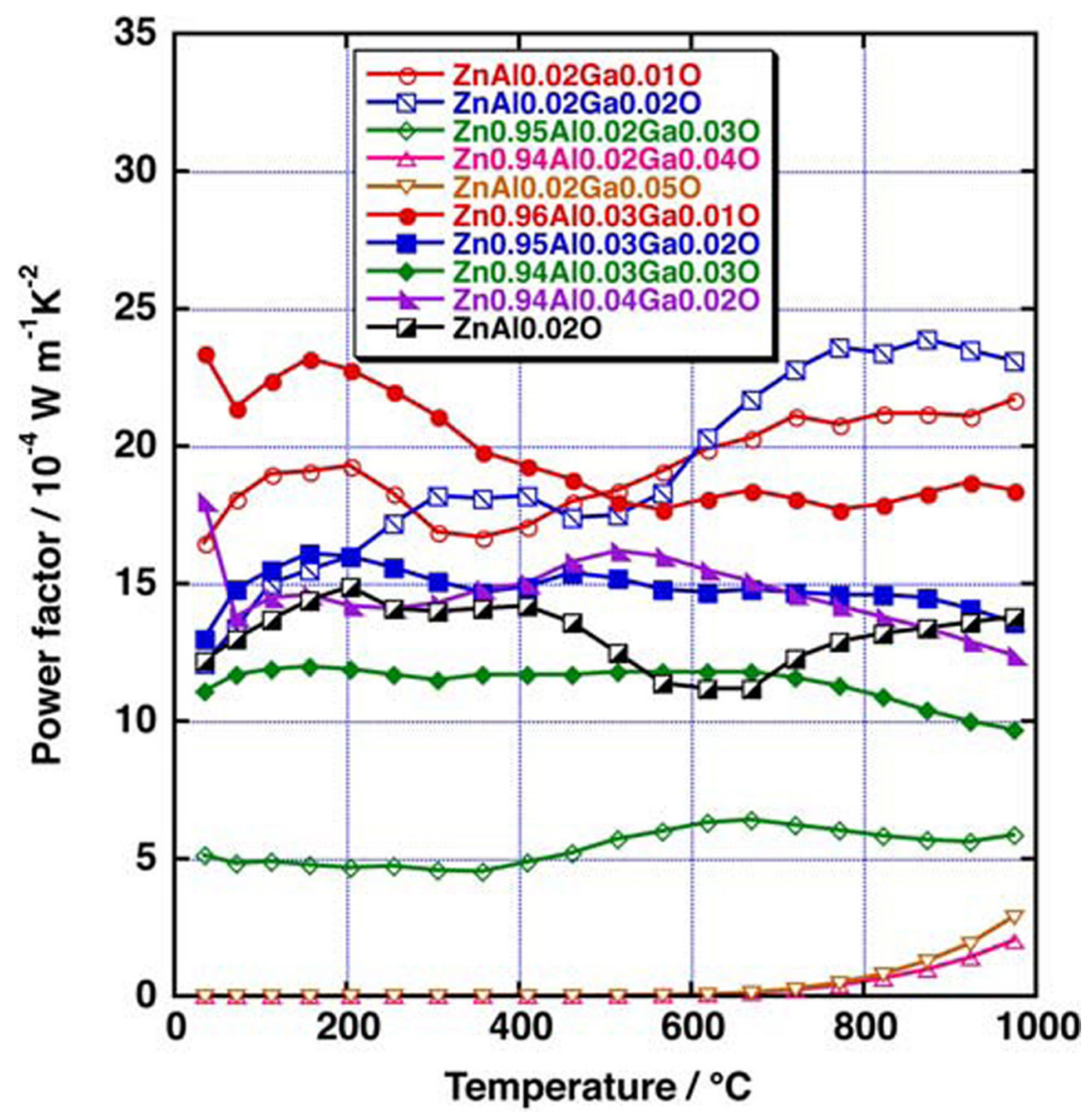

Fig. 8. Temperature dependence of TPF of $\mathrm{Zn}_{1-x-y} \mathrm{Al}_{x} \mathrm{Ga}_{y} \mathrm{O}$ ceramics. (Reproduced with permission from [88].)

\subsubsection{Methods of synthesis}

$\mathrm{ZnO}$ is widely synthesised using various liquid and vapour phase fabrication techniques. It can be synthesised in many different morphologies such as nanowires, nanospikes, nanopillars, nanorods and nanobelts. Over the years, liquid phase fabrication techniques such as hydrolysis, spray pyrolysis, sol-gel and hydrothermal synthesis have been employed to 
prepare $\mathrm{ZnO}$ for various applications[204-206] [207]. Other liquid phase methods to synthesise highly crystalline $\mathrm{ZnO}$ nanostructures include electrochemical techniques such as anodization and electrodeposition[208, 209].

Vapour deposition techniques such as RF/DC sputtering, ALD and MBE as well as chemical vapour deposition (CVD) technique and metal organic chemical vapour deposition (MOCVD) have been used to synthesise pure as well as doped $\mathrm{ZnO}$ thin films[210-213]. Other techniques such as spark plasma sintering (SPS) and PLD have also been widely used to synthesise densified $\mathrm{ZnO}$ in a powdered form[170][214, 215].

\subsection{Copper oxides $-\mathrm{Cu}_{2} \mathrm{O}$ and $\mathrm{CuO}$}

\subsubsection{Crystal structure}

Copper oxide occurs in two common phases: cuprous oxide $\left(\mathrm{Cu}_{2} \mathrm{O}\right)$ and cupric oxide $(\mathrm{CuO})$. $\mathrm{Cu}_{2} \mathrm{O}$ (copper(I) oxide) has been commonly used for application in solar cells, catalysts, and sensors[216]. It exhibits a cubic crystal structure with a forbidden direct bandgap of $\sim 1.9$ $2.2 \mathrm{eV}$, making it very challenging to study quantum confinement effects or modify its properties[217, 218]. $\mathrm{Cu}_{2} \mathrm{O}$ has also been shown to depart from stoichiometry towards excess oxygen, leading to a p-type semiconducting nature and has been one of the most studied materials in semiconducting physics[219]. On the other hand, $\mathrm{CuO}$ (copper(II) oxide) belongs to the monoclinic crystal system with a direct bandgap of 1.2-1.5 eV and has been studied for photoconductive applications and is also the basis for several high temperature superconductors[217, 220]. In $\mathrm{CuO}$, each $\mathrm{Cu}$ atom is coordinated by 4 oxygen atoms in an approximately square planar configuration. In a pure state and good stoichiometry, $\mathrm{CuO}$ behaves almost like an electrical insulator. However, non-stoichiometry leads to important semiconducting characteristics[221]. 


\subsubsection{TE properties of stoichiometric copper oxides}

A limited number of studies have been carried out on the TE properties of copper oxides in the 1990s. Jeong et al. examined the $S$ and $\sigma$ in uniaxially pressed $\mathrm{CuO}$ powder, which was subsequently sintered at different temperatures[222]. The $\mathrm{CuO}$ sample sintered at $1273 \mathrm{~K}$ in air, showed a peak $S$ of $\sim 650 \mu \mathrm{V} / \mathrm{K}$ between 400 to $500 \mathrm{~K}$. Beyond $500 \mathrm{~K}$, the $S$ dropped rapidly. The corresponding $\sigma$ as seen from Fig. 9a was approximately $1 \mathrm{~S} / \mathrm{m}$, resulting in a TPF of $0.42 \mu \mathrm{W} / \mathrm{m} . \mathrm{K}^{2}[222]$.

It has been shown that single crystal $\mathrm{Cu}_{2} \mathrm{O}$ exhibits a high $S$ at elevated temperatures $(\sim 1050 \mu \mathrm{V} / \mathrm{K}$ at $923 \mathrm{~K})$ [219]. On the other hand, the $S$ of $\mathrm{CuO}$ thin films has been shown to change with varying film thicknesses $(340 \mathrm{~nm}$ to $620 \mathrm{~nm})$ and exhibits a maximum value of $500 \mu \mathrm{V} / \mathrm{K}$ for $\sim 600 \mathrm{~nm}$ thick films (Fig. 9b) [221]. However, none of these works reported electrical or thermal conductivities. The full TE properties of intrinsic copper oxides are yet to be investigated.

\subsubsection{TE properties of non-stoichiometric, doped and composite copper oxides}

The doping technique has been shown to result in significant effect on the TE properties of copper oxides. Koffyberg et al. have demonstrated the TE effect in polycrystalline samples of Li doped $\mathrm{CuO}[223]$. They have shown an average p-type $S$ of $770 \mu \mathrm{V} / \mathrm{K}$ and $\sigma$ of $6.25 \mathrm{~S} / \mathrm{m}$, resulting in a TPF of $3.7 \mu \mathrm{W} / \mathrm{m} \cdot \mathrm{K}^{2}[223]$.

It seems that the most commonly investigated copper oxide composite for its TE properties is $\mathrm{La}_{2} \mathrm{CuO}_{4}$. It exhibits a simple layered structure comprising of $2 \mathrm{D}^{\mathrm{CuO}_{2}}$ planes in a unit cell and is the parent compound for high temperature superconductivity, which is related to the excess oxygen content and the structural change as a result of phase transition[224]. This layered structure makes the anisotropy of conduction very strong. Due to the anisotropic 
nature of their electrical conduction, such composites are potential TE materials. A detailed overview of its crystal phases is provided elsewhere[225].

For enhancing the TE properties of $\mathrm{La}_{2} \mathrm{CuO}_{4}$ metallic dopants can be incorporated. In this regard, TE properties of $\mathrm{La}_{2-x} \mathrm{R}_{x} \mathrm{CuO}_{4}$ polycrystalline ceramics, where $\mathrm{R}$ can be $\mathrm{Pr}, \mathrm{Y}$ or $\mathrm{Nb}$ have been investigated[226]. In this study, it has been shown that the choice of dopants plays a crucial role in determining the TE properties. Fig. 9c shows the variation of the TPF of La2${ }_{x} \mathrm{R}_{x} \mathrm{CuO}_{4}$ with temperature for different dopants. As can be seen, with increasing temperature the TPFs of all composites decrease, eventually becoming stable above 700 K[226]. Samples show $S$ ranging between 200 to $620 \mu \mathrm{V} / \mathrm{K}$. Amongst them $\mathrm{La}_{1.98} \mathrm{Y}_{0.02} \mathrm{CuO}_{4}$ ceramics exhibit a high TPF of $10^{3} \mu \mathrm{W} / \mathrm{m} . \mathrm{K}^{2}$. The maximum ZT was reported to be 0.17 at $330 \mathrm{~K}$, which is around 3 times higher than pure $\mathrm{La}_{2} \mathrm{CuO}_{4}[226]$.

Studies on TE properties of n-type $\mathrm{RE}_{2} \mathrm{CuO}_{4}$ oxides, where $\mathrm{RE}$ is a rare earth element such as neodymium, samarium or gadolinium, have shown TPFs and ZTs of the order of $10 \mu \mathrm{W} / \mathrm{m} . \mathrm{K}^{2}$ and 0.005 , respectively, at $950 \mathrm{~K}[227]$. The electrical resistivities of such composites show a negative temperature dependence and is at least a magnitude higher than many conventional TE materials. Such $\mathrm{RE}_{2} \mathrm{CuO}_{4}$ type oxides exhibit a high $\kappa$ of $\sim 30 \mathrm{~W} / \mathrm{m} . \mathrm{K}$ at $300 \mathrm{~K}$, which drops to $\sim 8 \mathrm{~W} / \mathrm{m} . \mathrm{K}$ at $950 \mathrm{~K}$ [227], and can potentially be suitable for thermopower wave applications. 

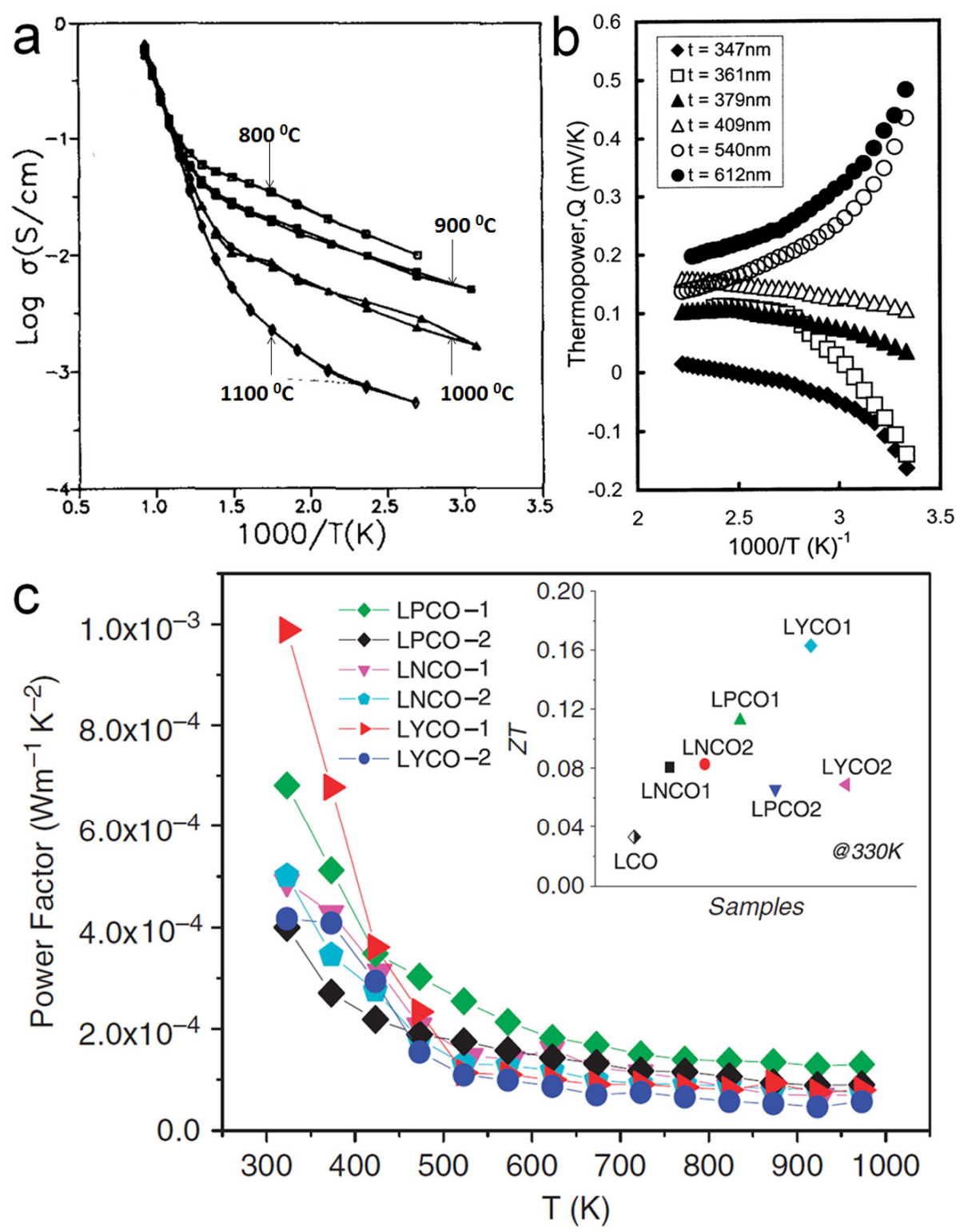

Fig. 9. (a) Electrical conductivity variation of $\mathrm{CuO}$ sintered at different temperatures, (b) Seebeck coefficient variation with temperature for $\mathrm{CuO}$ films of different thicknesses and (c) Temperature dependence of TPF for various $\mathrm{La}_{2} \mathrm{CuO}_{4}$ ceramics, (inset shows ZT values at $330 \mathrm{~K}$ ) [LNCO ( $\mathrm{Nb}$ doped $\left.\mathrm{La}_{2} \mathrm{CuO}_{4}\right)$, LPCO (Pr doped $\left.\mathrm{La}_{2} \mathrm{CuO}_{4}\right)$, LYCO (Y doped $\left.\left.\mathrm{La}_{2} \mathrm{CuO}_{4}\right)\right]$. (Reproduced with permission from (a) [222], (b)[226] and (c) [221].)

\subsubsection{Methods of synthesis}

Many liquid and vapour phase methods are used for synthesising $\mathrm{Cu}_{2} \mathrm{O}$ and $\mathrm{CuO}$. Liquid phase techniques of for the sol-gel[228], hydrothermal[229] and spray pyrolysis[230] have been used for the synthesis of copper oxides. Other liquid phase techniques commonly employed to prepare high purity copper oxides include electrochemical methods such as anodization and electrodeposition[231, 232]. The chemical synthesis methods, especially 
hydrothermal are much desired for many applications as they are low cost, offer morphology control and facilitate low temperature synthesis and are therefore viable for large scale production[229]. Additionally, they result in a departure from stoichiometry when it is needed due to the introduction of point defects and impurities in the crystal lattice. Vapour phase techniques such as RF sputtering, PLD, various evaporation approaches and MBE have been demonstrated to synthesise crystalline copper oxide thin films at different oxygen contents[220]. Additionally, the CVD technique has also been utilized to synthesise copper oxides[233].

In most copper oxide synthesis methods a mixture of phases like $\mathrm{Cu}, \mathrm{Cu}_{2} \mathrm{O}$ and $\mathrm{CuO}$ is obtained. Post-deposition annealing or deposition at high temperature is usually needed to achieve the desired phase. 


\subsection{Vanadium oxides}

\subsubsection{Crystal structure}

Vanadium oxide exists in many phases that include $\mathrm{VO}, \mathrm{VO}_{2}, \mathrm{~V}_{2} \mathrm{O}_{3}$ or $\mathrm{V}_{2} \mathrm{O}_{5}$. However, only $\mathrm{V}_{2} \mathrm{O}_{5}$ demonstrates $\mathrm{TE}$ properties and shows highly anisotropic n-type electrical conduction[234]. It has a direct bandgap of $\sim 2.4 \mathrm{eV}$ and is a promising electrode material for energy storage systems such as Li-ion batteries[235-238] and possesses a high ionic storage capacity because of its layered structure[239]. Over the years, it has also been intensely investigated for its electrochromic properties[240, 241]. Unlike other configurations of vanadium oxide that have been known to exhibit multiple crystal phases, $\mathrm{V}_{2} \mathrm{O}_{5}$ exists only as an orthorhombic crystal, which is fundamentally comprised of $\mathrm{VO}_{5}$ pyramids that form alternating double chains along the $b$-axis[242]. A detailed overview of the crystal structures of all phases of vanadium oxide is provided elsewhere[242].

\subsubsection{TE properties of stoichiometric $\mathrm{V}_{2} \mathrm{O}_{5}$}

Kounavis et al. have demonstrated that $\mathrm{V}_{2} \mathrm{O}_{5}$ gels exhibit a room temperature TPF of $0.3 \mu \mathrm{W} / \mathrm{m} . \mathrm{K}^{2}$ [243]. $\mathrm{V}_{2} \mathrm{O}_{5}$ films synthesised by sol-gel method exhibit $S$ of $\sim-200 \mu \mathrm{V} / \mathrm{K}$, but have very high resistances of the order of $10^{3}$ to $10^{4} \Omega$ [239]. Hence, it is evident that the $\sigma$ of $\mathrm{V}_{2} \mathrm{O}_{5}$ films requires significant enhancement for practical refrigeration and energy scavenging applications.

\subsubsection{TE properties of nanostructured, doped and composite $\mathrm{V}_{2} \mathrm{O}_{5}$}

Bahgat et al. have synthesized highly oriented nanocrystalline, hydrated vanadium pentoxide, $\left(\mathrm{V}_{2} \mathrm{O}_{5 .} n \mathrm{H}_{2} \mathrm{O}\right)$ films of $200 \mathrm{~nm}$ thickness. The $S$ and $\sigma$ of such films have been shown to increase with temperature, resulting in a peak TPF of $101.25 \mu \mathrm{W} / \mathrm{m} . \mathrm{K}^{2}$ at $480 \mathrm{~K}$ (Fig. 10a \& b) [244]. 
Iwanaga et al. have studied the TE properties of $\mathrm{V}_{2} \mathrm{O}_{5}$ thin films and reported that the introduction of metallic dopants ( $\mathrm{Na}$ in this case) can improve the TPF values dramatically. This is primarily due to an increase in $\sigma$ by a factor of up to $\sim 10^{4}$. At the same time, the $S$ reduces to almost half its value. The direct measurements of TPF have shown an enhanced TPF of $10 \mu \mathrm{W} / \mathrm{m} . \mathrm{K}^{2}$ (compared to $\sim 10^{-2} \mu \mathrm{W} / \mathrm{m} . \mathrm{K}^{2}$ for pure $\mathrm{V}_{2} \mathrm{O}_{5}$ films) for $35 \% \mathrm{Na}$ doping[245].

Liu et al. have shown that polyethylene oxide (PEO) intercalated layered $\mathrm{V}_{2} \mathrm{O}_{5}$ xerogel nanocomposites result in low TPFs.[246] $\mathrm{PbO}$ and $\mathrm{ZnO}$ based vandates have also been shown to exhibit $S$ of up to $-400 \mu \mathrm{V} / \mathrm{K}$ at room temperature[247]. However, $\sigma$ in such composites is low, so they can possibly be used only in temperature sensors.
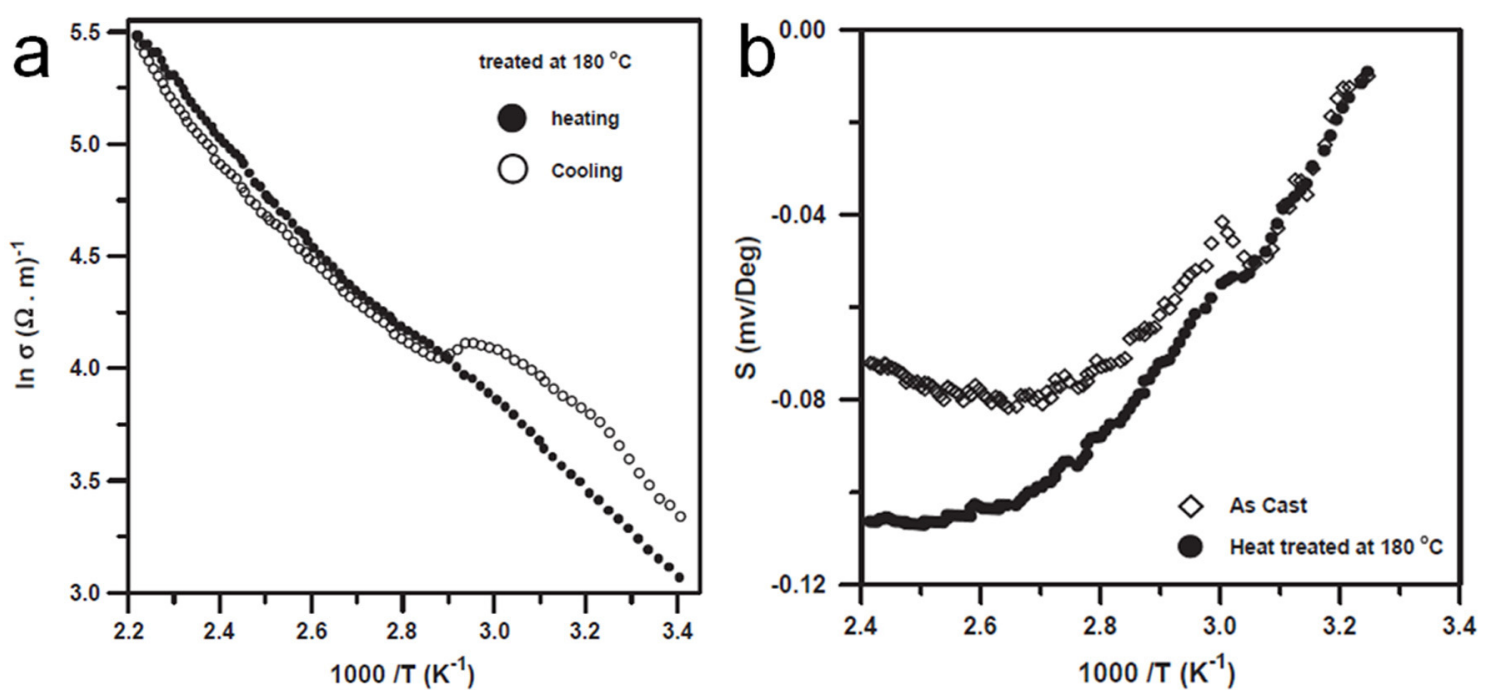

Fig. 10. Temperature dependence of (a) electrical conductivity, (b) Seebeck coefficient for the as-cast and heat treated films during heating and cooling cycles of hydrated $\mathrm{V}_{2} \mathrm{O}_{5}$. (Reproduced with permission from [244].)

\subsubsection{Methods of synthesis}

$\mathrm{V}_{2} \mathrm{O}_{5}$ films can be synthesised using various liquid and vapour phase techniques[248]. Commonly used liquid phase methods for the synthesis of $\mathrm{V}_{2} \mathrm{O}_{5}$ thin films are the sol-gel and the hydrothermal synthesis technique in which hydrated forms are obtained. The sol-gel 
synthesised hydrated nanocrystalline $\mathrm{V}_{2} \mathrm{O}_{5}$ has been shown to exhibit the highest TPF[244]. A melt quench technique has also been employed to dope various concentrations of $\mathrm{Na}^{+}$ions into sol-gel solutions and subsequently, thin films of $\mathrm{Na}$ intercalated $\mathrm{V}_{2} \mathrm{O}_{5}$ can be prepared[243, 245]. Hydrothermal synthesis is often utilized to synthesise $\mathrm{V}_{2} \mathrm{O}_{5}$ nanostructures such as nanotubes and nanowires[249, 250]. Other liquid phase methods include the electrodeposition and anodization techniques which have also been shown to synthesise $\mathrm{V}_{2} \mathrm{O}_{5}$ nanostructures[251-253].

Vapour phase techniques such as RF sputtering[254], ALD[255] and PLD[256] have also been shown to deposit crystalline $\mathrm{V}_{2} \mathrm{O}_{5}$ thin films of various phases. Additionally, the CVD method has also been demonstrated to form highly crystalline $\mathrm{V}_{2} \mathrm{O}_{5}$ thin films[257]. However, there are few reports on the TE properties of $\mathrm{V}_{2} \mathrm{O}_{5}$ prepared using vapour deposition techniques. 


\subsection{Cobalt oxides}

\subsubsection{Crystal structure}

Cobalt oxide based materials have received great attention for their application in gas sensing, heterogeneous catalysts, intercalation compounds for energy storages, electrochromic devices and more recently as TE materials [258, 259]. Cobalt oxides are generally found in two stable oxide compounds: $\mathrm{Co}_{3} \mathrm{O}_{4}$ and $\mathrm{CoO} \cdot \mathrm{Co}_{3} \mathrm{O}_{4}$ is the more stable of these two. Both $\mathrm{Co}_{3} \mathrm{O}_{4}$ and $\mathrm{CoO}$ exhibit a cubic lattice. $\mathrm{Co}_{3} \mathrm{O}_{4}$ is a spinel with the presence of both $\mathrm{Co}^{2+}$ and $\mathrm{Co}^{3+}$ ions in its lattice. $\mathrm{Co}_{3} \mathrm{O}_{4}$ exhibits a bandgap in the range of 1.4-1.8 eV, while $\mathrm{CoO}$ has a higher energy bandgap of 2.2-2.8 eV. Both $\mathrm{Co}_{3} \mathrm{O}_{4}$ and $\mathrm{CoO}$ are usually nonstoichiometric with excess oxygen, leading to p-type semiconducting behaviours[259].

\subsubsection{TE properties of stoichiometric cobalt oxides}

So far, the TE properties of pure cobalt oxides have not been investigated widely, mainly due to the fact that high resistivities result in a poor TE performance for many energy scavenging applications. It has been shown that in a bulk form $\mathrm{CoO}$ exhibits a TPF of $\sim 80 \mu \mathrm{W} / \mathrm{m} . \mathrm{K}^{2}$ at $1000 \mathrm{~K}[260]$. However, the use of various approaches suggested in section 3 such as the addition of metallic dopants, substructuring, and reducing the dimensionality have made doped cobalt oxides the best TMOs for various TE applications.

\subsubsection{TE properties of non-stoichiometric, doped, composite and nanostructured cobalt} oxides

Rare-earth cobalt oxides $\left(\mathrm{RECoO}_{3}\right)$ with perovskite crystal structures have been studied for their TE properties for energy scavenging and cooling properties and have shown relatively large figure of merits around the room temperature[82]. Their high-temperature performance is however limited.

P-type cobalt oxide composites are among the TE metal oxides with the largest ZT values reported to date. The most promising cobaltite composites for such TE applications are 
$\mathrm{Na}_{x} \mathrm{CoO}_{2}$ and $\mathrm{Ca}_{3} \mathrm{Co}_{4} \mathrm{O}_{9}[78]$. The high $\mathrm{ZT}$ values are associated with their crystal structures, which consist of $\mathrm{CoO}_{2}^{-}$planes composed of edge-sharing $\mathrm{CoO}_{6}$ octahedra, and other structural components between these layers. $\mathrm{Na}_{x} \mathrm{CoO}_{2}$ exhibits a weak monoclininc distortion with respect to the hexagonal unit cell caused by the ordering of a layer of sodium ions in between $\mathrm{CoO}_{2}$ planes, while $\mathrm{Ca}_{3} \mathrm{Co}_{4} \mathrm{O}_{9}$ comprises of a distorted rock-salt type layer of $\mathrm{Ca}_{2} \mathrm{CoO}_{3}$, which lowers thermal conductivity by shortening the phonon mean free path (Eq. 2a), and is located between two $\mathrm{CdI}_{2}$ type $\mathrm{CoO}_{2}$ layers that are mainly responsible for providing the path for electrical conduction. Hence, these composites are a classic example of substructuring, which is predicted to enhance TE performance (section 3.2).

Terasaki et al. are the pioneers of layered cobalt oxide base TE materials. They were the first group to demonstrate large TPFs of the order of $5 \times 10^{3} \mu \mathrm{W} / \mathrm{m} . \mathrm{K}^{2}$ (compared to $4 \times 10^{3} \mu \mathrm{W} / \mathrm{m} . \mathrm{K}^{2}$ for $\left.\mathrm{Bi}_{2} \mathrm{Te}_{3}\right)$ and $\mathrm{ZT}$ as high as 0.75 in $\mathrm{NaCo}_{2} \mathrm{O}_{4}$ single crystals at room temperature[11]. Fig. 11a \& b show the variation of resistivity and $S$ with temperature for the $\mathrm{NaCo}_{2} \mathrm{O}_{4}$ single crystals[11]. Subsequent studies have shown that polycrystalline $\mathrm{Na}_{x} \mathrm{CoO}_{2}$ exhibits TPF as high as $1.4 \times 10^{3} \mu \mathrm{W} / \mathrm{m} . \mathrm{K}^{2}$ for $x=0.85$ at room temperature[261, 262]. For $\mathrm{Na}_{x} \mathrm{CoO}_{2}$, silver (Ag) doping results in the enhancement of ZT[78]. Other metallic dopants such as $\mathrm{Cu}[95]$ and $\mathrm{Zn}[96]$ have also been shown to increase the TPFs, while Sr doping results in the improvement of ZT[263]. Polycrystalline $\mathrm{Na}_{x} \mathrm{CoO}_{2}$ typically shows a peak ZT of $\sim 0.11$. However, recently, two-dimensional (2D) and stacked $\mathrm{Na}_{x} \mathrm{CoO}_{2}$ nanostructures prepared by exfoliation/restacking method were reported to exhibit enhanced TE properties for energy scavenging applications, as expected from the discussion in section $2[264,265]$. The enhancement was attributed to the reduction of in-plane and cross-plane thermal conductivities in the super-lattice like structures, resulting in enhanced TPFs and ZTs of approximately $500 \mu \mathrm{W} / \mathrm{m} . \mathrm{K}^{2}$ and 0.4 , respectively. 
On the other hand, undoped $\mathrm{Ca}_{3} \mathrm{Co}_{4} \mathrm{O}_{9}$ exhibits $\sigma, S, \kappa$, TPF and $\mathrm{ZT}$ of $10^{4} \mathrm{~S} / \mathrm{m}, 150 \mu \mathrm{V} / \mathrm{K}$, $2 \mathrm{~W} / \mathrm{m} . \mathrm{K}, 225 \mu \mathrm{W} / \mathrm{m} . \mathrm{K}^{2}$ and 0.3 , respectively, at elevated temperatures as large as $1000 \mathrm{~K}$. Although, the room temperature TPFs performance of $\mathrm{Ca}_{3} \mathrm{Co}_{4} \mathrm{O}_{9}$ is inferior to $\mathrm{Na}_{x} \mathrm{CoO}_{2}$, it is more commonly used in various TE applications due to its superior stability to compositional changes and better performance at high temperatures[78].

Similar to $\mathrm{Na}_{x} \mathrm{CoO}_{2}$, the addition of $\mathrm{Ag}$ as a dopant[266, 267] or a second phase composite $[266,268,269]$ has been shown to improve $\mathrm{TE}$ properties of $\mathrm{Ca}_{3} \mathrm{Co}_{4} \mathrm{O} 9$. A $\mathrm{Ca}_{2.7} \mathrm{Ag}_{0.3 \mathrm{Co}} \mathrm{O} 9 / \mathrm{Ag}-10 \mathrm{wt} \%$ composite showed an enhanced $\mathrm{ZT}$ of 0.5 at $1000 \mathrm{~K}$. Bismuth (Bi) doping has also resulted in enhanced TPFs and reduced $\kappa$. However, the ZT of Bi-doped samples, is not as high as those of $\mathrm{Ag}$ doped oxides. $\mathrm{Ca}_{2.75} \mathrm{Gdd}_{0.25} \mathrm{Co}_{4} \mathrm{O}_{9}$ ceramics have also been shown to exhibit TPF and $\mathrm{ZT}$ of $480 \mu \mathrm{W} / \mathrm{m} \cdot \mathrm{K}^{2}$ and 0.23 respectively, at $923 \mathrm{~K}$ (Fig. 11c) [270]. It is seen that the $\mathrm{Ca}_{2.75} \mathrm{Gd}_{0.25} \mathrm{Co}_{4} \mathrm{O}_{9}$ ceramics synthesised using the SPS method exhibit slightly higher TPFs and ZTs compared to hot press (HP) synthesised samples (Fig. 11c). There are also reports on the doping of $\mathrm{Ca}_{3} \mathrm{Co}_{4} \mathrm{O}_{9}$ with transition metals $[271,272]$ such as copper and nickel. Gallium addition has been demonstrated to improve TPFs and ZTs[273]. Doping with lanthanum and lanthanide elements has also been studied but the TE enhancements have not been as impressive[78].
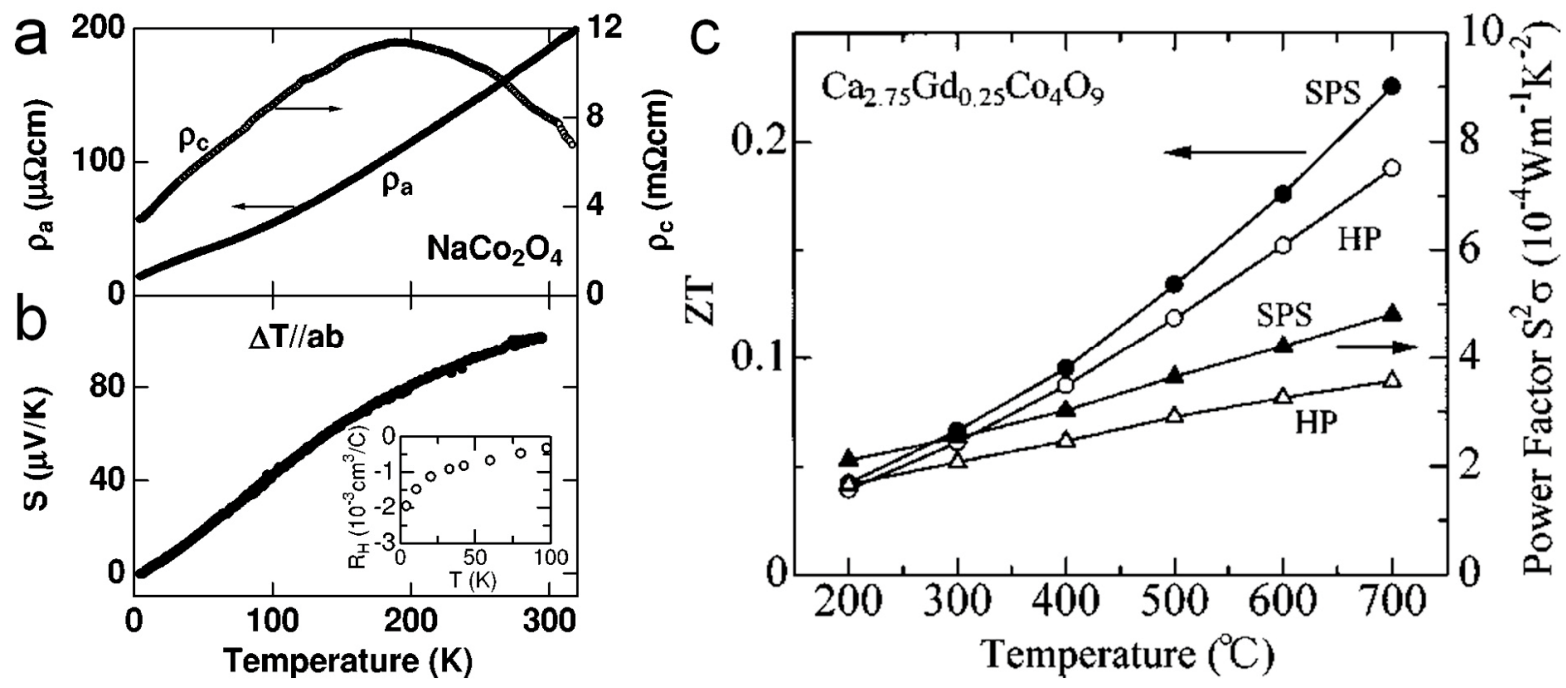
Fig. 11. (a) Resistivity and (b) Seebeck coefficient variations with temperature for $\mathrm{NaCo}_{2} \mathrm{O}_{4}$ single crystals in plane $\left(\rho_{\mathrm{a}}\right)$ and out of plane $\left(\rho_{\mathrm{c}}\right)$ and $(\mathrm{c})$ comparison of ZT and TPF for SPS and hot pressed (HP) synthesised $\mathrm{Ca}_{2} .{ }_{25} \mathrm{Gd}_{0.25} \mathrm{Co}_{4} \mathrm{O}_{9}$ samples. (Reproduced with permission from (a), (b) [11] and (c) [270].)

\subsubsection{Methods of synthesis}

Cobalt oxide can be synthesised using various liquid and vapour phase methods. Epitaxial thin films are generally preferred as they result in highly oriented structures[1, 274, 275]. Liquid phase techniques such as spray pyrolysis, sol-gel and hydrothermal have been employed to fabricate cobalt oxide thin films as well as nanostructures in various morphologies such as nanorods, hierarchical nanocolumns, nanocubes, nanowires and nanorods [258, 276-278]. Although, other liquid phase methods such as electrodeposition have also been employed[279]. An excellent review article summarises various liquid phase synthesis techniques for fabricating cobalt oxide nanostructures[278].

Vapour phase methods that include MBE, PLD and EBE have conventionally been used for the growth of epitaxial $\mathrm{Ca}_{3} \mathrm{Co}_{4} \mathrm{O}_{9}$ films. For $\mathrm{Na}_{x} \mathrm{Co}_{2}$ films however, the volatility of sodium ions poses difficulties in controlling stoichiometry. The CVD synthesis technique has been shown to be advantageous since it allows accurate tailoring of system composition, structure, morphology via suitable choice of a precursor compounds and deposition conditions[258]. 


\subsection{Rhodium oxides $-\mathrm{RhO}_{x}$}

\subsubsection{Crystal structure}

Rhodium oxides are generally found in two crystal oxide compounds: $\mathrm{RhO}_{2}$ and $\mathrm{Rh}_{2} \mathrm{O}_{3} \cdot \mathrm{RhO}_{2}$ exhibits a tetragonal rutile structure, which transforms into corundum type $\alpha-\mathrm{Rh}_{2} \mathrm{O}_{3}$ after annealing above $1000 \mathrm{~K}[280]$. Heating above such temperatures results in a transformation to orthorhombic type $\beta$ - $\mathrm{Rh}_{2} \mathrm{O}_{3}$ [281]. Rhodium oxides have been investigated primarily for applications in catalytic chemistry, electrochromisms and as a conductive transparent oxide[282-284]. Additionally, misfit-layered rhodium oxides with two-dimensional CdI2-type crystal structures, analogous to that of cobalt oxides, are among the best candidates for forming p-type TE materials[59]. As in the case for cobalt oxides, their superior thermopower properties originate from $\mathrm{CdI}_{2}$-type layers, which favour low spin state of $\mathrm{Rh}^{3+} / \mathrm{Rh}^{4+}$ with degeneracies of spin and orbital as the key factors[285]. The $\mathrm{CdI}_{2}$-type layer has a hexagonal symmetry, while the misfit layer is generally a square lattice. However, a layered Bi-Sr-Rh-O system with fluorite-type misfit layers with a trigonal symmetry has also been reported to exhibit similar TE properties[59].

\subsubsection{TE properties of stoichiometric $\mathrm{RhO}_{x}$}

There are no reports of stoichiometric $\mathrm{RhO}_{x}$ being employed in TE systems. What follows is a brief overview of the studies on rhodium oxide based metal oxide systems that are among the best p-type TE TMOs.

\subsubsection{TE properties of non-stoichiometric, composite and doped $\mathrm{RhO}_{x}$}

Okada et al. initially reported the first synthesized misfit-layered rhodium based metal oxide in polycrystalline form[286]. Samples of $\left(\mathrm{Bi}_{1-x} \mathrm{~Pb}_{x}\right)_{1.8} \mathrm{Sr}_{2} \mathrm{Rh}_{1.6} \mathrm{O}_{y} \quad(x=0,0.1,0.2)$ and $\mathrm{Bi}_{1.8} \mathrm{Ba}_{2} \mathrm{Rh}_{1.9} \mathrm{O}_{y}$ were investigated for their TE properties, with the most promising results being $125 \mu \mathrm{V} / \mathrm{K}, 213 \mathrm{~S} / \mathrm{m}$ and $3.3 \mu \mathrm{W} / \mathrm{m} . \mathrm{K}^{2}$ for $S, \sigma$ and $\mathrm{TPF}$, respectively, at room temperature (see Fig. 12a-c). In another study, polycrystalline samples of Co and Rh mixed 
solutions $\mathrm{Bi}_{1.7} \mathrm{Ba}_{2}\left(\mathrm{Co} 1-z \mathrm{Rh}_{z}\right) \mathrm{O}_{y}$ with hexagonal $(\mathrm{Co}, \mathrm{Rh}) \mathrm{O}_{2}$ layers have been synthesized in an effort to further alter the TE properties by decreasing $\kappa[287]$. Although $\kappa$ was reduced in the solid solution, the $\sigma$ also dropped due to the distortions made by different ionic size elements in $(\mathrm{Co}, \mathrm{Rh}) \mathrm{O}_{2}$ layers and therefore, TE performance did not improve.

Kobayashi et al. have synthesized rhodium oxide based single crystals in $\mathrm{Br}-\mathrm{Sr}-\mathrm{Rh}-\mathrm{O}$ systems with alternately stacked conductive $\mathrm{RhO}_{x}$ and insulating in $\left(\mathrm{Bi}_{0.75} \mathrm{Sr}_{0.25}\right) \mathrm{O}_{1.5}$ fluoritetype layers[59]. Interestingly, the misfit layer showed a trigonal symmetry with a rhombohedral unit cell, rather than the square-lattice usually observed in other oxides. Room temperature $S$ of up to $63 \mu \mathrm{V} / \mathrm{K}$ and $\sigma$ of $6.25 \times 10^{4} \mathrm{~S} / \mathrm{m}$ were obtained for $\mathrm{Bi}_{0.78} \mathrm{Sr}_{0.4} \mathrm{RhO}_{3+\mathrm{y}}$ crystals. The TPF of such a composite was estimated to be $248 \mu \mathrm{W} / \mathrm{m} . \mathrm{K}^{2}$, which is comparable to the values for cobalt oxide based systems[59]. Additionally, single crystals of $\mathrm{Ba}_{1.2} \mathrm{Rh}_{8} \mathrm{O}_{16}$ have been shown to exhibit $\kappa$ and $\mathrm{ZT}$ values of $3 \mathrm{~W} / \mathrm{m} . \mathrm{K}$ and 0.02 at $200 \mathrm{~K}$, respectively[288].

A recent first principle investigation of layered $\mathrm{K}_{x} \mathrm{RhO}_{2}$ composites based on ab-initio calculations and Boltzmann transport theory has suggested that the material system has the potential for exceptionally remarkable TE properties[289]. Calculations found large Seebeck coefficients in the temperature range of 0 to $700 \mathrm{~K}$ for hydrated phase of $\mathrm{K}_{x} \mathrm{RhO}_{2}$. Moreover a peak value of $\mathrm{ZT}=0.3$ is predicted for $\mathrm{K}_{7 / 8} \mathrm{RhO}_{2}$ at $100 \mathrm{~K}$, which is higher than $\mathrm{Na}_{x} \mathrm{CoO}_{2}$ systems. Even at room temperature, TPFs higher than $\mathrm{Na}_{x} \mathrm{CoO}_{2}$ are predicted[289]. 

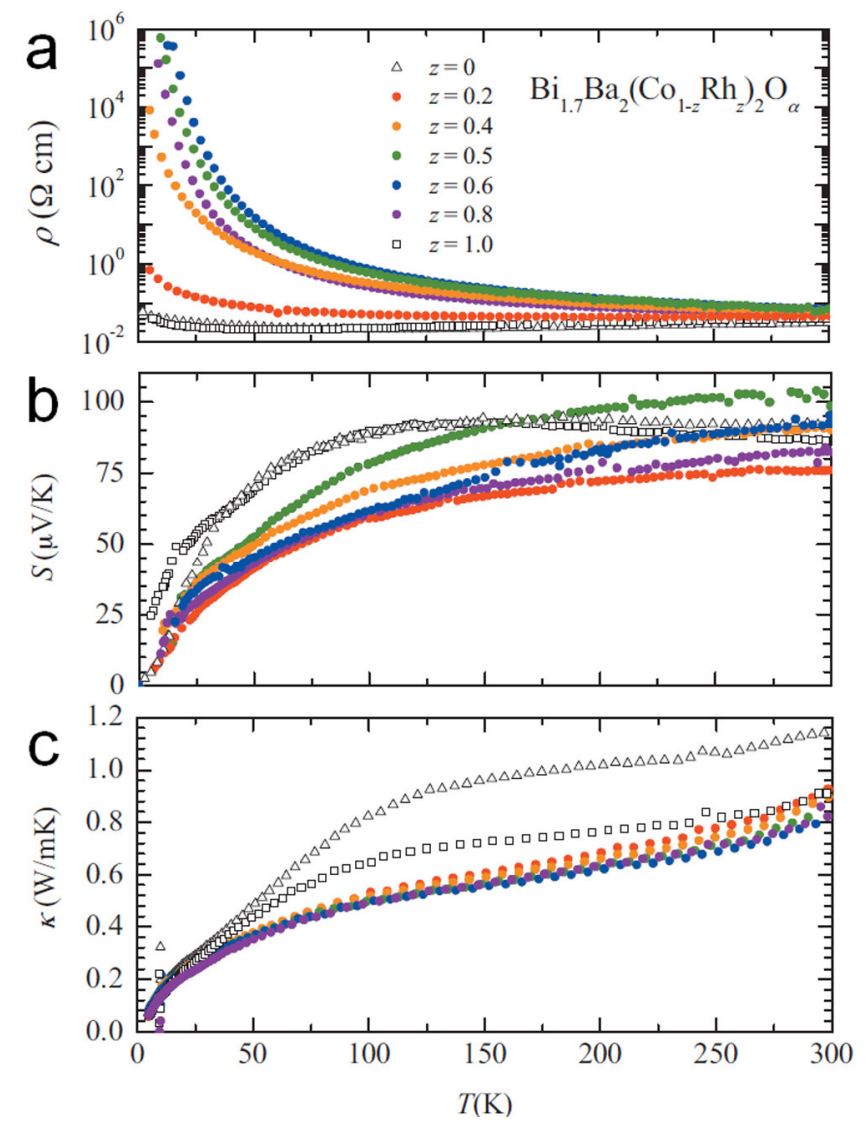

Fig. 12. Temperature $(T)$ dependence of (a) resistivity $(\rho)$, (b) Seebeck coefficient $(S)$, and (c) thermal conductivity $(\kappa)$ for $\mathrm{Bi}_{1.7} \mathrm{Ba}_{2}\left(\mathrm{Co}_{1-z} \mathrm{Rh}_{z}\right) \mathrm{O}_{y}$ of varying rhodium concentration $(z)$ (Reproduced with permission from [287].)

\subsubsection{Methods of synthesis}

Many liquid and vapour phase techniques are employed to synthesise rhodium oxides. Amongst the liquid phase synthesis techniques, sol-gel and hydrothermal are the most commonly used methods to synthesise $\mathrm{Rh}_{2} \mathrm{O}_{3}$ in various morphologies[290-292]. Vapour phase techniques such as RF sputtering, electron beam evaporation (EBE) and the CVD method are used for preparing crystalline rhodium oxide thin films[293]. Misfit, layered rhodium oxide composites such as $\left(\mathrm{Bi}_{1-x} \mathrm{~Pb}_{x}\right)_{1.8} \mathrm{Sr}_{2} \mathrm{Rh}_{1.6} \mathrm{O}_{y}$ are synthesised using the SSR technique[286, 287]. It should be considered that $\mathrm{RhO}_{2}$ is insoluble even in hot aqua regia, hence solution based synthesis techniques are not employed for forming $\mathrm{RhO}_{2}$. $\mathrm{SSR}$ is therefore commonly utilised[294]. 


\subsection{Molybdenum oxides $-\mathrm{MoO}_{x}$}

\subsubsection{Crystal structure}

The most common stoichiometries of $\mathrm{MoO}_{x}$ are $\mathrm{MoO}_{2}$ and $\mathrm{MoO}_{3}$. However, $\mathrm{MoO}_{3}$ is the most widely investigated stoichiometry of $\mathrm{MoO}_{x}$ for a variety of applications such as gas sensing, photochromic devices, light emitting diodes (LEDs), batteries and organic solar cells[238, 295-302]. The most common crystal phases of $\mathrm{MoO}_{3}$ are the thermodynamically stable $\alpha-\mathrm{MoO}_{3}$ and the metastable $\beta-\mathrm{MoO}_{3}[303-306]$. Bulk $\alpha-\mathrm{MoO}_{3}$ exhibits an indirect bandgap of $\sim 3 \mathrm{eV}$ and has an orthorhombic crystal structure, that comprises of dual layered planar crystals of distorted $\mathrm{MoO}_{6}$ octahedra that are held together by weak van der Waals forces. $\beta-\mathrm{MoO}_{3}$ on the other hand comprises of $\mathrm{MoO}_{6}$ octahedra that share corners in all the three dimensions, resulting in a monoclinic 3D structure[302, 307]. At temperatures above $620 \mathrm{~K}$, the $\beta$ phase transforms into the more stable, layered $\alpha-\mathrm{MoO}_{3}$ phase[303, 304].

\subsubsection{TE properties of stoichiometric $\mathrm{MoO}_{x}$}

There is no literature that reports the TE properties of stoichiometric molybdenum oxides, primarily due to their low $\sigma$. However, incorporation of various dopants and implementation of $\mathrm{MoO}_{x}$ composites have been shown to result in high TPFs.

\subsubsection{TE properties of non-stoichiometric, doped and composite $\mathrm{MoO}_{x}$}

Non-stoichiometric and doped molybdenum oxides have been shown to exhibit high TPFs. $\mathrm{Xu}$ et al. investigated the TE properties of highly reduced molybdenum oxides $\left(\mathrm{RMo}_{8} \mathrm{O}_{14}\right)$ where $\mathrm{R}=\mathrm{La}, \mathrm{Ce}, \mathrm{Nd}$ and Sm. Fig. 13a shows the TPFs of the four composites at different temperatures. It is seen that $\mathrm{NdMo}_{8} \mathrm{O}_{18}$ exhibits a peak TPF and $\mathrm{ZT}$ of $177 \mu \mathrm{W} / \mathrm{m} . \mathrm{K}^{2}$ and 0.1 , respectively, at $1000 \mathrm{~K}$. The $\kappa$ of the composite has been reported to be $3.19 \mathrm{~W} / \mathrm{m} . \mathrm{K}$ at $322 \mathrm{~K}$, which drops to $2 \mathrm{~W} / \mathrm{m} . \mathrm{K}$ at $1164 \mathrm{~K}[308,309]$. It is evident that the TPF is certainly large enough to make these molybdenum oxide composites promising for high temperature energy scavenging applications. 
It has also been shown that the use of composites can result in enhanced TE performance as suggested in section 3.4. A study reports that the TPFs of polyaniline (a typical conductive polymer) molybdenum trioxide $\left(\mathrm{PANI} / \mathrm{MoO}_{3}\right)$ composites, is high. A maximum TPF of $\sim 10^{2} \mu \mathrm{W} / \mathrm{m} . \mathrm{K}^{2}$ was observed for $10 \mathrm{wt} \%$ of $\mathrm{MoO}_{3}$ (Fig. 13b) [310].
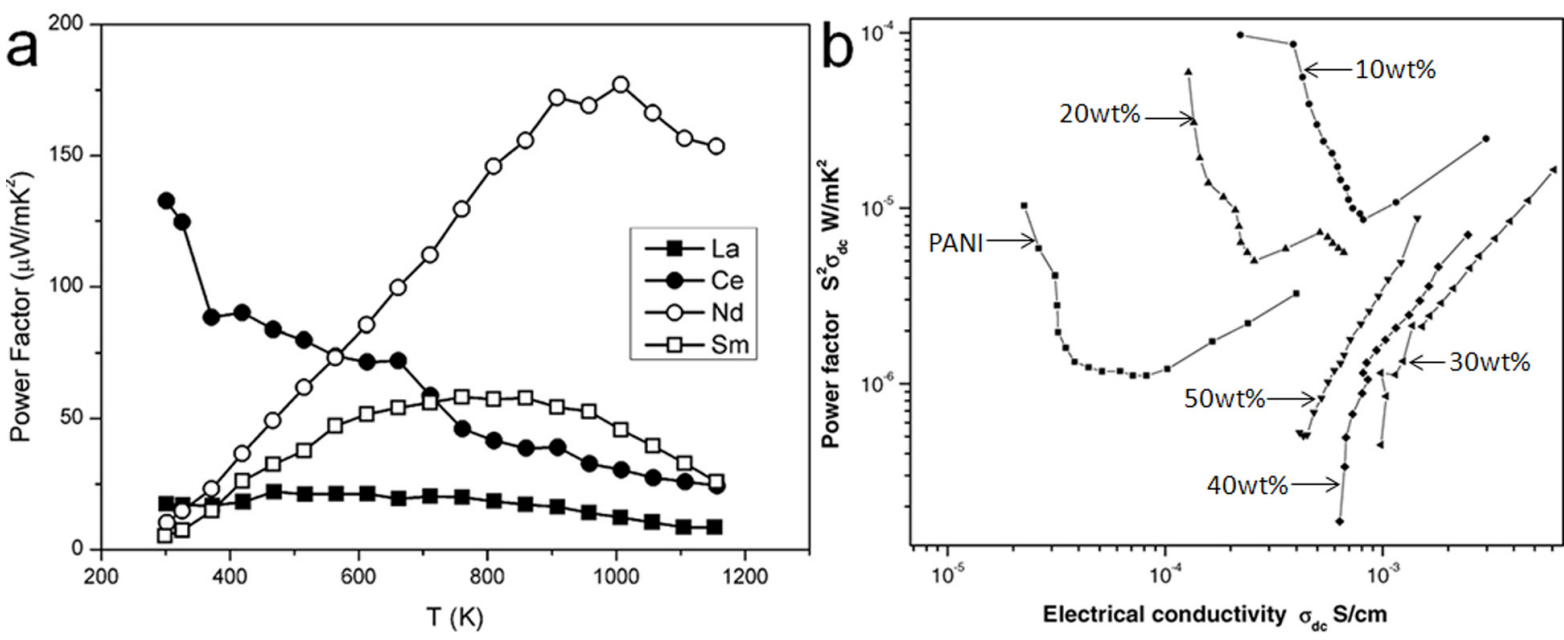

Fig. 13. (a) Temperature dependence of TPF of $\mathrm{RMo}_{8} \mathrm{O}_{14}(\mathrm{R}: \mathrm{La}, \mathrm{Ce}, \mathrm{Nd}, \mathrm{Sm}$ ) pellets, and (b) electrical conductivity $v$ TPF of PANI/MoO 3 composites $v s \mathrm{MoO}_{3}$ concentration in the composite. (Reproduced with permission from (a) [309] and (b) [310].)

\subsubsection{Methods of synthesis}

Similar to other TMOs, $\mathrm{MoO}_{3}$ can be synthesised using many different liquid and vapour phase techniques. The commonly used liquid phase techniques include sol-gel, hydrothermal, and electrodeposition[304]. Vapour phase techniques such as thermal evaporation, electron beam epitaxy, PLD, RF/DC sputtering, MBE and van der Waal epitaxy (VDWE) have been used for synthesising $\mathrm{MoO}_{3}$ in various thin film and nanostructured forms. Amongst these, MBE and VDWE have been shown to synthesise ordered, layered $\mathrm{MoO}_{3}$ structures. Additionally, CVD techniques are also employed to synthesise crystalline $\mathrm{MoO}_{3}$. A detailed overview of the synthesis techniques to produce various morphologies of $\mathrm{MoO}_{3}$ is provided elsewhere[302]. 


\subsection{Other transition metal oxides and their TE properties}

In this section, we will discuss other TMOs, whose TE properties have not been widely investigated. Most of these TMOs are wide bandgap materials, resulting in extremely poor electrical conductivities. However, a few oxides such as iron oxide, cadmium oxide, nickel oxide and doped zirconium oxide exhibit promising TE properties for various applications. In this section, we provide a brief overview of the small number of reports on the TE properties of the remaining TMOs in their stoichiometric and/or doped states.

\subsubsection{Iron oxides}

There are many known stable iron oxide stoichiometries available. Amongst them, $\mathrm{Fe}_{2} \mathrm{O}_{3}$ is the iron oxide compound that has been studied for its TE properties. An analysis of a limited number of reports suggests that $\mathrm{Fe}_{2} \mathrm{O}_{3}$ can potentially be a promising TMO for TE applications at high temperatures as it exhibits high TPFs at room as well as elevated temperatures

$\mathrm{Fe}_{2} \mathrm{O}_{3}$ thin films have been shown to exhibit peak $S$ of $1650 \mu \mathrm{V} / \mathrm{K}$ in the temperature range of $270-290 \mathrm{~K}$. A peak $\sigma$ of $5.5 \times 10^{3} \mathrm{~S} / \mathrm{m}$ has been reported in the same temperature range, resulting in a high TPF of $1.5 \times 10^{4} \mu \mathrm{W} / \mathrm{m} \cdot \mathrm{K}^{2}[311]$. Li- doped $\alpha-\mathrm{Fe}_{2} \mathrm{O}_{3}$ has been reported to exhibit a TPF of $5.5 \times 10^{3} \mu \mathrm{W} / \mathrm{m} . \mathrm{K}^{2}$ at temperature over $800 \mathrm{~K}$ for which a $\kappa$ of $4 \mathrm{~W} / \mathrm{m} . \mathrm{K}$ has been reported[312]. $\mathrm{Fe}_{2} \mathrm{O}_{3}-\mathrm{NiO}$ composites have also been shown to exhibit high TPFs at elevated temperatures $\left(900 \mu \mathrm{W} / \mathrm{m} . \mathrm{K}^{2}\right.$ at $\left.823 \mathrm{~K}\right)$ [313]. Nanostructuring technique has been predicted to enhance TE performance (section 3.3). Although, 1D electronic quantum confinement has been demonstrated in $\alpha-\mathrm{Fe}_{2} \mathrm{O}_{3}$ nanorods, they have not been examined for their TE properties[314]. 


\subsubsection{Chromium oxides}

There exists many crystalline phases of chromium oxides however, $\mathrm{Cr}_{2} \mathrm{O}_{3}$ is the most stable bulk form of this TMO,[315] with a few recent reports on its TE properties[311, 316]. $\mathrm{Cr}_{2} \mathrm{O}_{3}$ thin films have been shown to exhibit $S$ of $3500-4500 \mu \mathrm{V} / \mathrm{K}$ at room temperature. However, we wish to add that such dramatically high $S$ has not been confirmed by any other study so far. A $\sigma$ of $5.8 \times 10^{3} \mathrm{~S} / \mathrm{m}$ has been reported for stoichiometric $\mathrm{Cr}_{2} \mathrm{O}_{3}$ [311]. Another study demonstrates a TPF of $3.5 \mu \mathrm{W} / \mathrm{m} \cdot \mathrm{K}^{2}$ at a temperature of $1300 \mathrm{~K}$ in $\mathrm{Cr}_{2} \mathrm{O}_{3}$ [316].

The effect of $\mathrm{TiO}_{2}$ addition to $\mathrm{Cr}_{2} \mathrm{O}_{3}$ on its TE properties has also been investigated. A $2 \%$ $\mathrm{TiO}_{2}$ addition results in a slightly improved TPF of $5.6 \mu \mathrm{W} / \mathrm{m} . \mathrm{K}^{2}[317]$.

The TE properties of chromium oxide compounds such as $\mathrm{CuCrO}_{2}$ have also been studied. A maximum TPF and ZT of $236 \mu \mathrm{W} / \mathrm{m} \cdot \mathrm{K}^{2}$ and 0.1 at $1100 \mathrm{~K}$ has been obtained[318]. $\mathrm{CrO}_{0.1} \mathrm{~N}_{0.9}$ polycrystalline samples have also been reported to show a TPF of $80 \mu \mathrm{W} / \mathrm{m} . \mathrm{K}^{2}$ at $300 \mathrm{~K}[319]$.

The above discussion shows that sufficiently large TPFs have been demonstrated for $\mathrm{Cr}_{2} \mathrm{O}_{3}$ and its compounds. However, further studies are required to establish chromium oxide as a viable TE TMO for many applications.

\subsubsection{Scandium oxides}

Scandium oxide is a wide band gap (6 eV) insulating material, and is therefore not useful for TE conversion applications[118]. Doping can slightly improve electrical conduction; however, it is still insufficient for any meaningful TE energy scavenging applications. $\mathrm{Cu}$ doped scandium oxide epitaxial thin films exhibit $S$ and $\sigma$ of $40 \mu \mathrm{V} / \mathrm{K}$ and $110 \mathrm{~S} / \mathrm{m}$, respectively, at room temperature, resulting in extremely low TPF of $0.18 \mu \mathrm{W} / \mathrm{m} . \mathrm{K}^{2}[320]$. 


\subsubsection{Zirconium oxides}

Zirconium oxides are stable at extremely high temperatures and are generally used as ionic conductors at such temperatures. As such these oxides are frequently used in oxygen sensors and fuel cell membranes[321]. $\mathrm{ZrO}_{2}$ is the most common crystal phase of zirconium oxides which is found in three phases: a cubic phase with a fluorite structure that occurs at temperatures $>2850 \mathrm{~K}$ and transforms into a tetragonal phase at $2650 \mathrm{~K}$, which on further cooling transforms to a monoclinic phase[322]. It exhibits a wide bandgap of $5 \mathrm{eV}$ [118].

Pure $\mathrm{ZrO}_{2}$ does not exhibit good TE properties due to its poor $\sigma$. However, $\mathrm{ZrO}_{2} / \mathrm{CoSb}_{3}$ nanocomposites show a peak S of $140 \mu \mathrm{V} / \mathrm{K}$ at $700 \mathrm{~K}$ for $5 \% \mathrm{ZrO}_{2}$ and a corresponding $\sigma$ and $\kappa$ of $3.75 \times 10^{4} \mathrm{~S} / \mathrm{m}$ and $2.75 \mathrm{~W} / \mathrm{m} . \mathrm{K}$, respectively[114]. The resulting TPF and ZT is approximately $735 \mu \mathrm{W} / \mathrm{m} . \mathrm{K}^{2}$ and 0.2 , respectively. Therefore, it is obvious that the incorporation of $\mathrm{ZrO}_{2}$ can potentially be a good approach for obtaining enhanced TE properties for energy scavenging at elevated temperatures.

\subsubsection{Cadmium oxides}

Cadmium oxide is an n-type semiconductor, which exhibits a cubic rocksalt type crystal structure with a direct bandgap of $\sim 2.1 \mathrm{eV}$ at room temperature[323]. A study of highly crystalline $\mathrm{CdO}$ thin films have revealed high $\sigma$ of the order of $10^{5} \mathrm{~S} / \mathrm{m}$ and a peak $S$ of $90 \mu \mathrm{V} / \mathrm{K}$, resulting in a high $\mathrm{TPF}$ of $\sim 800 \mu \mathrm{W} / \mathrm{m} . \mathrm{K}^{2}$ [324]. Another study has demonstrated a TPF of $100 \mu \mathrm{W} / \mathrm{m} . \mathrm{K}^{2}$ at $700 \mathrm{~K}[325]$. Other studies on pure as well as doped CdO have revealed similar order of magnitude TPFs[326-328]. Therefore, it is evident that $\mathrm{CdO}$ can potentially be a viable n-type TE TMO at elevated temperatures.

\subsubsection{Nickel oxides}

Nickel oxide is a p-type semiconductor that exhibits a cubic rocksalt type crystal structure with a rather large bandgap of 3.6-4.0 eV. Although the $\sigma$ of stoichiometric $\mathrm{NiO}$ is extremely 
low, $\mathrm{Ni}^{2+}$ vacancies are easily formed in undoped $\mathrm{NiO}$, resulting in dramatic improvements in $\sigma[329]$.

In the past, a few studies have examined $\mathrm{TE}$ properties of $\mathrm{NiO}[330,331]$. One such study has

reported $S, \sigma$ of $101 \mu \mathrm{V} / \mathrm{K}$ and $10^{-2} \mathrm{~S} / \mathrm{m}$ respectively, at room temperature. The TPF is extremely low primarily due to poor electrical conductivity[331].

The use of metallic dopants such as $\mathrm{Li}$ and $\mathrm{Na}$ has been shown to result in enhanced $\mathrm{TE}$ properties[332] [333]. Li doped $\mathrm{NiO}$ exhibits TPFs of the order of $10^{2} \mu \mathrm{W} / \mathrm{m} \cdot \mathrm{K}^{2}$ at temperatures exceeding $1000 \mathrm{~K}$, suggesting its suitability as a promising metal oxide for energy scavenging and thermopower wave sources[332].

\subsubsection{Iridium oxides}

$\mathrm{IrO}_{2}$ is the most stable phase of iridium oxides and exhibits a $\mathrm{TiO}_{2}$ like rutile crystal structure. The TE properties of pure $\mathrm{IrO}_{2}$ have not been examined. However, Ca-Ir-O composites have been investigated for their TE properties by Keawprak et al[334-336]. They reported low TPFs and ZTs $\left(\sim 35 \mu \mathrm{W} / \mathrm{m} . \mathrm{K}^{2}\right.$ and 0.01 , respectively).

\subsubsection{Other TMOs}

Other transition metals such as Nb, La, Ac Y, Ta, Re, Hf, Ag and Te are usually employed as dopants in other TE TMOs for tuning their various TE properties in order to achieve higher TPFs and ZTs. However, reports on their stoichiometric TMOs are rare and yet to be fully investigated. 


\section{Applications of TE TMOs}

As discussed in Section 3, the applications of TE TMOs can be classified into four major categories. In this section, a brief description of such TMO-based TE applications is provided.

\subsection{Cooling and refrigeration}

One of the practical implementation of TE materials is for cooling and refrigeration[3]. TMOs generally do not provide considerable efficiencies for cooling and refrigeration near room temperatures. However, many of them including titanium oxide, copper oxide compounds $\left(\mathrm{La}_{2} \mathrm{CuO}_{4}\right)$ and doped cobalt oxides, are promising for cooling and refrigeration applications at low temperatures due to their large TPFs at cryogenic temperatures[337, 338]. The advantage of TMO-based cooling and refrigeration systems is their low cost and easy large-scale fabrication. Many TMOs can be synthesised in low dimensions, using wellestablished methods which were presented in Section 4, making them attractive for developing micro/nano cooling devices[339]. A schematic of such cooling devices is shown in Fig. 14, and consists of complementary arrays of n-type and p-type TE TMOs, which are electrically in series and thermally in parallel, transferring heat from one side of the module to another[261]. The need for micro-domain cooling is driven largely by the shrinking size of electronic devices. Most electronics and optoelectronic technologies require localised spot cooling of small components and TE modules are capable of very localised cooling[261]. Such modules are extensively used for maintaining laser diodes at constant temperatures in order to stabilise their operating wavelengths [340, 341]. They are also widely used for the temperature management of high power dissipating electronic equipment such as ICs, microprocessors, charge coupled devices (CCD), IR cooling in optoelectronic systems, air conditioners and laboratory cooling plates[67, 342, 343]. Additionally, a reversal of the 
current allows these devices to act as spot heaters as well, rendering them with additional usage flexibility[344].

Military applications such as night vision systems and heat seeking missiles depend on sensors in their infrared imaging systems. These sensors work efficiently at extremely low temperatures. TE TMO based cooling systems can be used to produce such low temperatures of the order of $\sim 190 \mathrm{~K}$ in these devices[67, 345]. Such cooling devices are also increasingly finding applications in the biological world. For a wide cryogenic implementation in the biological world, TMOs due to their non-toxicity and biological compatibility are potentially desirable.

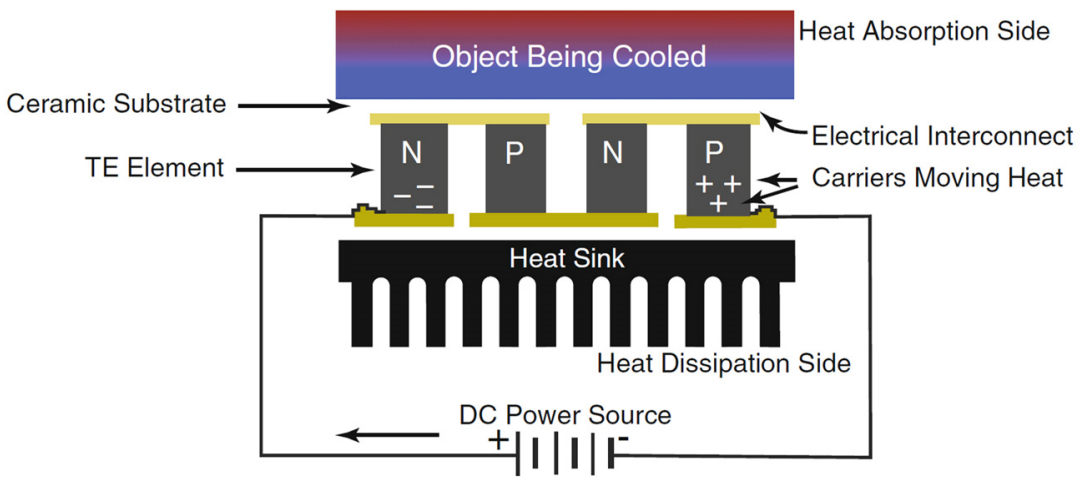

Fig. 14. Pictorial representation of a TE cooling device. (Reproduced with permission from [261].) 


\subsection{Energy harvesting from heat}

The application of TMOs for waste heat recovery is particularly attractive, given their stability at very high temperatures, even though the maximum theoretical efficiencies for TMOs in the high temperature regimes is in the range of 4-6\%[346]. Complex oxides such as p-type layered cobaltites and n-type doped $\mathrm{SrTiO}_{3}, \mathrm{CaMnO}_{3}$ and $\mathrm{ZnO}$ are among the best candidates for TE power generation modules operating at mid to high temperature ranges[12, 347, 348]. Among these, p-type $\mathrm{Ca}_{3} \mathrm{Co}_{4} \mathrm{O}_{9}$ (either undoped or doped with bismuth) and n-type doped $\mathrm{CaMnO}_{3}$ are commonly used in TE modules. TMO TE modules are being increasingly employed for waste heat recovery in vehicles by all major auto-makers in order to comply with stricter emission requirements[78, 349]. Such TE generators convert the waste heat from the exhaust into useful power that can be used to operate the on-board electrical systems, thereby increasing fuel efficiency[4]. Each kilogram of fuel saving reduces $\mathrm{CO}_{2}$ emissions by $3.16 \mathrm{~kg}$. Additionally, the application of TMO TE modules in the industrial waste heat recovery sector is also gaining increasing attention due to the tremendous economic and environmental benefits that can be realised especially in the aluminium smelting, glass manufacturing and cement production industries.

The first prototypes of power generation modules incorporating TMOs were reported by Shin et al. in which an output power of $14 \mathrm{~mW}$ was measured at a temperature gradient of $500 \mathrm{~K}$ ( $1000 \mathrm{~K}$ on the hot side and $500 \mathrm{~K}$ on the cool side) and the efficiency was calculated to be $0.64 \%[350,351]$. All-oxide TE modules were later developed by Matsubara et al. and Funahashi et al. that generated output powers as large as $94.4 \mathrm{~mW}[352,353]$. Subsequently, using the same p- and n-type oxides Funahashi et al. fabricated a module comprising of 140 oxide pairs on an alumina substrate resulting in an output power of $0.15 \mathrm{~W}$ with a temperature gradient of $551 \mathrm{~K}[354]$. The power generation efficiency was estimated to be around $1.4 \%$. A further improvement in the output power $(0.28 \mathrm{~W})$ was achieved through the 
fabrication of a pipe-shaped module comprising 54 oxide pairs.[355]. Another plate-shaped module fabricated using 8 pairs of p-type Co-394 and n-type $\mathrm{CaMn}_{0.98} \mathrm{Mo}_{0.02} \mathrm{O}_{3}(\mathrm{Mn}-113)$ bulks on alumina substrate reached an output power of $0.34 \mathrm{~W}[356]$. Other studies with cobalt and manganese based oxides have resulted in output powers of the same order[357$360]$.

The nanostructuring approach has also been implemented to improve the performance of TMO based TE modules. Such modules use nanostructured p-type cobalates, manganates or n-type $\mathrm{ZnO}$ and have been shown to generate powers as high as $0.4 \mathrm{~W}$ [361-363].

\subsection{Photovoltaic (PV) - solar thermoelectric generators (STEGs) and radioisotope thermoelectric generators (RITEGs)}

\subsubsection{PV-STEG}

Photovoltaic cells are widely deployed to harness solar energy and convert it to useful electrical energy. An interesting idea to improve the efficiency of these cells is the incorporation of TE devices, also known as solar thermoelectric generators (STEGs). These TE-solar hybrid systems can take advantage of the IR part of the solar spectrum, which is not effectively captured by conventional solar cells[364]. This idea was first proposed as early as 1954 by Telkes et al. and involves concentrating the solar energy to create heat which is harnessed by the TE systems to convert it into electricity[365]. A schematic of a STEG is shown in Fig. 15. The conversion efficiency of the STEG depends on the temperature difference between the hot $\left(T_{H}\right)$ and the cold $\left(T_{C}\right)$ side. The cooling on the opposite side is provided by circulating a liquid, which can simultaneously be utilised to drive a steam engine or a heating system for auxiliary solar heat utilisation[366]. Solar concentrator systems have been shown to achieve high temperatures of up to $1000 \mathrm{~K}[366]$. At such high temperatures, TMOs are highly desirable due to their high thermal stabilities and acceptable ZT values. In fact, Robert et al. have shown that doped cobalt oxides are highly promising for STEGs[366, 
367]. Weidenkaff et al. and Tomes et al. have also demonstrated STEGs based on TMOs such as cobalates, manganates and cuprates[102,362].

\subsubsection{RITEG}

The use of radioisotope thermoelectric generators (RITEGs) for powering space missions has been well established. This is because TE converters are extremely reliable for long operating lifetimes. They are compact, rugged, adaptable, and radiation-resistant and they generate no noise, vibrations or torque during the course of operation. Additionally, they do not need any start up device[368]. Spacecraft that venture into the outer universe, where the availability of solar energy is diminished, benefit from the durability and consistency of the electrical as well as thermal energy derived from radioisotope energy sources[369]. The decay of radioactive isotopes generates a significant amount of heat and it is highly desirable to use this heat in spacecraft thermal control, as energy resources are limited. A detailed discussion on the operation of these systems has been presented by Obrien et al[370].

The efficiency in such systems is highly sensitive to temperature and high operating temperatures are desirable in order to achieve an effective radiative heat rejection. As such, TE TMOs such as $\mathrm{ZnO}, \mathrm{ZrO}_{2}$ and cobalt oxides offer promising alternatives for any stable and cost effective RITEG development. Lange et al. have provided a comprehensive review on the current state-of-the-art RITEG technology and also discussed the scope of future improvements[368]. 


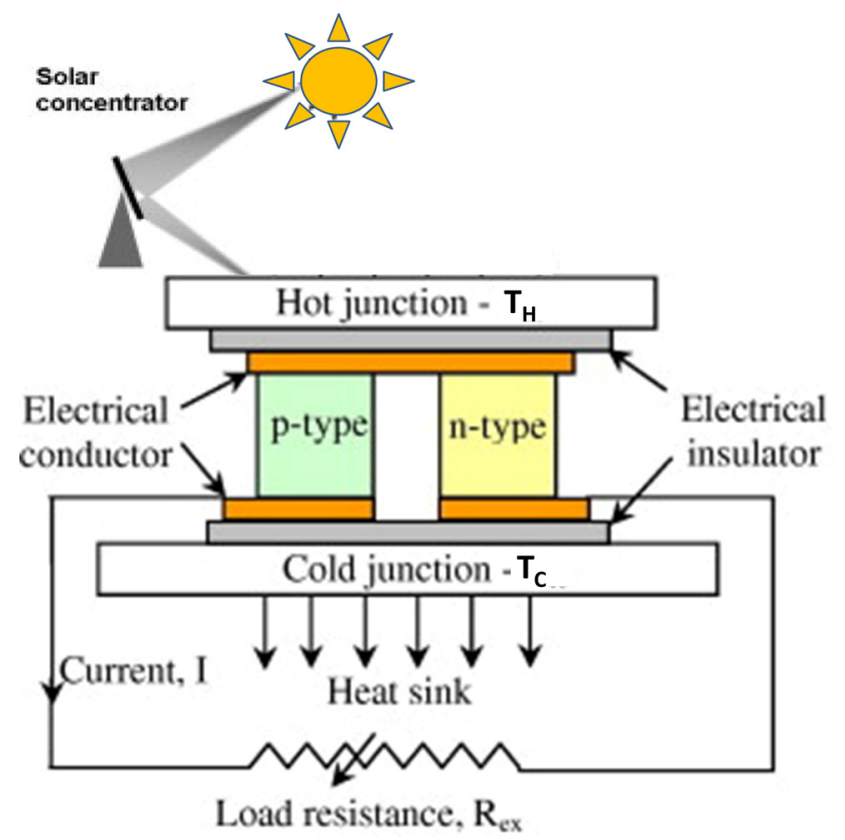

Fig. 15. Schematic of a solar thermoelectric generator (STEG), comprising of a solar concentrator and both $\mathrm{p}$ and $\mathrm{n}$ type TE elements. (Reproduced with permission from[371].) 


\subsection{Sensors}

TMO-based TE transducers can be implemented for a wide variety of sensing applications. An overview of the different sensing capabilities can be found in ref. [8]. In brief, they can be widely used in measuring temperature[372-375], in measuring generated heat from chemical reactions[376], in gas sensing [377-381] and biological sensing[376, 382] and be incorporated into other sensing systems. In such sensors, a variation in the generated voltages induced due to the Seebeck effect in TE materials are used to assess the sensor performance[383].

For TMO-based temperature sensors, a high $S$ (to generate large output voltage hence obtaining large signal to noise ratios) and low $\sigma$ (to limit the wastage of energy), $\kappa$ (to limit the exchange of heat between the measurement point and the rest of the measurment system) are desirable. This ensures that a high sensitivity is maintained for a prolonged time, without an unnecessary exchange of heat.

TMOs such as $\mathrm{ZnO}, \mathrm{TiO}_{2} \mathrm{CuO}$ and $\mathrm{V}_{2} \mathrm{O}_{5}$ have been employed in temperature sensors and infrared detectors[372-375].

Additionally, such thermal sensors can be used to detect various electrical, magnetic, chemical and radiation signals[8, 384]. For high temperature sensing applications, TE TMOs such as $\mathrm{ZnO}, \mathrm{TiO}_{2}, \mathrm{Fe}_{2} \mathrm{O}_{3}$ and $\mathrm{ZrO}_{2}$ are highly desirable, as they offer high temperature stability and high sensitivities at such elevated temperatures. TMO based sensors can also be integrated with microfluidics to measure very small heat exchanges in biological fluids and biochemical reactions at a wide range of operating temperatures. It is suggested that TMOs such as $\mathrm{ZnO}$ can also be ideal materials for such transducers due to their bio-compatibility and good TE properties[43, 385].

The TE properties of TMOs are also exploited for sensing a wide variety of gases. TE gas sensors based on TMOs such as $\mathrm{NiO}, \mathrm{Co}_{3} \mathrm{O}_{4}, \mathrm{TiO}_{2}$ and $\mathrm{Fe}_{2} \mathrm{O}_{3}$ have already been 
reported[377-380]. Interestingly, such sensors can operate as both semiconducting and thermoelectric gas sensors, providing unique output information for the operators.

\subsection{Thermopower wave sources}

Miniaturization of energy sources is a key challenge to overcome in order to develop the next generation of micro/nano electronic devices. Current energy generation technologies cannot be scaled down to the micro/nano level, while maintaining their energy discharge capabilities.

A novel concept of thermopower waves has been demonstrated to be highly promising for the development of the next generation micro/nano scale power sources[5-7, 9, 386]. In such systems, thermopower waves are propagated along a TE system, which generally comprises of a modest to high thermally conductive material. A pictorial representation of a thin film thermopower device is shown in Fig. 16 a. As a result of the coupling of intense exothermic chemical reaction to free charge carriers in the TE material, which should also be highly electrically conducting, an output power is generated. A preferably modest to high $\kappa$ of the core TE material is required in such thermopower wave sources in order to facilitate the sustained propagation of thermopower waves. High $\sigma$ is needed to increase the output current and as a result output power. Therefore, thermopower wave sources require materials with a high TPF. TMOs such as $\mathrm{ZnO}$ and $\mathrm{MnO}_{2}$ have resulted in the highest voltage outputs (500 $\mathrm{mV}$ and $1.8 \mathrm{~V}$, respectively) (Fig. $16 \mathrm{~b} \& \mathrm{c}$ ) among all thermopower wave systems reported so far[5-7, 9, 69, 386, 387]. An added advantage is that the high temperature stability of TMOs provides the opportunity of refuelling such systems, as the TE materials remain largely intact after the reaction. 

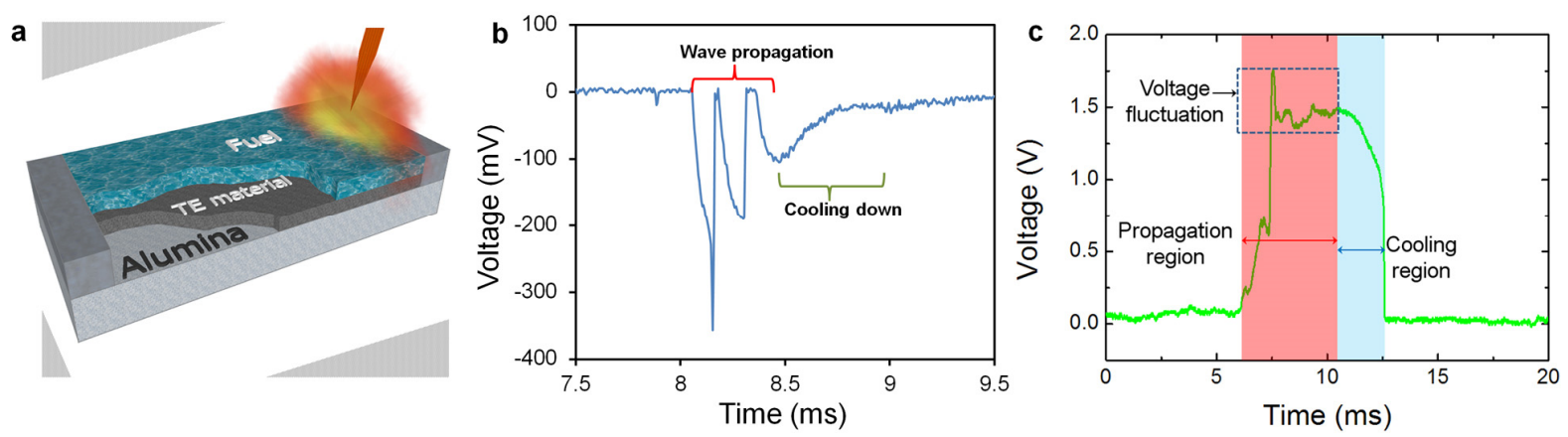

Fig. 16. (a) Schematic of thin film thermopower wave system and output voltage profiles for (b) $\mathrm{ZnO}$ and (c) $\mathrm{MnO}_{2}$ based thermopower wave sources. (Reproduced with permission from (b) [5] and (c) [9].)

\section{Conclusion and future outlook}

In summary, we presented a comprehensive analysis of various TMOs and their TE properties. The article included an analysis of the theory governing the thermal and electrical conductivities, and Seebeck coefficients of bulk and low dimensional TMOs. An overview of the crystal structures of TMOs, along with various liquid and vapour phase techniques to synthesise them were presented. The effects of stoichiometry alteration, doping, compositing, and nanostructuring were discussed for target TE TMOs at cryogenic, ambient and elevated temperatures, where applicable. Additionally, a description of TE TMOs' major applications was also provided. It was shown that TMOs exhibit promising TE properties that can be exploited for a wide range of applications.

Modification strategies based on reducing dimensions of TMOs have already resulted in enhanced TPFs and ZTs through engineering of their density of states. Enhanced ZTs can certainly be achieved by nanostructuring, substructuring, compositing, doping and changing the stoichiometry of TMOs. Theoretical grounds suggest that even higher ZTs can be obtained. This will enable widespread implementation of such TMOs in a variety of highly efficient cooling and refrigeration, energy scavenging, sensing and thermopower systems even at micro/nano dimensions. Theoretical models predict extraordinary enhancements in 
TPFs and figures of merits in TMO based segmented 1D (0D) structures such as QDSLs and SNWs. However, such structures based on TMOs are still in their infancy and there is a need to extensively investigate their TE properties. Such structures will potentially result in dramatic improvements in TPFs and ZTs of TMOs, allowing their widespread implementation.

TMOs offer exciting avenues to harness industrial waste heat, providing cost effective and environmentally friendly electricity generation capabilities. Additionally, TMOs can also be implemented in TE modules for scavenging waste heat from exhausts in automobiles and the heat from the sun for useful power. The efficient implementation of such applications on a large scale inevitably requires high operating temperature ranges for which TMOs are the ideal candidate materials.

TMOs with high Seebeck coefficients and tunable electrical properties can be implemented in temperature, gas and bio sensors with high sensitivities, for applications in which very small heat generations or alteration of electrical and thermal properties should be detected. Many TMOs are biocompatible so they are great candidates in bio-applications. They can also endure low or high extremes of temperatures. TE TMOs can also be used to generate voltages at low dimensions to detect very minute heat exchanges. Such heat exchanger systems can be integrated with nanofluidics in many lab-on-a-chip applications.

The high TPFs of many TMOs at elevated temperatures also makes them attractive materials for thermopower wave sources. Already, TMOs such as $\mathrm{ZnO}$ and $\mathrm{MnO}_{2}$ have resulted in the highest output voltages in such energy sources. Considering that significant enhancements in TPF can be seen in TMOs, achieving output voltages as high as $10 \mathrm{~V}$ in thermopower wave sources is not beyond possibility. 
The environmental compatibility, low cost and highly engineer-able properties are very attractive features that TMOs offer. Alteration of stoichiometry, addition of dopants, formation of composites, nanostructuring and substructuring approaches have already shown their invaluable capabilities to adjust the TE parameters in many TMOs. However, there are still many challenges to be addressed and a fundamental understanding of the TE parameters in TMOs should be fully gained. The low efficiency of TMO-based TE materials is still their major drawback for many applications. Therefore, incorporation of such TMOs into many TE modules has been limited.

The transport phenomena at the boundaries and interfaces will require in-depth investigations to enable further morphological tuning of electrical and thermal properties in TMOs, making them viable candidates in a wide variety of TE applications. There are many unknowns regarding the effects of oxygen deficiency and dopants in TMOs. The same can be said for the effects of nanostructuring, substructuring and compositing. Still, the TE parameters of many TMOs have not been measured at different temperatures. The effects of superconductivity, junctions and environmental conditions have not been investigated for many TMOs and should be studied to gain a complete understanding of their properties. We believe that TMOs will play a pivotal role in the future development of applications such as cooling, heat scavenging, sensing and thermopower wave sources. 


\section{Acknowledgements}

The authors thank colleagues and collaborators who have contributed to aspects of research reported in this work. M.B. and S.S. acknowledge fellowships from the Australian Research Council through Discovery Projects DP1092717 and DP110100262, respectively.

\section{References}

[1] Ohta H, Sugiura K, Koumoto K. Recent progress in oxide thermoelectric materials: p-type $\mathrm{Ca}_{3} \mathrm{CO}_{4} \mathrm{O}_{9}$ and n-type $\mathrm{SrTiO}_{3}$. Inorg Chem 2008;47:8429-36.

[2] Biswas K, He JQ, Blum ID, Wu CI, Hogan TP, Seidman DN, et al. High-performance bulk thermoelectrics with all-scale hierarchical architectures. Nature 2012;489:414-8.

[3] Goldsmid HJ, Douglas RW. The use of semiconductors in thermoelectric refrigeration. Brit J Appl Phys 1954;5:386-90.

[4] Tritt TM. Thermoelectric Phenomena, Materials, and Applications. In: Clarke DR, Fratzl P, editors. Ann Rev Mater Res 2011;412011:433-48.

[5] Walia S, Weber R, Balendhran S, Yao D, Abrahamson JT, Zhuiykov S, et al. ZnO based thermopower wave sources. Chem Comm 2012;48:7462-4.

[6] Walia S, Weber R, Latham K, Petersen P, Abrahamson JT, Strano MS, et al. Oscillatory Thermopower Waves Based on $\mathrm{Bi}_{2} \mathrm{Te}_{3}$ Films. Adv Funct Mater 2011;21:2072-9.

[7] Walia S, Weber R, Sriram S, Bhaskaran M, Latham K, Zhuiykov S, et al. $\mathrm{Sb}_{2} \mathrm{Te}_{3}$ and $\mathrm{Bi}_{2} \mathrm{Te}_{3}$ based thermopower wave sources. Energ Environ Sci 2011;4:3558-64.

[8] Riffat SB, Ma XL. Thermoelectrics: a review of present and potential applications. Appl Therm Eng 2003;23:913-35.

[9] Walia S, Balendhran S, Yi P, Yao D, Zhuiykov S, Pannirselvam M, et al. $\mathrm{MnO}_{2}$ based Thermopower Wave Sources with Exceptionally large Output Voltages. J Phys Chem C 2013; accepted.

[10] Pickett WE. Electronic structure of the high-temperature oxide superconductors. Rev Mod Phys 1989;61:433-512.

[11] Terasaki I, Sasago Y, Uchinokura K. Large thermoelectric power in $\mathrm{NaCo}_{2} \mathrm{O}_{4}$ single crystals. Phys Rev B 1997;56:12685-7.

[12] Koumoto K, Terasaki I, Funahashi R. Complex Oxide Materials for Potential Thermoelectric Applications. MRS Bull 2006;31:206-10.

[13] Terasaki I, Iwakawa M, Nakano T, Tsukuda A, Kobayashi W. Novel thermoelectric properties of complex transition-metal oxides. Dalton T 2010;39:1005-11.

[14] Terasaki I. High-temperature oxide thermoelectrics. J Appl Phys 2011;110.

[15] He J, Liu Y, Funahashi R. Oxide thermoelectrics: The challenges, progress, and outlook. J Mater Res 2011;26:1762.

[16] Snyder GJ, Toberer ES. Complex thermoelectric materials. Nat Mater 2008;7:105-14.

[17] Tritt TM. Thermal conductivity: theory, properties, and applications: Springer; 2005.

[18] Balandin AA. Thermal properties of graphene and nanostructured carbon materials. Nat Mater 2011;10:569-81.

[19] Keyes RW. High-temperature thermal conductivity of insulating crystals-Relationship to the melting point. Phys Rev 1959;115:564-7. 
[20] Hicks LD, Dresselhaus MS. Effect of quantum-well structures on the thermoelectric figure of merit Phys Rev B 1993;47:12727-31.

[21] Balandin A, Wang KL. Effect of phonon confinement on the thermoelectric figure of merit of quantum wells. J Appl Phys 1998;84:6149-53.

[22] Koumoto K, Wang YF, Zhang RZ, Kosuga A, Funahashi R. Oxide Thermoelectric Materials: A Nanostructuring Approach. Ann Rev Mater Res 2010;402010:363-94.

[23] Hicks LD, Dresselhaus MS. Thermoelectric figure of merit of a one-dimensional conductor. Phys Rev B 1993;47:16631-4.

[24] Zou J, Balandin A. Phonon heat conduction in a semiconductor nanowire. J Appl Phys 2001;89:2932-8.

[25] Law M, Goldberger J, Yang P. Semiconductor nanowires and nanotubes. Annu Rev Mater Res 2004;34:83-122.

[26] Tian ZR, Voigt JA, Liu J, Mckenzie B, Mcdermott MJ, Rodriguez MA, et al. Complex and oriented $\mathrm{ZnO}$ nanostructures. Nat Mater 2003;2:821-6.

[27] Lin YM, Rabin O, Dresselhaus MS. Segmented nanowires: a theoretical study of thermoelectric properties. Inter Conf on Thermoelectrics, Proceedings ICT 2002

2002:265-68.

[28] Lin Y-M, Dresselhaus MS. Thermoelectric properties of superlattice nanowires. Phys Rev B 2003;68:075304.

[29] Heremans JP. Low-dimensional thermoelectricity. Acta Phys Pol A 2005;108:609-34.

[30] Yadav GG, Zhang G, Qiu B, Susoreny JA, Ruan X, Wu Y. Self-templated synthesis and thermal conductivity investigation for ultrathin perovskite oxide nanowires. Nanoscale 2011;3:4078-81.

[31] Tsuda N, Nasu K, Fujimori A, Siratori K. Electronic conduction in oxides. Springer; 2000.

[32] Forro L, Chauvet O, Emin D, Zuppiroli L, Berger H, Levy F. High mobility n-type charge carriers in large single crystals of anatase $\left(\mathrm{TiO}_{2}\right)$. J Appl Phys 1994;75:633-5.

[33] Tokura Y, Nagaosa N. Orbital physics in transition-metal oxides. Science 2000;288:4628.

[34] Henrich VE, Cox PA. The surface science of metal oxides. Cambridge University Press; 1996.

[35] Shakouri A. Recent developments in semiconductor thermoelectric physics and materials. Mater Res 2011;41:399.

[36] Forro L, Chauvet O, Emin D, Zuppiroli L, Berger H, Levy F. High mobility n type charge carriers in large single crystals of anatase ( $\left.\mathrm{TiO}_{2}\right)$. J Appl Phys 1994;75:633-5.

[37] Bauer C, Boschloo G, Mukhtar E, Hagfeldt A. Ultrafast relaxation dynamics of charge carriers relaxation in $\mathrm{ZnO}$ nanocrystalline thin films. Chem Phys Lett 2004;387:176-81.

[38] Hendry E, Koeberg M, O'Regan B, Bonn M. Local field effects on electron transport in nanostructured $\mathrm{TiO} 2$ revealed by terahertz spectroscopy. Nano Lett 2006;6:755-9.

[39] Johnson JC, Knutsen KP, Yan H, Law M, Zhang Y, Yang P, et al. Ultrafast carrier dynamics in single $\mathrm{ZnO}$ nanowire and nanoribbon lasers. Nano Lett 2004;4:197-204.

[40] Canadell E, Whangbo MH. Conceptual aspects of structure-property correlations and electronic instabilities, with applications to low-dimensional transition-metal oxides. Chem Rev 1991;91:965-1034.

[41] Balendhran S, Deng J, Ou JZ, Walia S, Scott J, Tang J, et al. Enhanced Charge Carrier Mobility in Two-Dimensional High Dielectric Molybdenum Oxide. Adv Mater 2013;25:10914.

[42] Takada K, Sakurai H, Takayama-Muromachi E, Izumi F, Dilanian RA, Sasaki T. Superconductivity in two-dimensional $\mathrm{CoO}_{2}$ layers. Nature 2003;422:53-5. 
[43] Wang ZL. Zinc oxide nanostructures: growth, properties and applications. J Phys: Cond Matter 2004;16:R829.

[44] Sakaki H. Scattering suppression and high-mobility effect of size-quantized electrons in ultrafine semiconductor wire structures. Jpn J Appl Phys 1980;19:L735-L8.

[45] Ramayya EB, Vasileska D, Goodnick SM, Knezevic I. Electron Mobility in Silicon Nanowires. Nanotechnology IEEE Trans 2007;6:113-7.

[46] Lu JG, Chang P, Fan Z. Quasi-one-dimensional metal oxide materials-Synthesis, properties and applications. Mat Sci Eng R: Rep 2006;52:49-91.

[47] Hosono H. Ionic amorphous oxide semiconductors: Material design, carrier transport, and device application. J Non-Cryst solids. 2006;352:851-8.

[48] Comini E, Baratto C, Faglia G, Ferroni M, Vomiero A, Sberveglieri G. Quasi-one dimensional metal oxide semiconductors: Preparation, characterization and application as chemical sensors. Prog Mat Sci 2009;54:1-67.

[49] Vomiero A, Concina I, Comini E, Soldano C, Ferroni M, Faglia G, et al. Onedimensional nanostructured oxides for thermoelectric applications and excitonic solar cells. Nano Energy. 2012;1:372-90.

[50] Wang RY, Feser JP, Lee J-S, Talapin DV, Segalman R, Majumdar A. Enhanced thermopower in PbSe nanocrystal quantum dot superlattices. Nano Lett 2008;8:2283-8.

[51] Dresselhaus MS, Chen G, Tang MY, Yang RG, Lee H, Wang DZ, et al. New directions for low-dimensional thermoelectric materials. Adv Mater 2007;19:1043-53.

[52] Limelette P, Hébert S, Hardy V, Frésard R, Simon C, Maignan A. Scaling behavior in thermoelectric misfit cobalt oxides. Phys Rev Lett 2006;97:46601.

[53] Wang YY, Rogado NS, Cava RJ, Ong NP. Spin entropy as the likely source of enhanced thermopower in $\mathrm{Na}_{x} \mathrm{Co}_{2} \mathrm{O}_{4}$. Nature 2003;423:425-8.

[54] Medlin D, Snyder G. Interfaces in bulk thermoelectric materials: A review for Current Opinion in Colloid and Interface Science. Curr Opin Colloid In 2009;14:226-35.

[55] Zide JMO, Vashaee D, Bian ZX, Zeng G, Bowers JE, Shakouri A, et al. Demonstration of electron filtering to increase the Seebeck coefficient in $\mathrm{In}_{(0.53)} \mathrm{Ga}(0.47) \mathrm{As} / \mathrm{In}_{(0.53)} \mathrm{Ga}(0.28) \mathrm{Al}_{(0.19)}$ As superlattices. Phys Rev B 2006;74.

[56] Ohta H, Kim S, Mune Y, Mizoguchi T, Nomura K, Ohta S, et al. Giant thermoelectric Seebeck coefficient of two-dimensional electron gas in $\mathrm{SrTiO}_{3}$. Nat Mater 2007;6:129-34.

[57] Ohta H. Thermoelectrics based on strontium titanate. Mat Tod 2007;10:44-9.

[58] Motohashi T, Naujalis E, Ueda R, Isawa K, Karppinen M, Yamauchi H. Simultaneously enhanced thermoelectric power and reduced resistivity of $\mathrm{NaCoO}$ by controlling $\mathrm{Na}$ nonstoichiometry. Appl Phys Lett 2001;79:1480.

[59] Kobayashi W, Hébert S, Pelloquin D, Pérez O, Maignan A. Enhanced thermoelectric properties in a layered rhodium oxide with a trigonal symmetry. Phys Rev B 2007;76:245102.

[60] Zheng HD, Ou JZ, Strano MS, Kaner RB, Mitchell A, Kalantar-Zadeh K. Nanostructured Tungsten Oxide - Properties, Synthesis, and Applications. Adv Funct Mater 2011;21:2175-96.

[61] Breedon M, Rahmani MB, Keshmiri S-H, Wlodarski W, Kalantar-zadeh K. Aqueous synthesis of interconnected $\mathrm{ZnO}$ nanowires using spray pyrolysis deposited seed layers. Mater Lett 2010;64:291-4.

[62] Lou XW, Zeng HC. Hydrothermal synthesis of $\alpha-\mathrm{MoO}_{3}$ nanorods via acidification of ammonium heptamolybdate tetrahydrate. Chem Mater 2002;14:4781-9.

[63] Boukai AI, Bunimovich Y, Tahir-Kheli J, Yu JK, Goddard WA, Heath JR. Silicon nanowires as efficient thermoelectric materials. Nature 2008;451:168-71.

[64] Mahan GD, Sofo JO. The best thermoelectric. P Natl Acad Sci USA. 1996;93:7436-9. 
[65] Jie J, Wang G, Han X, Hou J. Synthesis and characterization of ZnO: In nanowires with superlattice structure. J Phys Chem B 2004;108:17027-31.

[66] Devan RS, Patil RA, Lin JH, Ma YR. One-Dimensional Metal-Oxide Nanostructures: Recent Developments in Synthesis, Characterization, and Applications. Adv Funct Mater 2012;22:3326-70.

[67] Bell LE. Cooling, heating, generating power, and recovering waste heat with thermoelectric systems. Science 2008;321:1457-61.

[68] Schieferdecker J, Quad R, Holzenkämpfer E, Schulze M. Infrared thermopile sensors with high sensitivity and very low temperature coefficient. Sensors and Actuat A: Phys 1995;47:422-7.

[69] Choi W, Hong S, Abrahamson JT, Han JH, Song C, Nair N, et al. Chemically driven carbon-nanotube-guided thermopower waves. Nat Mater 2010;9:423-9.

[70] Zebarjadi M, Esfarjani K, Dresselhaus MS, Ren ZF, Chen G. Perspectives on thermoelectrics: from fundamentals to device applications. Energ Environ Sci 2012;5:514762.

[71] Chiritescu C, Cahill DG, Nguyen N, Johnson D, Bodapati A, Keblinski P, et al. Ultralow Thermal Conductivity in Disordered, Layered WSe 2 Crystals. Science 2007;315:351-3.

[72] Minnich AJ, Dresselhaus MS, Ren ZF, Chen G. Bulk nanostructured thermoelectric materials: current research and future prospects. Energ Environ Sci 2009;2:466-79.

[73] Mukerjee S, Moore JE. Doping dependence of thermopower and thermoelectricity in strongly correlated materials. Appl Phys Lett 2007;90:112107-3.

[74] Nolas GS, Sharp J, Goldsmid J. Thermoelectrics: basic principles and new materials developments: Springer; 2001.

[75] Poudel B, Hao Q, Ma Y, Lan Y, Minnich A, Yu B, et al. High-thermoelectric performance of nanostructured bismuth antimony telluride bulk alloys. Science 2008;320:634-8.

[76] Sootsman JR, Chung DY, Kanatzidis MG. New and Old Concepts in Thermoelectric Materials. Angew Chem-Int Ed 2009;48:8616-39.

[77] Guilmeau E, Berardan D, Simon C, Maignan A, Raveau B, Ovono DO, et al. Tuning the transport and thermoelectric properties of $\mathrm{In}_{2} \mathrm{O}_{3}$ bulk ceramics through doping at In-site. $\mathrm{J}$ Appl Phys 2009;106:053715-7.

[78] Fergus JW. Oxide materials for high temperature thermoelectric energy conversion. J Eur Cer Soc 2012;32:525-40.

[79] Wang Y, Sui Y, Fan HJ, Wang XJ, Su YT, Su WH, et al. High Temperature Thermoelectric Response of Electron-Doped CaMnO3. Chem Mater 2009;21:4653-60.

[80] Wang Y, Sui Y, Su WH. High temperature thermoelectric characteristics of $\mathrm{Ca}(0.9) \mathrm{R}_{(0.1)} \mathrm{MnO}_{(3)}(\mathrm{R}=\mathrm{La}, \mathrm{Pr}, \mathrm{Yb})$. J Appl Phys 2008;104.

[81] Wang Y, Sui Y, Wang XJ, Su WH. Enhancement of thermoelectric efficiency in (Ca, Dy) $\mathrm{MnO}_{3}-(\mathrm{Ca}, \mathrm{Yb}) \mathrm{MnO}_{3}$ solid solutions. Appl Phys Lett 2010;97.

[82] Moon JW, Masuda Y, Seo WS, Koumoto K. Influence of ionic size of rare-earth site on the thermoelectric properties of $\mathrm{RCoO}_{3}$-type perovskite cobalt oxides. Mater Sci Eng B-Solid State Mater Adv Technol 2001;85:70-5.

[83] Ohtaki M, Tsubota T, Eguchi K, Arai H. High-temperature thermoelectric properties of $\left(\mathrm{Zn}_{1-\mathrm{x}} \mathrm{Al} \mathrm{l}_{\mathrm{x}}\right) \mathrm{O}$. J Appl Phys 1996;79:1816-8.

[84] Fujishiro Y, Miyata M, Awano M, Maeda K. Characterization of thermoelectric metal oxide elements prepared by the pulse electric-current sintering method. J Am Ceram Soc 2004;87:1890-4.

[85] Kaga H, Kinemuchi Y, Yihnaz H, Watarl K, Nakano H, Nakano H, et al. Orientation dependence of transport property and microstructural characterization of Al-doped $\mathrm{ZnO}$ ceramics. Acta Mater 2007;55:4753-7. 
[86] Park K, Ko KY, Seo WS, Cho WS, Kim JG, Kim JY. High-temperature thermoelectric properties of polycrystalline Zn1-x-yAlx Tiy $\mathrm{Z}_{\mathrm{y}}$ ceramics. J Eur Ceram Soc 2007;27:813-7.

[87] Cheng H, Xu XJ, Hng HH, Ma J. Characterization of Al-doped ZnO thermoelectric materials prepared by RF plasma powder processing and hot press sintering. Ceram Int 2009;35:3067-72.

[88] Ohtaki M, Araki K, Yamamoto K. High Thermoelectric Performance of Dually Doped ZnO Ceramics. J Electron Mater 2009;38:1234-8.

[89] Wiff JP, Kinemuchi Y, Kaga H, Ito C, Watari K. Correlations between thermoelectric properties and effective mass caused by lattice distortion in Al-doped $\mathrm{ZnO}$ ceramics. J Eur Ceram Soc 2009;29:1413-8.

[90] Ma N, Li JF, Zhang BP, Lin YH, Ren LR, Chen GF. Microstructure and thermoelectric properties of $\mathrm{Zn}_{1-\mathrm{x}} \mathrm{Al}_{\mathrm{x}} \mathrm{O}$ ceramics fabricated by spark plasma sintering. J Phys Chem Solids 2010;71:1344-9.

[91] Jood P, Mehta RJ, Zhang YL, Peleckis G, Wang XL, Siegel RW, et al. Al-Doped Zinc Oxide Nanocomposites with Enhanced Thermoelectric Properties. Nano Lett 2011;11:433742.

[92] Qu XR, Wang W, Lv SC, Jia DC. Thermoelectric properties and electronic structure of Al-doped ZnO. Solid State Commun 2011;151:332-6.

[93] Yamaguchi H, Chonan Y, Oda M, Komiyama T, Aoyama T, Sugiyama S. Thermoelectric Properties of $\mathrm{ZnO}$ Ceramics Co-Doped with Al and Transition Metals. J Electron Mater 2011;40:723-7.

[94] Teehan S, Efstathiadis H, Haldar P. Thermoelectric power factor enhancement of $\mathrm{AZO} / \mathrm{In}-\mathrm{AZO}$ quantum well multilayer structures as compared to bulk films. J Alloy Compd 2012;539:129-36.

[95] Park K, Jang K, Kwon HC, Kim JG, Cho WS. Influence of partial substitution of Cu for $\mathrm{Co}$ on the thermoelectric properties of $\mathrm{NaCo}_{2} \mathrm{O}_{4}$. J Alloy Compd 2006;419:213-9.

[96] Park K, Lee J. Enhanced thermoelectric properties of $\mathrm{NaCo}_{2} \mathrm{O}_{4}$ by adding $\mathrm{ZnO}$. Mater Lett 2008;62:2366-8.

[97] Georges A, Kotliar G, Krauth W, Rozenberg MJ. Dynamical mean-field theory of strongly correlated fermion systems and the limit of infinite dimensions. Rev Mod Phys 1996;68:13.

[98] Katsnelson MI, Lichtenstein AI. Electronic structure and magnetic properties of correlated metals. Eur Phys J - B 2002;30:9-15.

[99] Restrepo O, Varga K, Pantelides S. First-principles calculations of electron mobilities in silicon: Phonon and Coulomb scattering. Appl Phys Lett 2009;94:212103--3.

[100] Wang Z, Wang S, Obukhov S, Vast N, Sjakste J, Tyuterev V, et al. Thermoelectric transport properties of silicon: Toward an ab initio approach. Phys Rev B 2011;83:205208.

[101] Zebarjadi M, Esfarjani K, Bian Z, Shakouri A. Low-Temperature Thermoelectric Power Factor Enhancement by Controlling Nanoparticle Size Distribution. Nano Lett 2011;11:225.

[102] Weidenkaff A, Robert R, Aguirre M, Bocher L, Lippert T, Canulescu S. Development of thermoelectric oxides for renewable energy conversion technologies. Renew Ener 2008;33:342-7.

[103] Weidenkaff A, Robert R, Aguirre MH, Bocher L, Schlapbach L. Nanostructured thermoelectric oxides with low thermal conductivity. Physica Status Solidi-Rapid Res Lett 2007;1:247-9.

[104] Callaway J. Model for Lattice Thermal Conductivity at Low Temperatures. Phys Rev 1959;113:1046-51.

[105] Broido D, Malorny M, Birner G, Mingo N, Stewart D. Intrinsic lattice thermal conductivity of semiconductors from first principles. Appl Phys Lett 2007;91:231922--3. 
[106] Ward A, Broido D. Intrinsic phonon relaxation times from first-principles studies of the thermal conductivities of Si and Ge. Phys Rev B 2010;81:085205.

[107] de Koker N. Thermal conductivity of $\mathrm{MgO}$ periclase from equilibrium first principles molecular dynamics. Phys Rev Lett 2009;103:125902.

[108] Esfarjani K, Stokes HT. Method to extract anharmonic force constants from first principles calculations. Phys Rev B 2008;77:144112.

[109] Henry AS, Chen G. Spectral phonon transport properties of silicon based on molecular dynamics simulations and lattice dynamics. J Comput Theoretical Nanosci 2008;5:141-52.

[110] Lundstrom M. Fundamentals of carrier transport: Cambridge University Press; 2009.

[111] Vining CB. A model for the high-temperature transport properties of heavily doped ntype silicon-germanium alloys. J Appl Physics 1991;69:331-41.

[112] Yang RG, Chen G, Dresselhaus MS. Thermal conductivity of simple and tubular nanowire composites in the longitudinal direction. Phys Rev B 2005;72.

[113] He J, Liu YF, Funahashi R. Oxide thermoelectrics: The challenges, progress, and outlook. Journal of Materials Research. 2011;26:1762-72.

[114] Stiewe C, He Z, Platzek D, Karpinski G, Müller E, Li S, et al. Control of thermoelectric properties in $\mathrm{ZrO}_{2} / \mathrm{CoSb}_{3}$ nano-dispersed composites. Materialwissenschaft und Werkstofftechnik. 2007;38:773-6.

[115] Maekawa S, Tohyama T, Barnes SE, Ishihara S, Koshibae W, Khaliullin G. Physics of transition metal oxides: Springer; 2004.

[116] Cox PA. Transition metal oxides: an introduction to their electronic structure and properties. Oxford Univ Pr; 2010.

[117] Rao CNR, Raveau B. Transition Metal Oxides: Structure, Properties, and Synthesis of Ceramic Oxides. Wiley; 1998.

[118] Emeline AV, Kataeva GV, Ryabchuk VK, Serpone N. Photostimulated generation of defects and surface reactions on a series of wide band gap metal-oxide solids. J Phys Chem B 1999;103:9190-9.

[119] Matsui M, Akaogi M. Molecular dynamics simulation of the structural and physical properties of the four polymorphs of $\mathrm{TiO}_{2}$. Molecular Simulation 1991;6:239-44.

[120] Zhang HZ, Banfield JF. Understanding polymorphic phase transformation behavior during growth of nanocrystalline aggregates: Insights from $\mathrm{TiO}_{2}$. J Phys Chem B 2000;104:3481-7.

[121] Diebold U. The surface science of titanium dioxide. Surf Sci Rep 2003;48:53-229.

[122] Bavykin DV, Friedrich JM, Walsh FC. Protonated titanates and $\mathrm{TiO}_{2}$ nanostructured materials: Synthesis, properties, and applications. Adv Mater 2006;18:2807-24.

[123] He QY, Hao Q, Chen G, Poudel B, Wang XW, Wang DZ, et al. Thermoelectric property studies on bulk $\mathrm{TiO}_{\mathrm{x}}$ with $\mathrm{x}$ from 1 to 2 . Appl Phys Lett 2007;91.

[124] Lu Y, Hirohashi M, Sato K. Thermoelectric properties of non-stoichiometric titanium dioxide $\mathrm{TiO}_{2-x}$ fabricated by reduction treatment using carbon powder. Mater Trans. 2006;47:1449-52.

[125] Tang JK, Wang WD, Zhao GL, Li Q. Colossal positive Seebeck coefficient and low thermal conductivity in reduced $\mathrm{TiO}_{2}$. J Phys-Cond Matter 2009;21.

[126] Tsuyumoto I, Hosono T, Murata M. Thermoelectric power in nonstoichiometric orthorhombic titanium oxides. J Am Ceram Soc 2006;89:2301-3.

[127] Bak T, Nowotny MK, Sheppard LR, Nowotny J. Effect of prolonged oxidation on semiconducting properties of titanium dioxide. J Phys Chem C 2008;112:13248-57.

[128] Miao L, Tanemura S, Huang R, Liu CY, Huang CM, Xu G. Large Seebeck Coefficients of Protonated Titanate Nanotubes for High-Temperature Thermoelectric Conversion. ACS Appl Mater Interfaces 2010;2:2355-9. 
[129] Kurita D, Ohta S, Sugiura K, Ohta H, Koumoto K. Carrier generation and transport properties of heavily $\mathrm{Nb}$-doped anatase $\mathrm{TiO}_{2}$ epitaxial films at high temperatures. J Appl Phys 2006;100.

[130] Sheppard LR, Bak T, Nowotny J. Electrical properties of niobium-doped titanium dioxide. 3. Thermoelectric power. J Phys Chem C 2008;112:611-7.

[131] Sheppard LR, Bak T, Nowotny J. Electrical properties of niobium-doped titanium dioxide. 1. Defect disorder. J Phys Chem B 2006;110:22447-54.

[132] Okuda T, Nakanishi K, Miyasaka S, Tokura Y. Large thermoelectric response of metallic perovskites: $\mathrm{Sr}_{1-x} \mathrm{Lax}_{x} \mathrm{TiO}_{3}(0<=\mathrm{x}<=0.1)$. Phys Rev B 2001;63.

[133] Ohta S, Nomura T, Ohta H, Koumoto K. High-temperature carrier transport and thermoelectric properties of heavily La- or $\mathrm{Nb}$-doped $\mathrm{SrTiO}_{3}$ single crystals. J Appl Phys 2005;97.

[134] Ravichandran J, Siemons W, Oh DW, Kardel JT, Chari A, Heijmerikx H, et al. Hightemperature thermoelectric response of double-doped $\mathrm{SrTiO}_{3}$ epitaxial films. Phys Rev B $2010 ; 82$.

[135] Jalan B, Stemmer S. Large Seebeck coefficients and thermoelectric power factor of Ladoped SrTiO3 thin films. Appl Phys Lett 2010;97.

[136] Muta H, Kurosaki K, Yamanaka S. Thermoelectric properties of rare earth doped $\mathrm{SrTiO}_{3}$. J Alloy Compd 2003;350:292-5.

[137] Yamamoto M, Ohta H, Koumoto K. Thermoelectric phase diagram in a $\mathrm{CaTiO}_{3}-$ $\mathrm{SrTiO}_{3}-\mathrm{BaTiO}_{3}$ system. Appl Phys Lett 2007;90.

[138] Lakshmi BB, Patrissi CJ, Martin CR. Sol-gel template synthesis of semiconductor oxide micro- and nanostructures. Chem Mater. 1997;9:2544-50.

[139] Zhang LH, Tosho T, Okinaka N, Akiyama T. Thermoelectric properties of combustionsynthesized lanthanum-doped strontium titanate. Mater Trans 2007;48:1079-83.

[140] Wei WF, Cui XW, Chen WX, Ivey DG. Manganese oxide-based materials as electrochemical supercapacitor electrodes. Chem Soc Rev 2011;40:1697-721.

[141] Xiao W, Wang DL, Lou XW. Shape-Controlled Synthesis of $\mathrm{MnO}_{2}$ Nanostructures with Enhanced Electrocatalytic Activity for Oxygen Reduction. J Phys Chem C 2010;114:1694-700.

[142] Song FF, Wu LM, Liang S. Giant Seebeck coefficient thermoelectric device of $\mathrm{MnO}_{2}$ powder. Nanotechnology 2012;23.

[143] Cockayne E, Li L. First-principles DFT+U studies of the atomic, electronic, and magnetic structure of alpha- $\mathrm{MnO}_{2}$ (cryptomelane). Chem Phys Lett 2012;544:53-8.

[144] Post JE, Vondreele RB, Buseck PR. Symmetry and cation displacements in hollanditesStructure refinements of hollandite, cryptomelane and priderite. Acta Cryst Sect B-Struct Sci 1982;38:1056-65.

[145] Devaraj S, Munichandraiah N. Effect of crystallographic structure of $\mathrm{MnO}_{2}$ on its electrochemical capacitance properties. J Phys Chem C 2008;112:4406-17.

[146] Preisler E. Semiconductor properties of manganese dioxide. J Appl Electrochem 1976;6:311-20.

[147] U1 Islam A, Islam R, Khan KA. Studies on the thermoelectric effect in semiconducting $\mathrm{MnO}_{2}$ thin films. Journal of Materials Science-Materials in Electronics. 2005;16:203-7.

[148] Ang R, Lu WJ, Zhang RL, Zhao BC, Zhu XB, Song WH, et al. Effects of Co doping in bilayered manganite $\mathrm{LaSr}_{2} \mathrm{Mn}_{2} \mathrm{O}_{7}$ : Resistivity, thermoelectric power, and thermal conductivity. Phys Rev B 2005;72.

[149] Zhang FP, Lu QM, Zhang X, Zhang JX. First principle investigation of electronic structure of $\mathrm{CaMnO}_{3}$ thermoelectric compound oxide. J Alloy Compd 2011;509:542-5. 
[150] Flahaut D, Mihara T, Funahashi R, Nabeshima N, Lee $K$, Ohta $H$, et al. Thermoelectrical properties of A-site substituted $\mathrm{Ca}_{1-\mathrm{x}} \mathrm{Re}_{\mathrm{x}} \mathrm{MnO}_{3}$ system. J Appl Phys $2006 ; 100$.

[151] Sato H, Enoki T, Isobe M, Ueda Y. Transport properties and magnetism of a helically Hund-coupled conductor: beta- $\mathrm{MnO}_{2}$. Phys Rev B 2000;61:3563-9.

[152] Zhang X, Yang WS, Yang JJ, Evans DG. Synthesis and characterization of alpha$\mathrm{MnO}_{2}$ nanowires: Self-assembly and phase transformation to beta- $\mathrm{MnO}_{2}$ microcrystals. $\mathrm{J}$ Cryst Growth 2008;310:716-22.

[153] Wang X, Li YD. Synthesis and formation mechanism of manganese dioxide nanowires/nanorods. Chem- Eur Jour 2003;9:300-6.

[154] Devenney M, Donne S, Gorer S. Application of combinatorial methodologies to the synthesis and characterization of electrolytic manganese dioxide. J Appl Electrochem 2004;34:643-51.

[155] Chou S, Cheng F, Chen J. Electrodeposition synthesis and electrochemical properties of nanostructured $\gamma-\mathrm{MnO}_{2}$ films. J Power Sour 2006;162:727-34.

[156] Dong B, Xue T, Xu C-L, Li H-L. Electrodeposition of mesoporous manganese dioxide films from lyotropic liquid crystalline phases. Micropor Mesopor Mat 2008;112:627-31.

[157] Wang X, Wang X, Huang W, Sebastian P, Gamboa S. Sol-gel template synthesis of highly ordered $\mathrm{MnO}_{2}$ nanowire arrays. J Power Sour 2005;140:211-5.

[158] Nilsen O, Fjellvåg H, Kjekshus A. Growth of manganese oxide thin films by atomic layer deposition. Thin Solid Films 2003;444:44-51.

[159] Isber S, Majdalani E, Tabbal M, Christidis T, Zahraman K, Nsouli B. Study of manganese oxide thin films grown by pulsed laser deposition. Thin Solid Films 2009;517:1592-5.

[160] Guo LW, Peng DL, Makino H, Hanada T, Hong SK, Sumiyama K, et al. Structural characteristics and magnetic properties of $\mathrm{MnO}_{2}$ films grown by plasma-assisted molecular beam epitaxy. J Appl Phys 2001;90:351-4.

[161] Wang HQ, Dong X, Peng SJ, Dong L, Wang Y. Improvement of thermoelectric properties of $\mathrm{WO}_{3}$ ceramics by $\mathrm{ZnO}$ addition. J Alloy Compd 2012;527:204-9.

[162] Salje EKH, Rehmann S, Pobell F, Morris D, Knight KS, Herrmannsdorfer T, et al. Crystal structure and paramagnetic behaviour of epsilon- $\mathrm{WO}_{3-\mathrm{x}}$. J Phys-Cond Matter. 1997;9:6563-77.

[163] Vogt T, Woodward PM, Hunter BA. The high-temperature phases of $\mathrm{WO}_{3}$. J Sol State Chem 1999;144:209-15.

[164] Goulding MR, Thomas CB. Transport properties of amorphous films of tungstic oxide sublimed under different conditions. Thin Solid Films 1979;62:175-88.

[165] Patil PS, Patil PR, Ennaoui EA. Characterization of ultrasonic spray pyrolyzed tungsten oxide thin films. Thin Solid Films 2000;370:38-44.

[166] Makarov VO, Trontelj M. Sintering and electrical conductivity of doped $\mathrm{WO}_{3}$. J Eur Cer Soc 1996;16:791-4.

[167] Vemuri RS, Bharathi KK, Gullapalli SK, Ramana CV. Effect of Structure and Size on the Electrical Properties of Nanocrystalline $\mathrm{WO}_{3}$ Films. ACS Appl Mater Inter 2010;2:26238 .

[168] Hutchins MG, Abu-Alkhair O, El-Nahass MM, Abdel-Hady K. Electrical conduction mechanisms in thermally evaporated tungsten trioxide $\left(\mathrm{WO}_{3}\right)$ thin films. J Phys-Cond Matter. 2006;18:9987-97.

[169] Wang HT, Xu YB, Goto M, Tanaka Y, Yamazaki M, Kasahara A, et al. Thermal conductivity measurement of tungsten oxide nanoscale thin films. Mater Trans 2006;47:1894-7. 
[170] Molenda J, Kubik A. Transport properties and reactivity of tungsten trioxide. Solid State Ionics. 1999;117:57-64.

[171] Wang HQ, Hua ZQ, Peng SJ, Dong X, Dong L, Wang Y. Effect of $\mathrm{CeO}_{2}$ on the thermoelectric properties of $\mathrm{WO}_{3}$-based ceramics. Cer Inter 2012;38:1133-7.

[172] Patil PS, Mujawar SH, Inamdar AI, Shinde PS, Deshmukh HP, Sadale SB. Structural, electrical and optical properties of $\mathrm{TiO}_{2}$ doped $\mathrm{WO}_{3}$ thin films. Appl Surf Sci 2005;252:164350 .

[173] Marsen B, Miller EL, Paluselli D, Rocheleau RE. Progress in sputtered tungsten trioxide for photoelectrode applications. Int J Hydrogen Ener 2007;32:3110-5.

[174] Cantalini C, Sun H, Faccio M, Pelino M, Santucci S, Lozzi L, et al. $\mathrm{NO}_{2}$ sensitivity of $\mathrm{WO}_{3}$ thin film obtained by high vacuum thermal evaporation. Sensors and Actuat B: Chem 1996;31:81-7.

[175] Breedon M, Spizzirri P, Taylor M, du Plessis J, McCulloch D, Zhu J, et al. Synthesis of Nanostructured Tungsten Oxide Thin Films: A Simple, Controllable, Inexpensive, Aqueous Sol- Gel Method. Cryst Growth \& Des 2009;10:430-9.

[176] Baeck S, Jaramillo T, Stucky G, McFarland E. Controlled electrodeposition of nanoparticulate tungsten oxide. Nano Lett 2002;2:831-4.

[177] Kalantar-zadeh K, Sadek AZ, Zheng H, Bansal V, Bhargava SK, Wlodarski W, et al. Nanostructured $\mathrm{WO}_{3}$ films using high temperature anodization. Sensors and Actuat B: Chem 2009;142:230-5.

[178] Zhao Y, Feng Z-C, Liang Y. Pulsed laser deposition of $\mathrm{WO}_{3}$-base film for $\mathrm{NO}_{2}$ gas sensor application. Sensors and Actuat B: Chem 2000;66:171-3.

[179] Sivakumar R, Gopalakrishnan R, Jayachandran M, Sanjeeviraja C. Preparation and characterization of electron beam evaporated $\mathrm{WO}_{3}$ thin films. Opt Mater 2007;29:679-87.

[180] Buchine BA, Hughes WL, Degertekin FL, Wang ZL. Bulk acoustic resonator based on piezoelectric ZnO belts. Nano Lett 2006;6:1155-9.

[181] He JH, Hsin CL, Liu J, Chen LJ, Wang ZL. Piezoelectric gated diode of a single ZnO nanowire. Adv Mater 2007;19:781-4.

[182] Lu M-P, Song J, Lu M-Y, Chen M-T, Gao Y, Chen L-J, et al. Piezoelectric nanogenerator using p-type $\mathrm{ZnO}$ nanowire arrays. Nano Lett 2009;9:1223-7.

[183] Wang ZL, Song J. Piezoelectric nanogenerators based on zinc oxide nanowire arrays. Science 2006;312:242-6.

[184] Coleman V, Jagadish C. Basic properties and applications of ZnO. Zinc Oxide Bulk, Thin films and Nanostructures, Processing, Properties and Applications. $1^{\text {st }}$ ed. Elsevier; 2006.

[185] Ong KP, Singh DJ, Wu P. Analysis of the thermoelectric properties of n-type ZnO. Phys Rev B 2011;83.

[186] Kinemuchi Y, Mikami M, Kobayashi K, Watari K, Hotta Y. Thermoelectric Properties of Nanograined ZnO. J Electron Mater 2010;39:2059-63.

[187] Fujishiro Y, Miyata M, Awano M, Maeda K. Effect of microstructural control on thermoelectric properties of hot-pressed aluminum-doped zinc oxide. J Am Ceram Soc 2003;86:2063-6.

[188] Kim KH, Shim SH, Shim KB, Niihara K, Hojo J. Microstructural and thermoelectric characteristics of zinc oxide-based thermoelectric materials fabricated using a spark plasma sintering process. J Am Ceram Soc 2005;88:628-32.

[189] Park K, Ko KY. Effect of TiO2 on high-temperature thermoelectric properties of $\mathrm{ZnO}$. J Alloy Compd 2007;430:200-4.

[190] Park K, Seong JK. Influence of simultaneous addition of $\mathrm{Sb}_{2} \mathrm{O}_{3}$ and $\mathrm{SnO}_{2}$ on thermoelectric properties of $\mathrm{Zn}_{1-\mathrm{x}-\mathrm{y}} \mathrm{Sb}_{\mathrm{x}} \mathrm{Sn}_{\mathrm{y}} \mathrm{O}$ prepared by tape casting. J Alloy Compd 2008;464:1-5. 
[191] Park K, Seong JK, Kwon Y, Nahm S, Cho WS. Influence of $\mathrm{SnO}_{2}$ addition on the thermoelectric properties of $\mathrm{Zn}_{1-\mathrm{x}} \mathrm{Sn}_{\mathrm{x}} \mathrm{O}(0.01<=\mathrm{x}<=0.05)$. Mater Res Bull 2008;43:54-61.

[192] Park K, Seong JK, Nahm S. Improvement of thermoelectric properties with the addition of Sb to ZnO. J Alloy Compd 2008;455:331-5.

[193] Guilmeau E, Maignan A, Martin C. Thermoelectric Oxides: Effect of Doping in Delafossites and Zinc Oxide. J Electron Mater 2009;38:1104-8.

[194] Park K, Seong JK, Kim GH. NiO added $\mathrm{Zn}_{1-\mathrm{x}} \mathrm{Ni}_{\mathrm{x}} \mathrm{O}(0<=\mathrm{x}<=0.05)$ for thermoelectric power generation. J Alloy Compd 2009;473:423-7.

[195] Berardan D, Byl C, Dragoe N. Influence of the Preparation Conditions on the Thermoelectric Properties of Al-Doped ZnO. J Am Ceram Soc 2010;93:2352-8.

[196] Colder H, Guilmeau E, Harnois C, Marinel S, Retoux R, Savary E. Preparation of Nidoped $\mathrm{ZnO}$ ceramics for thermoelectric applications. J Eur Ceram Soc 2011;31:2957-63.

[197] Michiue Y, Mori T, Prytuliak A, Matsushita Y, Tanaka M, Kimizuka N. Electrical, optical, and thermoelectric properties of $\mathrm{Ga}_{2} \mathrm{O}_{3}(\mathrm{ZnO})_{(9)}$. RSC Adv 2011;1:1788-93.

[198] Jung KH, Lee KH, Seo WS, Choi SM. An enhancement of a thermoelectric power factor in a Ga-doped $\mathrm{ZnO}$ system: A chemical compression by enlarged Ga solubility. Appl Phys Lett 2012;100.

[199] Paul GK, Sen SK. Sol-gel preparation, characterization and studies on electrical and thermoelectrical properties of gallium doped zinc oxide films. Mater Lett 2002;57:742-6.

[200] Gregoryz OJ, Amani M. Thermoelectric Properties of $\mathrm{Zn}_{\mathrm{x}} \mathrm{In}_{\mathrm{y}} \mathrm{O}_{\mathrm{x}+1.5 \mathrm{y}}$ Films. J Electrochem Soc 2011;158:J15-J9.

[201] Seo DK, Shin S, Cho HH, Kong BH, Whang DM, Cho HK. Drastic improvement of oxide thermoelectric performance using thermal and plasma treatments of the InGaZnO thin films grown by sputtering. Acta Mater 2011;59:6743-50.

[202] Shi LH, Chen J, Zhang G, Li BW. Thermoelectric figure of merit in Ga-doped 0001 ZnO nanowires. Phys Lett A. 2012;376:978-81.

[203] Yang Y, Pradel KC, Jing Q, Wu JM, Zhang F, Zhou Y, et al. Thermoelectric Nanogenerators Based on Single Sb-Doped ZnO Micro/Nanobelts. ACS Nano 2012;6:69849.

[204] Rodríguez-Gattorno G, Santiago-Jacinto P, Rendon-Vazquez L, Németh J, Dékány I, Díaz D. Novel synthesis pathway of $\mathrm{ZnO}$ nanoparticles from the spontaneous hydrolysis of zinc carboxylate salts. J Phys Chem B 2003;107:12597-604.

[205] Caglar M, Ilican S, Caglar Y, Yakuphanoglu F. The effects of Al doping on the optical constants of $\mathrm{ZnO}$ thin films prepared by spray pyrolysis method. J Mater Sci-Mater El 2008;19:704-8.

[206] Zhang J, Sun L, Yin J, Su H, Liao C, Yan C. Control of ZnO morphology via a simple solution route. Chem Mater 2002;14:4172-7.

[207] Kamalasanan M, Chandra S. Sol-gel synthesis of ZnO thin films. Thin Solid Films 1996;288:112-5.

[208] Choi K-S, Lichtenegger HC, Stucky GD, McFarland EW. Electrochemical synthesis of nanostructured $\mathrm{ZnO}$ films utilizing self-assembly of surfactant molecules at solid-liquid interfaces. J Am Chem Soc 2002;124:12402-3.

[209] He S, Zheng M, Yao L, Yuan X, Li M, Ma L, et al. Preparation and properties of ZnO nanostructures by electrochemical anodization method. Appl Surf Sci 2010;256:2557-62.

[210] Banerjee A, Ghosh C, Chattopadhyay K, Minoura H, Sarkar AK, Akiba A, et al. Lowtemperature deposition of $\mathrm{ZnO}$ thin films on PET and glass substrates by DC-sputtering technique. Thin Solid Films 2006;496:112-6.

[211] Yi G-C, Wang C, Park WI. ZnO nanorods: synthesis, characterization and applications. Semicond Sci Tech 2005;20:S22. 
[212] Pung S-Y, Choy K-L, Hou X, Shan C. Preferential growth of ZnO thin films by the atomic layer deposition technique. Nanotechnology 2008;19:435609.

[213] Gonzalez-Valls I, Lira-Cantu M. Vertically-aligned nanostructures of ZnO for excitonic solar cells: a review. Ener Environ Sci 2009;2:19-34.

[214] Kim KH, Shim SH, Shim KB, Niihara K, Hojo J. Microstructural and Thermoelectric Characteristics of Zinc Oxide-Based Thermoelectric Materials Fabricated Using a Spark Plasma Sintering Process. J Am Ceram Soc 2005;88:628-32.

[215] Jin B, Im S, Lee S. Violet and UV luminescence emitted from ZnO thin films grown on sapphire by pulsed laser deposition. Thin Solid Films 2000;366:107-10.

[216] Gou X, Wang G, Yang J, Park J, Wexler D. Chemical synthesis, characterisation and gas sensing performance of copper oxide nanoribbons. J Mater Chem 2008; 18:965-9.

[217] Ito T, Yamaguchi H, Okabe K, Masumi T. Single-crystal growth and characterization of $\mathrm{Cu}_{2} \mathrm{O}$ and $\mathrm{CuO}$. J Mater Sci 1998;33:3555-66.

[218] Yin M, Wu C-K, Lou Y, Burda C, Koberstein JT, Zhu Y, et al. Copper oxide nanocrystals. J Am Chem Soc 2005;127:9506-11.

[219] Zirin MH, Trivich D. Thermoelectric effect in single-crystal cuprous oxide at high temperatures. J Chem Phys 1963;39:870-\&.

[220] Balamurugan B, Mehta B. Optical and structural properties of nanocrystalline copper oxide thin films prepared by activated reactive evaporation. Thin Solid Films 2001;396:90-6.

[221] Muhibbullah M, Hakim MO, Choudhury MGM. Studies on Seebeck effect in spray deposited CuO thin film on glass substrate. Thin Solid Films 2003;423:103-7.

[222] Jeong YK, Choi GM. Nonstoichiometry and electrical conduction of CuO. J Phys Chem Solids. 1996;57:81-4.

[223] Koffyberg FP, Benko FA. A Photo-Electrochemical determination of the position of the conduction and valence band edges of $\mathrm{p}$ type CuO. J Appl Phys 1982;53:1173-7.

[224] Yu JD, Inaguma Y, Itoh M, Oguni M, Kyomen T. Effect of oxygen content on the anomalies at successive phase transitions of $\mathrm{La}_{2} \mathrm{CuO}_{4+\text { delta }}$ single crystal below $320 \mathrm{~K}$. Phys Rev B 1996;54:7455-61.

[225] Hord R, Luetkens H, Pascua G, Buckow A, Hofmann K, Krockenberger Y, et al. Enhanced two-dimensional behavior of metastable $\mathrm{T}-\mathrm{La}_{2} \mathrm{CuO}_{4}$, the parent compound of electron-doped cuprate superconductors. Phys Rev B 2010;82.

[226] Liu Y, Lin YH, Zhang BP, Zhu HM, Nan CW, Lan JL, et al. High-Temperature Thermoelectric Properties in the $\mathrm{La}_{2-\mathrm{x}} \mathrm{R}_{\mathrm{x}} \mathrm{CuO}_{4}(\mathrm{R}$ : Pr, Y, Nb) Ceramics. J Am Ceram Soc 2009;92:934-7.

[227] Yamanaka S, Kobayashi H, Kurosaki K. Thermoelectric properties of layered rare earth copper oxides. J Alloy Compd 2003;349:321-4.

[228] Armelao L, Barreca D, Bertapelle M, Bottaro G, Sada C, Tondello E. A sol-gel approach to nanophasic copper oxide thin films. Thin Solid Films 2003;442:48-52.

[229] Li S, Zhang H, Ji Y, Yang D. CuO nanodendrites synthesized by a novel hydrothermal route. Nanotechnology 2004;15:1428.

[230] Kosugi T, Kaneko S. Novel Spray-Pyrolysis Deposition of Cuprous Oxide Thin Films. J Am Ceram Soc 2005;81:3117-24.

[231] Allam NK, Grimes CA. Electrochemical fabrication of complex copper oxide nanoarchitectures copper anodization in aqueous and non-aqueous electrolytes. Mat Lett 2011;65:1949-55.

[232] Switzer JA, Kothari HM, Poizot P, Nakanishi S, Bohannan EW. Enantiospecific electrodeposition of a chiral catalyst. Nature 2003;425:490-3.

[233] Maruyama T. Copper oxide thin films prepared by chemical vapor deposition from copper dipivaloylmethanate. Sol Ener Mat Sol C 1998;56:85-92. 
[234] Eyert V, Höck K-H. Electronic structure of $\mathrm{V}_{2} \mathrm{O}_{5}$ : Role of octahedral deformations. Phys Rev B 1998;57:12727.

[235] Cao AM, Hu JS, Liang HP, Wan LJ. Self-assembled vanadium pentoxide $\left(\mathrm{V}_{2} \mathrm{O}_{5}\right)$ hollow microspheres from nanorods and their application in lithium-ion batteries. Angew Chem-Int Ed 2005;44:4391-5.

[236] Sides CR, Martin CR. Nanostructured electrodes and the low-temperature performance of Li-ion batteries. Adv Mater 2005;17:125.

[237] Liu J, Xia H, Xue DF, Lu L. Double-Shelled Nanocapsules of $\mathrm{V}_{2} \mathrm{O}_{5}$-Based Composites as High-Performance Anode and Cathode Materials for Li Ion Batteries. J Am Chem Soc 2009;131:12086-+.

[238] Chernova NA, Roppolo M, Dillon AC, Whittingham MS. Layered vanadium and molybdenum oxides: batteries and electrochromics. J Mater Chem 2009;19:2526-52.

[239] El Mandouh ZS, Selim MS. Physical properties of vanadium pentoxide sol gel films. Thin Solid Films 2000;371:259-63.

[240] Talledo A, Granqvist CG. Electrochromic vanadium-pentoxide based filmsStructural,Electrochemical and optical properties. J Appl Phys 1995;77:4655-66.

[241] Xiong CR, Aliev AE, Gnade B, Balkus KJ. Fabrication of silver vanadium oxide and V2O5 nanowires for electrochromics. ACS Nano 2008;2:293-301.

[242] Darling RB, Iwanaga S. Structure, properties, and MEMS and microelectronic applications of vanadium oxides. Sadhana-Academy Proc Eng Sci 2009;34:531-42.

[243] Kounavis P, Vomvas A, Mytilineou E, Roilos M, Murawski L. Thermopower, conductivity and the Hall-effect in $\mathrm{V}_{2} \mathrm{O}_{5}$ gels. J Phys C-Sol State Phys 1988;21:967-73.

[244] Bahgat AA, Ibrahim FA, El-Desoky MM. Electrical and optical properties of highly oriented nanocrystalline vanadium pentoxide. Thin Solid Films 2005;489:68-73.

[245] Iwanaga S, Marciniak M, Darling RB, Ohuchi FS. Thermopower and electrical conductivity of sodium-doped $\mathrm{V}_{2} \mathrm{O}_{5}$ thin films. J Appl Phys 2007;101.

[246] Liu YJ, Schindler JL, DeGroot DC, Kannewurf CR, Hirpo W, Kanatzidis MG. Synthesis, structure, and reactions of poly(ethylene oxide) $\mathrm{V}_{2} \mathrm{O}_{5}$ intercalative nanocomposites. Chem Mater 1996;8:525-34.

[247] Ramesh KV, Sastry DL. Transport properties of $\mathrm{ZnO}$ substituted lead vanadate glass system at eutectic composition. Mat Sci Eng B 2006;126:66-73.

[248] Beke S. A review of the growth of $\mathrm{V}_{2} \mathrm{O}_{5}$ films from 1885 to 2010. Thin Solid Films 2011;519:1761-71.

[249] Chirayil T, Zavalij PY, Whittingham MS. Hydrothermal synthesis of vanadium oxides. Chem Mater 1998;10:2629-40.

[250] Pan D, Shuyuan Z, Chen Y, Hou J. Hydrothermal preparation of long nanowires of vanadium oxide. J Mater Res 2002;17:1981-4.

[251] Takahashi K, Limmer SJ, Wang Y, Cao G. Synthesis and electrochemical properties of single-crystal V2O5 nanorod arrays by template-based electrodeposition. J Phys Chem B 2004;108:9795-800.

[252] Takahashi K, Limmer SJ, Cao G. Template-based growth of V2O5 nanorods by electrodeposition. Optical Science and Technology, SPIE's 48th Annual Meeting: Inter Soc Opt and Phot 2003. p. 33-42.

[253] Stefanovich G, Pergament A, Velichko A, Stefanovich L. Anodic oxidation of vanadium and properties of vanadium oxide films. J Phys Cond Mat 2004;16:4013.

[254] Navone C, Pereira-Ramos J, Baddour-Hadjean R, Salot R. High-capacity crystalline $\mathrm{V}_{2} \mathrm{O}_{5}$ thick films prepared by $\mathrm{RF}$ sputtering as positive electrodes for rechargeable lithium microbatteries. J Electrochem Soc 2006;153:A2287-A93.

[255] Badot J-C, Mantoux A, Baffier N, Dubrunfaut O, Lincot D. Electrical properties of $\mathrm{V}_{2} \mathrm{O}_{5}$ thin films obtained by atomic layer deposition (ALD). J Mater Chem 2004;14:3411-5. 
[256] Ramana C, Smith R, Hussain O, Julien C. Growth and surface characterization of V2O5 thin films made by pulsed-laser deposition. J Vac Sci Technol A 2004;22:2453-8.

[257] Barreca D, Armelao L, Caccavale F, Di Noto V, Gregori A, Rizzi GA, et al. Highly oriented V2O5 nanocrystalline thin films by plasma-enhanced chemical vapor deposition. Chem Mater 2000;12:98-103.

[258] Barreca D, Massignan C, Daolio S, Fabrizio M, Piccirillo C, Armelao L, et al. Composition and microstructure of cobalt oxide thin films obtained from a novel cobalt(II) precursor by chemical vapor deposition. Chem Mater 2001;13:588-93.

[259] Wollenstein J, Burgmair M, Plescher G, Sulima T, Hildenbrand J, Bottner H, et al. Cobalt oxide based gas sensors on silicon substrate for operation at low temperatures. Sensors Actuat B-Chem. 2003;93:442-8.

[260] Kowalski K, Ijjaali M, Bak T, Dupre B, Gleitzer C, Nowotny J, et al. Semiconducting Properties of CoO Thin Films. Ionics. 2001;7:394-9.

[261] Tong XC. Thermoelectric Cooling Through Thermoelectric Materials. Adv Mater for Thermal Manag Electron Pack 2011. p. 477-525.

[262] Lee M, Viciu L, Li L, Wang YY, Foo ML, Watauchi S, et al. Large enhancement of the thermopower in $\mathrm{Na}_{x} \mathrm{CoO}_{2}$ at high Na doping. Nat Mater 2006;5:537-40.

[263] Nagira T, Ito M, Katsuyama S, Majima K, Nagai H. Thermoelectric properties of ( $\mathrm{Na}_{1-}$ $\left.{ }_{\mathrm{y}} \mathrm{M}_{\mathrm{y}}\right)_{\mathrm{x}} \mathrm{Co}_{2} \mathrm{O}_{4}(\mathrm{M}=\mathrm{K}, \mathrm{Sr}, \mathrm{Y}, \mathrm{Nd}, \mathrm{Sm}$ and $\mathrm{Yb} ; \mathrm{y}=0.01-0.35)$. J. Alloy. Compd. 2003;348:263-9.

[264] Kim JY, Kim JI, Seo WS. Exfoliation Route to Nanostructured Cobalt Oxide with Enhanced Thermoelectric Performance. Appl Phys Exp 2011;4.

[265] Kim J-Y, Kim J-I, Choi S-M, Lim YS, Seo W-S, Hwang HJ. Nanostructured thermoelectric cobalt oxide by exfoliation/restacking route. J Appl Phys 2012;112:113705-8.

[266] Wang Y, Sui Y, Cheng J, Wang X, Su W. Comparison of the high temperature thermoelectric properties for Ag-doped and Ag-added $\mathrm{Ca}_{3} \mathrm{Co}_{4} \mathrm{O}_{9}$. J Alloy Compd 2009;477:817-21.

[267] Zhang F, Lu Q, Zhang J. Synthesis and high temperature thermoelectric properties of $\mathrm{Ba}_{\mathrm{x}} \mathrm{Ag}_{\mathrm{y}} \mathrm{Ca}_{3}-\mathrm{x}-\mathrm{y} \mathrm{Co}_{4} \mathrm{O}_{9}$ compounds. J Alloy Compd 2009;484:550-4.

[268] Song Y, Sun Q, Zhao L, Wang F, Jiang Z. Synthesis and thermoelectric power factor of (Ca0.95 $\left.\mathrm{Bi}_{0.05}\right)_{3} \mathrm{Co}_{4} \mathrm{O}_{9} / \mathrm{Ag}$ composites. Mater Chem Phys 2009;113:645-9.

[269] Wang Y, Sui Y, Cheng J, Wang X, Su W. Efficient room temperature thermoelectric characteristics of $\mathrm{Ca}_{3}-\mathrm{Ag}_{\mathrm{x}} \mathrm{Co}_{4} \mathrm{O}_{9+\delta} / \mathrm{Ag}_{\mathrm{y}}$ composites. J Phys D: Appl Phys 2008;41:045406.

[270] Matsubara I, Funahashi R, Takeuchi T, Sodeoka S. Thermoelectric properties of spark plasma sintered $\mathrm{Ca}_{2.75} \mathrm{Gd}_{0.25} \mathrm{Co}_{4} \mathrm{O}_{9}$ ceramics. J Appl Phys 2001;90:462-5.

[271] Yao Q, Wang D, Chen L, Shi X, Zhou M. Effects of partial substitution of transition metals for cobalt on the high-temperature thermoelectric properties of $\mathrm{Ca}_{3} \mathrm{Co}_{4} \mathrm{O}_{9+\delta}$. $\mathrm{J}$ Appl Phys 2005;97:103905--5.

[272] Wang Y, Sui Y, Wang X, Su W, Liu X. Enhanced high temperature thermoelectric characteristics of transition metals doped $\mathrm{Ca}_{3} \mathrm{Co}_{4} \mathrm{O}_{9+\delta}$ by cold high-pressure fabrication. $\mathrm{J}$ Appl Phys 2010;107:033708--9.

[273] Nong N, Liu CJ, Ohtaki M. Improvement on the high temperature thermoelectric performance of Ga-doped misfit-layered $\mathrm{Ca}_{3} \mathrm{Co}_{4-} \mathrm{xaa}_{\mathrm{x}} \mathrm{O}_{9+\delta}(\mathrm{x}=0,0.05,0.1$, and 0.2). $\mathrm{J}$ Alloy Compd 2010;491:53-6.

[274] Sugiura K, Ohta H, Nomura K, Hirano M, Hosono H, Koumoto K. High electrical conductivity of layered cobalt oxide $\mathrm{Ca}_{3} \mathrm{Co}_{4} \mathrm{O}_{9}$ epitaxial films grown by topotactic ionexchange method. Appl Phys Lett 2006;89:032111.

[275] Sugiura K, Ohta H, Nomura K, Hirano M, Hosono H, Koumoto K. Fabrication and thermoelectric properties of layered cobaltite, gamma-Sro. ${ }_{2} \mathrm{Na}_{0.21} \mathrm{CoO}_{2}$ epitaxial films. Appl Phys Lett 2006;88. 
[276] Wang G, Shen X, Horvat J, Wang B, Liu H, Wexler D, et al. Hydrothermal synthesis and optical, magnetic, and supercapacitance properties of nanoporous cobalt oxide nanorods. J Phys Chem C 2009;113:4357-61.

[277] Shao Y, Sun J, Gao L. Hydrothermal Synthesis of Hierarchical Nanocolumns of Cobalt Hydroxide and Cobalt Oxide. J Phys Chem C 2009;113:6566-72.

[278] Xie XW, Shen WJ. Morphology control of cobalt oxide nanocrystals for promoting their catalytic performance. Nanoscale. 2009;1:50-60.

[279] Casella IG. Electrodeposition of cobalt oxide films from carbonate solutions containing Co (II)-tartrate complexes. Journal of Electroanalytical Chemistry. 2002;520:119-25.

[280] Grillo ME. Stability of corundum- versus rutile-type structures of ruthenium and rhodium oxides. Phys Rev B 2004;70.

[281] Music S, Saric A, Popovic S, Ivanda M. Formation and characterisation of nanosize alpha- $\mathrm{Rh}_{2} \mathrm{O}_{3}$ particles. J Molec Str 2009;924-26:221-4.

[282] Watson P, Somorjai G. The hydrogenation of carbon monoxide over rhodium oxide surfaces. J Catal 1981;72:347-63.

[283] Dautremont-Smith W. Transition metal oxide electrochromic materials and displays: a review: Part 2: oxides with anodic coloration. Displays. 1982;3:67-80.

[284] Ligthart DAJM, van Santen RA, Hensen EJM. Supported Rhodium Oxide Nanoparticles as Highly Active $\mathrm{CO}$ Oxidation Catalysts. Angew Chem Int Edit 2011;50:5306-10.

[285] Koshibae W, Tsutsui K, Maekawa S. Thermopower in cobalt oxides. Phys Rev B 2000;62:6869-72.

[286] Okada S, Terasaki I. Physical properties of Bi-based rhodium oxides with $\mathrm{RhO}_{2}$ hexagonal layers. Jpn J Appl Phys Part 1-Reg Papers Brief Commun Rev Pap 2005;44:18347.

[287] Okada S, Sakai A, Kanno T, Yotsuhashi S, Adachi H. Thermoelectric properties of bismuth based cobalt-rhodium oxides with hexagonal $(\mathrm{Co}, \mathrm{Rh}) \mathrm{O}_{2}$ layers. J Appl Phys $2009 ; 105$.

[288] Kobayashi W, Tamura W, Terasaki I. Thermal conductivity of thermoelectric rhodium oxides measured by a modified Harman method. J Phys Soc Jpn 2008;77.

[289] Saeed Y, Singh N, Schwingenschlögl U. Colossal Thermoelectric Power Factor in $\mathrm{K}_{7 / 8} \mathrm{RhO}_{2}$. Adv Funct Mater 2012;22:2792-6.

[290] Wang HH, Yan MM, Jiang ZY. Electrochromic properties of rhodium oxide films prepared by a sol-gel method. Thin Solid Films 2001;401:211-5.

[291] Wang HH, Zhao CJ, Yan MM, Jiang ZY. Preparation of rhodium oxide films and its electrochromic study. Acta Chim Sin 2002;60:1203-8.

[292] Moran-Miguelez E, Alario-Franco M. Hydrothermal synthesis and reactivity of rhodium dioxide and oxyhydroxide. Thermochimica Acta 1983;60:181-6.

[293] Marot L, Mathys D, Temmerman GD, Oelhafen P. Characterization of substoichiometric rhodium oxide deposited by magnetron sputtering. Surf Sci 2008;602:3375-80.

[294] Muller O, Roy R. Formation and stability of the platinum and rhodium oxides at high oxygen pressures and the structures of $\mathrm{Pt}_{3} \mathrm{O}_{4}, \beta-\mathrm{PtO}_{2}$ and $\mathrm{RhO}_{2}$. J Less Common Metals. 1968;16:129-46.

[295] Yao JN, Hashimoto K, Fujishima A. Photochromism induced in an electrolytically pretreated $\mathrm{MoO}_{3}$ thin film by visible light. Nature. 1992;355:624-6.

[296] He T, Yao JN. Photochromism in composite and hybrid materials based on transitionmetal oxides and polyoxometalates. Prog Mater Sci 2006;51:810-79.

[297] Azad AM, Mhaisalkar SG, Birkefeld LD, Akbar SA, Goto KS. Behavior of a new $\mathrm{ZrO}_{2}-\mathrm{MoO}_{3}$ sensor for carbon-monoxide detection. J Electrochem Soc 1992;139:2913-20. 
[298] Ouyang QY, Li L, Wang QS, Zhang Y, Wang TS, Meng FN, et al. Facile synthesis and enhanced $\mathrm{H}_{2} \mathrm{~S}$ sensing performances of Fe-doped alpha-MoO 3 micro-structures. Sensors Actuat B-Chem 2012;169:17-25.

[299] Zhao DW, Sun XW, Jiang CY, Kyaw AKK, Lo GQ, Kwong DL. Efficient tandem organic solar cells with an $\mathrm{Al} / \mathrm{MoO}_{3}$ intermediate layer. Appl Phys Lett 2008;93.

[300] Cattin L, Dahou F, Lare Y, Morsli M, Tricot R, Houari S, et al. $\mathrm{MoO}_{3}$ surface passivation of the transparent anode in organic solar cells using ultrathin films. J Appl Phys $2009 ; 105$.

[301] Zhang FJ, Xu XW, Tang WH, Zhang J, Zhuo ZL, Wang J, et al. Recent development of the inverted configuration organic solar cells. Sol Energy Mat Sol C 2011;95:1785-99.

[302] Balendhran S, Walia S, Nili H, Ou JZ, Zhuiykov S, Kaner RB, et al. Two-Dimensional Molybdenum Trioxide and Dichalcogenides. Adv Funct Mater

2013:10.1002/adfm.201300125.

[303] Carcia PF, McCarron EM. Synthesis and properties of thin-film polymorphs of molybdenum trioxide Thin Solid Films. 1987;155:53-63.

[304] Di Yao D, Ou JZ, Latham K, Zhuiykov S, O'Mullane AP, Kalantar-zadeh K. Electrodeposited alpha- and beta-Phase MoO3 Films and Investigation of Their Gasochromic Properties. Cryst Growth Des 2012;12:1865-70.

[305] Kalantar-zadeh K, Tang JS, Wang MS, Wang KL, Shailos A, Galatsis K, et al. Synthesis of nanometre-thick $\mathrm{MoO}_{3}$ sheets. Nanoscale 2009;2:429-33.

[306] Scanlon DO, Watson GW, Payne DJ, Atkinson GR, Egdell RG, Law DSL. Theoretical and Experimental Study of the Electronic Structures of $\mathrm{MoO}_{3}$ and $\mathrm{MoO}_{2}$. J Phys Chem $\mathrm{C}$ 2010;114:4636-45.

[307] Scanlon DO, Watson GW, Payne D, Atkinson G, Egdell R, Law D. Theoretical and Experimental Study of the Electronic Structures of $\mathrm{MoO}_{3}$ and $\mathrm{MoO}_{2}$. J Phys Chem $\mathrm{C}$ 2010;114:4636-45.

[308] Xu JX, Sonne M, Pryds N, Kleinke H. Thermoelectric properties of molybdenum oxides $\mathrm{LnMo}_{(8)} \mathrm{O}_{(14)}(\mathrm{Ln}=\mathrm{La}, \mathrm{Ce}, \mathrm{Pr}, \mathrm{Nd}$ and Sm). J Alloy Compd 2010;489:353-6.

[309] Xu JX, Sonne M, Yanangiya SI, Van Nong N, Pryds N, Nygren M, et al. High thermoelectric performance of reduced lanthanide molybdenum oxides densified by spark plasma sintering. J Alloy Compd 2010;500:22-5.

[310] Anilkumar KR, Parveen A, Badiger GR, Prasad M. Thermoelectric Power Factor for Polyaniline/Molybdenum Trioxide Composites. Ferroelectrics 2009;386:88-93.

[311] Mulenko SA. Synthesis of nanometric iron and chromium oxide films by reactive pulsed laser deposition for photo-thermo sensors. In: Veiko VP, Vartanyan TA, editors. Fundamentals of Laser-Assisted Micro- and Nanotechnologies 2010. Bellingham: Spie-Int Soc Optical Engineering; 2011.

[312] Sugihara S, Suzuki C, Kameya R. High thermoelectric performance of metal substituted samples of $\alpha \mathrm{Fe}_{2} \mathrm{O}_{3}$ and computation of their electronic structures by the DVX $\alpha$ method. Inter J Quantum Chem 2009;109:2788-92.

[313] Rajendran S, Rao VS. An anomalous behaviour in the phase stability of the system Fe2O3 and NiO. J Mater Sci 1994;29:5673-9.

[314] Vayssieres L, Sathe C, Butorin SM, Shuh DK, Nordgren J, Guo J. One-Dimensional Quantum-Confinement Effect in $\alpha-\mathrm{Fe}_{2} \mathrm{O}_{3}$ Ultrafine Nanorod Arrays. $\mathrm{Adv}$ Mater 2005; 17:2320-3.

[315] Maldonado F, Novillo C, Stashans A. Ab initio calculation of chromium oxide containing Ti dopant. Chem Phys 2012;393:148-52.

[316] Young EWA, Gerretsen JH, Dewit JHW. The oxygen partial pressure dependence of the defect structure of chromium(III) oxide. J Electrochem Soc 1987;134:2257-60. 
[317] Nagai H, Ohbayashi K. Effect of $\mathrm{TiO}_{2}$ on the Sintering and the Electrical Conductivity of $\mathrm{Cr}_{2} \mathrm{O}_{3}$. J Am Ceram Soc 1989;72:400-3.

[318] Hayashi K, Sato K, Nozaki T, Kajitani T. Effect of doping on thermoelectric properties of delafossite-type oxide $\mathrm{CuCrO}_{2}$. Jpn J Appl Phys 2008;47:59-63.

[319] Tomes P, Logvinovich D, Hejtmanek J, Aguirre MH, Weidenkaff A. Magnetic influence on thermoelectric properties of $\mathrm{CrO}_{0.1} \mathrm{~N}_{0.9}$. Acta Mater 2011;59:1134-40.

[320] Kakehi Y, Satoh K, Yotsuya T, Ashida A, Yoshimura T, Fujimura N. Electrical and optical properties of excess oxygen intercalated $\mathrm{CuScO}_{2}(0001)$ epitaxial films prepared by oxygen radical annealing. Thin Solid Films. 2008;516:5785-9.

[321] Zhuiykov S. Electrochemistry of zirconia gas sensors: CRC Press; 2010.

[322] Zandiehnadem F, Murray RA, Ching WY. Electronic structures of three phases of zirconium oxide. Physica B,C. 1988;150:19-24.

[323] Jefferson PH, Hatfield S, Veal TD, King P, McConville CF, Zúñiga-Pérez J, et al. Bandgap and effective mass of epitaxial cadmium oxide. Appl Phys Lett 2008;92:022101--3.

[324] Gurumurugan K, Mangalaraj D, Narayandass SK, Nakanishi Y. DC reactive magnetron sputtered CdO thin films. Mater Lett 1996;28:307-12.

[325] Wright R. The Variation with Temperature of the Electrical Properties of a Degenerate Electronic Semiconductor as exemplified by Cadmium Oxide. P Phys Soc S-A. 2002;64:350.

[326] Salunkhe RR, Dhawale DS, Gujar TP, Lokhande CD. Structural, electrical and optical studies of SILAR deposited cadmium oxide thin films: Annealing effect. Mater Res Bull 2009;44:364-8.

[327] Gurumurugan K, Mangalaraj D, Narayandass SK, Sekar K, Vallabhan CG. Characterization of transparent conducting $\mathrm{CdO}$ films deposited by spray pyrolysis. Semicond Sci Tech 1999;9:1827.

[328] Li B, Zhang J. Electrical Conductivity of Cadmium Oxide-Antimony Oxide System Ceramics. J Am Ceram Soc 1989;72:2377-80.

[329] Irwin MD, Buchholz DB, Hains AW, Chang RP, Marks TJ. p-Type semiconducting nickel oxide as an efficiency-enhancing anode interfacial layer in polymer bulkheterojunction solar cells. P Natl Acad Sci USA. 2008;105:2783-7.

[330] Parravano G. Thermoelectric Behavior of Nickel Oxide. J Chem Phys 1955;23:5.

[331] Patil PS, Kadam LD. Preparation and characterization of spray pyrolyzed nickel oxide (NiO) thin films. Appl Surf Sci 2002;199:211-21.

[332] Shin W, Murayama N. Li-doped nickel oxide as a thermoelectric material. Japanese Journal of Appl Phys 1999;38:L1336-L8.

[333] Dutt MB, Banerjee R, Barua AK. Transport properties of Lithium and Sodium doped Nickel oxide. Physica Status Solidi a-Appl Res 1981;65:365-70.

[334] Keawprak N, Tu R, Goto T. Thermoelectricity of $\mathrm{CaIrO}_{3}$ ceramics prepared by spark plasma sintering. J Cer Soc Jpn 2009;117:466-9.

[335] Keawprak N, Tu R, Goto T. Thermoelectric Properties of Ca-Ir-O Compounds Prepared by Spark Plasma Sintering. Mater Trans 2009;50:853-8.

[336] Keawprak N, Tu R, Goto T. Thermoelectric properties of Sr-Ir-O compounds prepared by spark plasma sintering. J Alloy Compd 2010;491:441-6.

[337] Macklin WJ, Moseley PT. On the use of oxides for thermoelectric refrigeration. Mat Sci Eng B 1990;7:111-7.

[338] Androulakis J, Migiakis P, Giapintzakis J. La0. 95 $\mathrm{Sr}_{0 .}{ }_{05} \mathrm{CoO}_{3}$ : An efficient roomtemperature thermoelectric oxide. Arxiv preprint cond-mat/0312670. 2003.

[339] Gross AJ, Hwang GS, Huang BL, Yang HX, Ghafouri N, Kim H, et al. Multistage Planar Thermoelectric Microcoolers. J Microelectromech S 2011;20:1201-10. 
[340] Yang RQ, Hill CJ, Mansour K, Qiu YM, Soibel A, Muller RE, et al. Distributed feedback mid-IR interband cascade lasers at thermoelectric cooler temperatures. IEEE Jour Sel Topics in Quantum Electronics. 2007;13:1074-8.

[341] DiSalvo FJ. Thermoelectric cooling and power generation. Science 1999;285:703-6.

[342] Chein R, Huang GM. Thermoelectric cooler application in electronic cooling. Appl Therm Eng 2004;24:2207-17.

[343] Sharp J, Bierschenk J, Lyon HB. Overview of solid-state thermoelectric refrigerators and possible applications to on-chip thermal management. Proceedings of the IEEE 2006;94:1602-12.

[344] Venkatasubramanian R, Siivola E, Colpitts T, O'Quinn B. Thin-film thermoelectric devices with high room-temperature figures of merit. Nature. 2001;413:597-602.

[345] Macklin W, Moseley P. On the use of oxides for thermoelectric refrigeration. Mat Sci Eng B 1990;7:111-7.

[346] Jeffrey WF. Oxide materials for high temperature thermoelectric energy conversion. J Eur Ceram Soc 2012;32.

[347] Ohtaki M. Recent aspects of oxide thermoelectric materials for power generation from mid-to-high temperature heat source. J Ceram Soc Jpn 2011;119:770-5.

[348] Doumerc JP, Blangero M, Pollet M, Carlier D, Darriet J, Delmas C, et al. Transition metal oxides for thermoelectric generation. In: Lin HT, Koumoto K, Kriven WM, Garcia E, Reimanis IE, Norton DP, et al., editors. Developments in Strategic Materials. Westerville: Amer Ceramic Soc 2009: 25-40.

[349] Kawamoto H. R \& D Trends in High Efficiency Thermoelectric Conversion Materials for Waste Heat Recovery. Science \& Technology Trends 2009:54-69.

[350] Shin W, Murayama N, Ikeda K, Sago S. Fabrication of oxide thermoelectric generator element. Jpn. J. Appl. Phys. Part 1 - Regul. Pap. Short Notes Rev Pap 2000;39:1254-5.

[351] Shin W, Murayama N, Ikeda K, Sago S. Thermoelectric power generation using Lidoped $\mathrm{NiO}$ and $(\mathrm{Ba}, \mathrm{Sr}) \mathrm{PbO}_{3}$ module. J Power Sour 2001;103:80-5.

[352] Matsubara I, Funahashi R, Takeuchi T, Sodeoka S, Shimizu T, Ueno K. Fabrication of an all-oxide thermoelectric power generator. Appl Phys Lett 2001;78:3627-9.

[353] Funahashi R, Urata S, Mizuno K, Kouuchi T, Mikami M. CaBiCoO/ LaBiNiO thermoelectric devices with high output power density. Appl Phys Lett 2004;85:1036.

[354] Funahashi R, Mikami M, Mihara T, Urata S, Ando N. A portable thermoelectricpower-generating module composed of oxide devices. J Appl Phys 2006;99.

[355] Funahashi R, Urata S. Fabrication and application of an oxide thermoelectric system. Int. J Appl Ceram Technol 2007;4:297-307.

[356] Kosuga A, Urata S, Kurosaki K, Yamanaka S, Funahashi R. Mechanical Properties of $\mathrm{Ca}_{0.9} \mathrm{Yb}_{0.1} \mathrm{MnO}_{3} / \mathrm{Ag}$ Composites for n-Type Legs of Thermoelectric Oxide Devices. Jpn J Appl Phys 2008;47:6399-403.

[357] Reddy ES, Noudem J, Hebert S, Goupil C. Fabrication and properties of four-leg oxide thermoelectric modules. J Physics D: Appl Phys 2005;38:3751.

[358] Noudem JG, Lemonnier S, Prevel M, Reddy ES, Guilmeau E, Goupil C. Thermoelectric ceramics for generators. J Eur Ceram Soc 2008;28.

[359] Su HM, Jiang Y, Lan XZ, Liu XM, Zhong HH, Yu DB. $\mathrm{Ca}_{3-x} \mathrm{Bi}_{x} \mathrm{Co}_{4} \mathrm{O}_{9}$ and $\mathrm{Ca}_{1}$ ${ }_{y} \mathrm{Sm}_{y} \mathrm{MnO}_{3}$ thermoelectric materials and their power-generation devices. Phys Status Solidi A-Appl Mat 2011;208:147-55.

[360] Lim CH, Choi SM, Seo WS, Park HH. A Power-Generation Test for Oxide-Based Thermoelectric Modules Using p-Type $\mathrm{Ca}_{3} \mathrm{Co}_{4} \mathrm{O}_{9}$ and n-Type $\mathrm{Ca}_{0 .} \mathrm{Nd}_{0.1} \mathrm{MnO}_{3}$ Legs. J Electron Mater 2012;41:1247-55.

[361] Souma T, Ohtaki M, Ohnishi K, Shigeno M, Ohba Y, Shimozaki T. Power generation characteristics of oxide thermoelectric modules incorporating nanostructured $\mathrm{ZnO}$ sintered 
materials. In: Kim I, editor. Proceedings Ict 07: Twenty-Sixth International Conference on Thermoelectrics. New York: IEEE 2008. 38-41.

[362] Tomes P, Trottmann M, Suter C, Aguirre MH, Steinfeld A, Haueter P, et al. Thermoelectric Oxide Modules (TOMs) for the Direct Conversion of Simulated Solar Radiation into Electrical Energy. Materials 2010;3:2801-14.

[363] Choi SM, Lee KH, Lim CH, Seo WS. Oxide-based thermoelectric power generation module using p-type $\mathrm{Ca}_{3} \mathrm{Co}_{4} \mathrm{O}_{9}$ and n-type $(\mathrm{ZnO})_{(7)} \mathrm{In}_{2} \mathrm{O}_{3}$ legs. Energy Conv Manag 2011;52:335-9.

[364] Tritt TM, Boettner H, Chen L. Thermoelectrics: Direct solar thermal energy conversion. MRS Bull 2008;33:366-8.

[365] Telkes M. Solar thermoelectric generators. J Appl Phys 1954;25:765-77.

[366] Robert R, Romer S, Reller A, Weidenkaff A. Nanostructured complex cobalt oxides as potential materials for solar thermoelectric power generators. Adv Eng Mater 2005;7:303-8.

[367] Robert R, Bocher L, Sipos B, Döbeli M, Weidenkaff A. Ni-doped cobaltates as potential materials for high temperature solar thermoelectric converters. Prog Solid State Ch 2007;35:447-55.

[368] Lange RG, Carroll WP. Review of recent advances of radioisotope power systems. Energy Conv Manag 2008;49:393-401.

[369] Williams HR, Ambrosi RM, Bannister NP, Samara-Ratna P, Sykes J. A conceptual spacecraft radioisotope thermoelectric and heating unit (RTHU). Int $J$ Energ Res 2012;36:1192-200.

[370] O'Brien RC, Ambrosi RM, Bannister NP, Howe SD, Atkinson HV. Safe radioisotope thermoelectric generators and heat sources for space applications. J Nucl Mater 2008;377:506-21.

[371] Singh R, Tundee S, Akbarzadeh A. Electric power generation from solar pond using combined thermosyphon and thermoelectric modules. Sol Energy 2011;85:371-8.

[372] Rajendra Kumar RT, Karunagaran B, Mangalaraj D, Narayandass SK, Manoravi P, Joseph M, et al. Pulsed laser deposited vanadium oxide thin films for uncooled infrared detectors. Sensors Actuat A - Phys 2003;107:62-7.

[373] Ha T-J, Park H-H, Jung S-Y, Yoon S-J, Kim J-S, Jang HW. Effect of porosity on the Seebeck coefficient of mesoporous $\mathrm{TiO}_{2}$ thin films. Thin Solid Films 2010;518:7196-8.

[374] Roediger T, Knauss H, Gaisbauer U, Kraemer E, Jenkins S, von Wolfersdorf J. Timeresolved heat transfer measurements on the tip wall of a ribbed channel using a novel heat flux sensor-part I: Sensor and benchmarks. J turbomach 2008;130.

[375] Yang Y, Pradel KC, Jing Q, Wu JM, Zhang F, Zhou Y, et al. Thermoelectric Nanogenerators Based on Single Sb-Doped ZnO Micro/Nanobelts. Acs Nano. 2012;6:6984-9. [376] Janata J, Bezegh A. Chemical sensors. Anal chem 1988;60:62R-74R.

[377] Matsumiya M, Qiu F, Shin W, Izu N, Matsubara I, Murayama N, et al. Thermoelectric $\mathrm{CO}$ Gas Sensor Using Thin-Film Catalyst of $\mathrm{Au}$ and $\mathrm{Co}_{3} \mathrm{O}_{4}$. J Electrochem Soc 2004;151:H7H10.

[378] Rettig F, Moos R. Direct thermoelectric gas sensors: Design aspects and first gas sensors. Sensors Actuat B - Chem. 2007;123:413-9.

[379] Nishibori M, Shin W, Tajima K, Houlet LF, Izu N, Itoh T, et al. Thermoelectric gas sensor using Au loaded titania CO oxidation catalyst. J Ceram Soc Jap 2007;115:37-41.

[380] Shin W, Matsumiya M, Izu N, Murayama N. Hydrogen-selective thermoelectric gas sensor. Sensors and Actuators B: Chem 2003;93:304-8.

[381] Sadek AZ, Choopun S, Wlodarski W, Ippolito SJ, Kalantar-zadeh K. Characterization of $\mathrm{ZnO}$ Nanobelt-Based Gas Sensor for $\mathrm{H}_{2}, \mathrm{NO}_{2}$ and Hydrocarbon sensing. Sensors Journal, IEEE 2007;7:919-24. 
[382] Wang Z. Novel nanostructures of $\mathrm{ZnO}$ for nanoscale photonics, optoelectronics, piezoelectricity, and sensing. Appl Phys A 2007;88:7-15.

[383] Simon I, Bârsan N, Bauer M, Weimar U. Micromachined metal oxide gas sensors: opportunities to improve sensor performance. Sensors Actuat B - Chem 2001;73:1-26.

[384] Vanherwaarden AW, Sarro PM. Thermal sensors based on the Seebeck effect. Sensor Actuator 1986;10:321-46.

[385] Darling RB, Iwanaga S. Structure, properties, and MEMS and microelectronic applications of vanadium oxides. Sadhana 2009;34:531-42.

[386] Choi W, Abrahamson JT, Strano JM, Strano MS. Carbon nanotube-guided thermopower waves. Mater Today 2010;13:22-33.

[387] Hong S, Kim W, Jeon S-J, Lim SC, Lee H-J, Hyun S, et al. Enhanced Electrical Potential of Thermoelectric Power Waves by $\mathrm{Sb}_{2} \mathrm{Te}_{3}$-Coated Multiwalled Carbon Nanotube Arrays. J Phys Chem C 2013.

\section{Figure captions}

Fig. 1. Operating temperature ranges of various TMOs and TMO composites. (Reproduced with permission from [15].)

Fig. 2. (a) A 2D quantum well structure with width $W$, (b) $1 \mathrm{D}$ conductor (nanowire) with a square cross section of width $a$, (c) a segmented nanowire superlattice of diameter $d_{w}$ comprising of quantum dots $(0 \mathrm{D})$ of alternating materials $\mathrm{A}$ and $\mathrm{B}$, with respective segment lengths $L_{A}$ and $L_{B}$. (d) Energy dependence of the electronic DOS in 3D, 2D, 1D and 0D materials. ((c), (d) Reproduced with permission from [28] and [29].)

Fig. 3. Schematic depiction of the substructuring approach in doped cobalt oxide, comprising of ordered $\mathrm{CoO}_{2}$ layers that are separated by disordered layers (of $\mathrm{Na}$ dopant) to achieve a good electrical conductivity and poor phonon conductivity. (Reproduced with permission from[42].)

Fig. 4. (a) Seebeck coefficient (red) and electrical resistivity (blue) of reduced single crystal rutile $\mathrm{TiO}_{x}$ as a function of annealing temperature and (b) Seebeck coefficient as a function of temperature for a sample annealed in $\mathrm{H}_{2}$ at $1053 \mathrm{~K}$. (Reproduced with permission from [125].)

Fig. 5. (a) Electrical conductivity, (b) Seebeck coefficient, (c) thermal conductivity, (d) TPF and (e) ZT vs temperature for different concentrations of La dopant in STO thin films. (Reproduced with permission from [134].)

Fig. 6. (a) Resistivity, (b) Seebeck coefficient, (c) TPF and (d) ZT of GPR (red) and SSR synthesised (black) Yb-doped $\mathrm{CaMnO}_{3}$ nanoparticles (Reproduced from [22].)

Fig. 7. (a) Seebeck coefficient, (b) electrical conductivity variation with temperature for $\alpha$ $\mathrm{WO}_{3}$ films and (c) TPF obtained for varying $\mathrm{ZnO}$ doping concentrations in $\mathrm{WO}_{3}$ ceramics. (Reproduced with permission from (a), (b) [168] and (c) [161].) 
Fig. 8. Temperature dependence of TPF of $\mathrm{Zn}_{1-x-y} \mathrm{Al}_{x} \mathrm{Ga}_{y} \mathrm{O}$ ceramics. (Reproduced with permission from [88].)

Fig. 9. (a) Electrical conductivity variation of $\mathrm{CuO}$ sintered at different temperatures, (b) Seebeck coefficient variation with temperature for $\mathrm{CuO}$ films of different thicknesses and (c) Temperature dependence of TPF for various $\mathrm{La}_{2} \mathrm{CuO}_{4}$ ceramics, (inset shows $\mathrm{ZT}$ values at $330 \mathrm{~K})$ [LNCO $\left(\mathrm{Nb}\right.$ doped $\left.\mathrm{La}_{2} \mathrm{CuO}_{4}\right)$, LPCO (Pr doped $\left.\mathrm{La}_{2} \mathrm{CuO}_{4}\right), \mathrm{LYCO}$ (Y doped $\mathrm{La}_{2} \mathrm{CuO}_{4}$ )]. (Reproduced with permission from (a) [222], (b)[226] and (c) [221].)

Fig. 10. Temperature dependence of (a) electrical conductivity, (b) Seebeck coefficient for the as-cast and heat treated films during heating and cooling cycles of hydrated $\mathrm{V}_{2} \mathrm{O}_{5}$. (Reproduced with permission from [244].)

Fig. 11. (a) Resistivity and (b) Seebeck coefficient variations with temperature for $\mathrm{NaCo}_{2} \mathrm{O}_{4}$ single crystals in plane $\left(\rho_{\mathrm{a}}\right)$ and out of plane $\left(\rho_{\mathrm{c}}\right)$ and (c) comparison of ZT and TPF for SPS and hot pressed (HP) synthesised $\mathrm{Ca}_{2} .{ }_{25} \mathrm{Gd}_{0.25} \mathrm{Co}_{4} \mathrm{O}_{9}$ samples. (Reproduced with permission from (a), (b) [11] and (c) [270].)

Fig. 12. Temperature $(T)$ dependence of (a) resistivity $(\rho)$, (b) Seebeck coefficient $(S)$, and (c) thermal conductivity $(\kappa)$ for $\mathrm{Bi}_{1.7} \mathrm{Ba}_{2}\left(\mathrm{Co}_{1-z} \mathrm{Rh}_{z}\right) \mathrm{O}_{y}$ of varying rhodium concentration $(z)$ (Reproduced with permission from [287].)

Fig. 13. (a) Temperature dependence of TPF of $\mathrm{RMo}_{8} \mathrm{O}_{14}(\mathrm{R}: \mathrm{La}, \mathrm{Ce}, \mathrm{Nd}, \mathrm{Sm}$ ) pellets, and (b) electrical conductivity $v s$ TPF of $\mathrm{PANI} / \mathrm{MoO}_{3}$ composites $v s \mathrm{MoO}_{3}$ concentration in the composite. (Reproduced with permission from (a) [309] and (b) [310].)

Fig. 14. Pictorial representation of a TE cooling device. (Reproduced with permission from [261].)

Fig. 15. Schematic of a solar thermoelectric generator (STEG), comprising of a solar concentrator and both $\mathrm{p}$ and $\mathrm{n}$ type TE elements. (Reproduced with permission from[371].)

Fig. 16. (a) Schematic of thin film thermopower wave system and output voltage profiles for (b) $\mathrm{ZnO}$ and (c) $\mathrm{MnO}_{2}$ based thermopower wave sources. (Reproduced with permission from (b) [5] and (c) [9].) 